\author{
UNIVERSIDADE DE SÃO PAULO \\ Instituto de Física de São Carlos - IFSC \\ Instituto de Química de São Carlos - IQSC \\ Escola de Engenharia de São Carlos - EESC
}

\title{
ESTUDOS SOBRE A DOPAGEM DE POLIANILINA DEPOSITADA SOBRE SUBSTRATOS POLIMÉRICOS
}

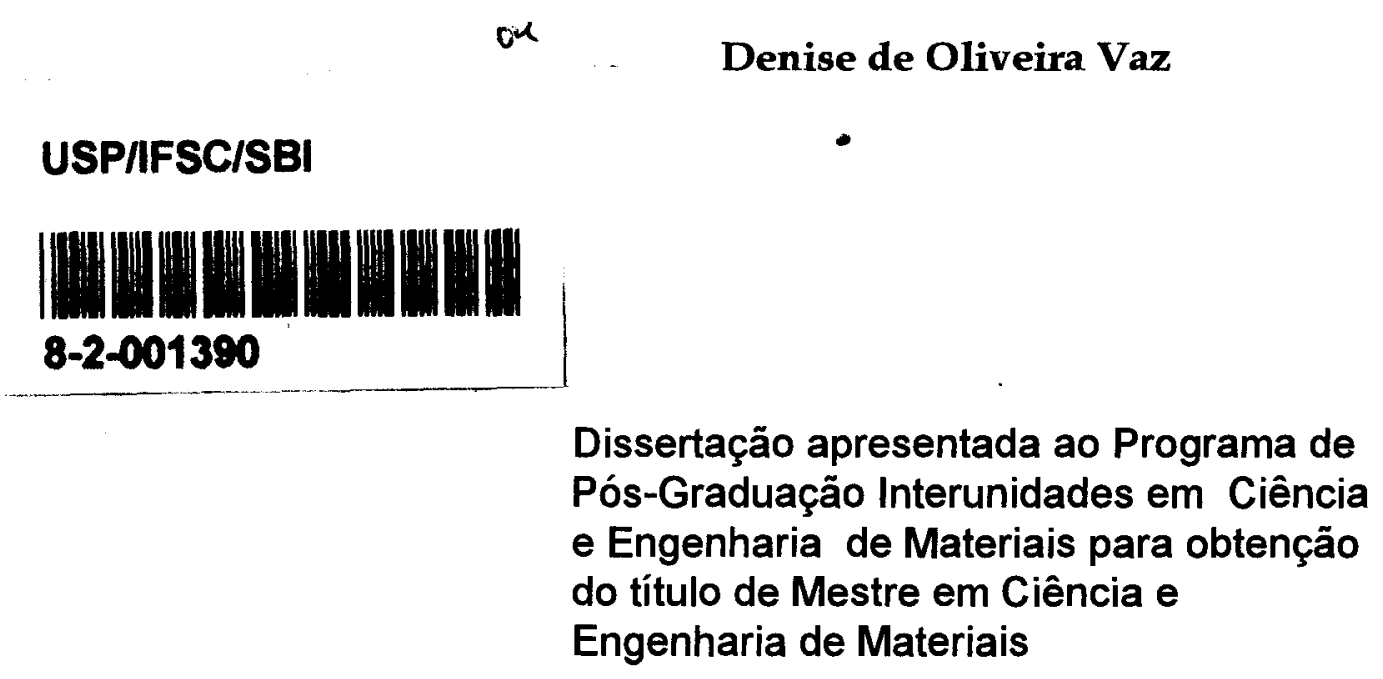

Orientador: Prof.Dr.Luiz Henrique Capparelli Mattoso

São Carlos - SP

2001

IFSC-USP SERVIGO DEBIBLIO, ECA
INFORMAGÁ 
MEMBROS DA COMISSÃO JULGADORA DA DISSERTAÇÃO DE MESTRADO DE DENISE DE OLIVEIRA $V A Z$, APRESENTADA AO PROGRAMA DE PÓS-GRADUAÇÃO INTERUNIDADES, ÁREA EM CIÊNCIA E ENGENHARIA DE MATERIAIS, DA UNIVERSIDADE DE SÃO PAULO, EM 12/03/2001.

\section{COMISSÃO JULGADORA:}

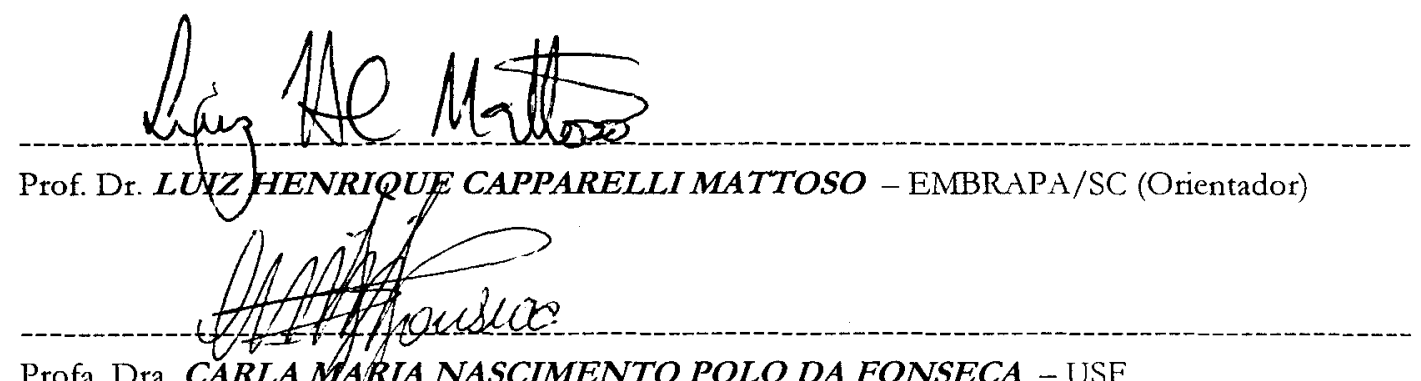

Profa. Dra. CARLA AARLA NASCIMENTO POLO DA FONSECA - USF

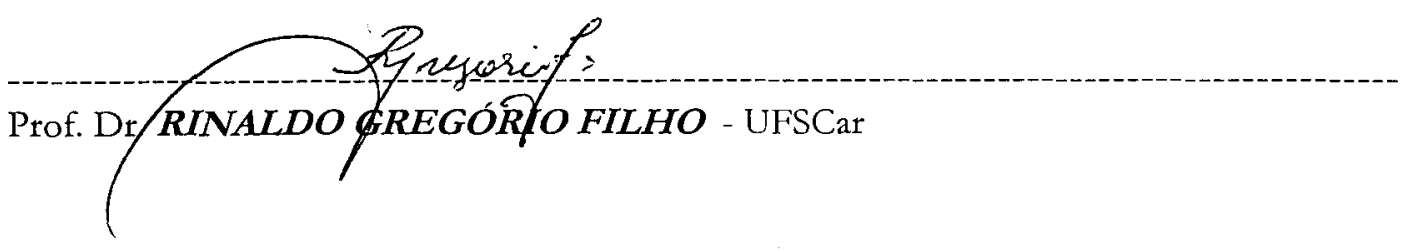


À Kirra e Sophia (grandes Mestres e amigas), grata pelas lições recebidas:

Blessed be!

À memória da minha inesquecível vovó Henriqueta Northfleet, por me ensinar aquele velho adágio árabe: "A sabedoria está nas coisas simples". 
"Descrumalua a confianea de que a vida

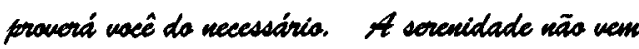
do tor a que se quer. mas do guerer a que de teme."

(Tom McGrath, in Stress Therapy, 1997)

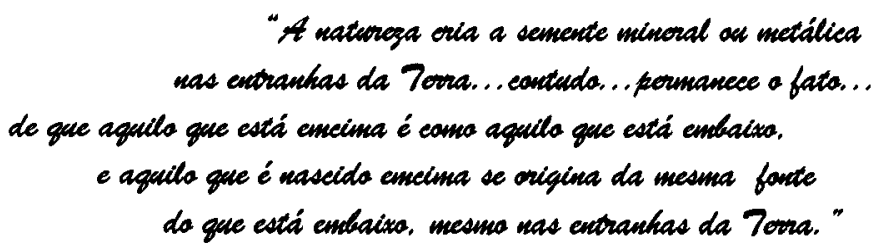

(Michael Sendivogius, in New Chemical Light, 1566)

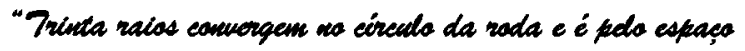
que ka extre des ande reside sua willidade.

A argilla modda - se en forma de uasas

e ne uagles reside seca cutlidade.

Ahem-se portas e jandas noura easa o é pelos espaceas waglas gue pademeas ateligá-las.

Assins. do vĩa-sor ven a cutlidade e do sor a passessãa.

(Lao Tsé, in Tao Te King, séc. VI A. C.) 


\section{AGRADECIMENTOS}

Ao Prof. Dr. Luiz Henrique C. Mattoso pela orientação, por seu constante bom humor e rapidez na resolução dos problemas.

Ao Prof. Dr. Luis Antônio Pessan (DeMa/UFSCar) pela colaboração na execução das análises termogravimétricas, fornecimento do policarbonato em pó e amizade.

Ao Prof. Dr. Adhemar Rúvulo Filho (Química/UFSCar) pelo empréstimo de sua prensa manual.

Ao Prof. Dr. José Alberto Giacometti e professores do Grupo de Polímeros "Prof. Bernhard Gross" da Física da USP/São Carlos, pela colaboração no empréstimo de seu laboratório para dopar amostras com Descarga Corona, bem como pelo empréstimo do kit para medidas de condutividade elétrica.

A todos os colegas do Grupo de Polímeros Condutores da Física da USP/São Carlos e da Embrapa Instrumentação Agropecuária, em especial aos colegas: Leonardo Paterno, pelas discussões sobre polianilina e ao Dr. Aldo E.Job, por ter sido tão gentil e bem humorado, instruindo-me quanto à síntese da polianilina e medidas de condutividade elétrica. Agradeço ao amigo Dr. José A. Malmonge pelo fornecimento de alguns artigos importantes para este trabalho, bem como algumas discussões. 


\section{Publicações da autora desta Dissertação no período de 1998 à 2000}

\section{I - Artigos em Jornais}

VAZ, D.O. Moléculas Gigantes que Conduzem Eletricidade. Primeira Página, São Carlos, SP, p.C 2, 12 set. 1999.

VAZ, D.O. De que é constituída a Lua ? Primeira Página, São Carlos, SP, p.C 2, 03 out. 1999.

VAZ, D.O. Prêmio Nobel de Química do ano 2000: "A Eletrônica do Futuro". Primeira Página, São Carlos, SP, p. C 5, 07 dez. 2000.

\section{II - Artigos em Revistas Especializadas em Polímeros}

VAZ, D.O.; MATTOSO, L.H.C.; JOB, A.E.; HERMANN Jr., P.S.P.; "Comparison between Different Conditions of the Chemical Polymerization of Polyaniline on top of PET films". Journal of Applied Polymer Science (artigo aceito para publicação em abril de 2000).

VAZ, D.O.; MATTOSO, L.H.C. "Effects of heat treatment and doping on adhesion and electrical conductivity of polyaniline deposited onto polycarbonate and poly(ethylene terephtalate) films". (artigo em preparação, a ser submetido para o Special Issue of Macromolecular Symposia / Polymer Composites Session).

VAZ, D.O.; JORGE, L.A.C.; MATTOSO, L.H.C. "A new method to analyse the doping onto polyaniline films", (artigo em preparação)

\section{III - Trabalhos apresentados em Congressos}

VAZ, D.O.; MATTOSO, L.H.C.; TRAVAIN, S.A.; GIACOMETTI, J.A.

"Estabilidade da dopagem de compósitos de poli(tereftalato de etileno) e polianilina". $14^{\circ}$ CBECIMAT (Congresso Brasileiro em Ciência e Eng. de Materiais), São Pedro, SP, dezembro/2000 (resumo).

VAZ, D.O.; JORGE, L.A.C.; MATTOSO, L.H.C. "Estudo da estabilidade da dopagem da polianilina usando-se software para análise de imagem". SICEM (Simpósio em Ciência e Eng. de Materiais), São Carlos, SP, novembro/2000 (apresentação oral).

VAZ, D.O.; MATTOSO, L.H.C. "Effects of heat treatment and doping on adhesion and electrical conductivity of polyaniline deposited onto polycarbonate and poly(ethylene terephtalate) films",MoDeSt Conference -2000 (Modification, Degradation and Stabilization of Polymers), Palermo, Itália, setembro/2000 (artigo extendido). 
SUMÁRIO

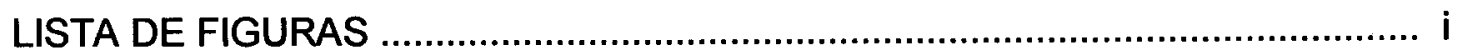

LISTA DE TABELAS …….........................................................................

RESUMO........................................................................................................

ABSTRACT

INTRODUÇÃO

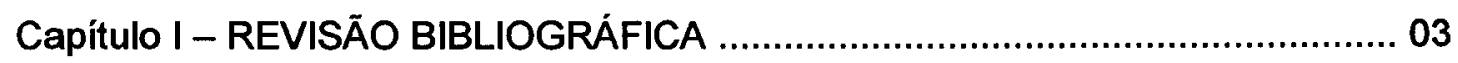

1.1.Polímeros Condutores Intrínsecos ……………………..................................

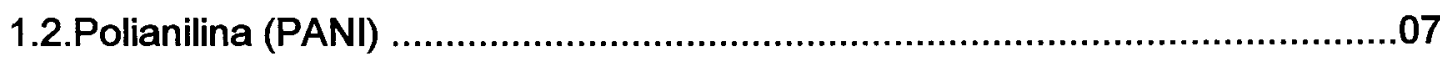

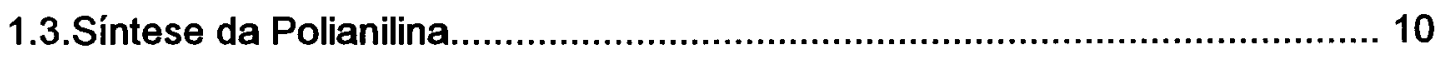

1.4.Dopagem e Condutividade Elétrica...............................................................11

1.5.Poli(tereftalato de etileno) - (PET) ...............................................................14

1.6.Policarbonato de Bisfenol- A - (PC) ………………….............................15

1.7.Compósitos de PANI e Polímeros Convencionais ........................................17

1.8. Imagem Digital ................................................................................................21

Capítulo II - PROCEDIMENTO EXPERIMENTAL …............................................23

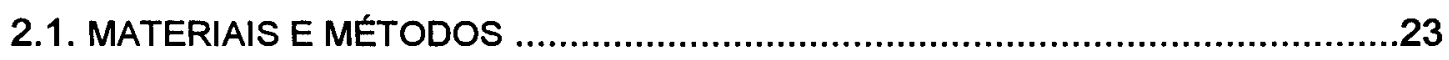

2.1.1. Preparação dos filmes de PET ………………………………….......23

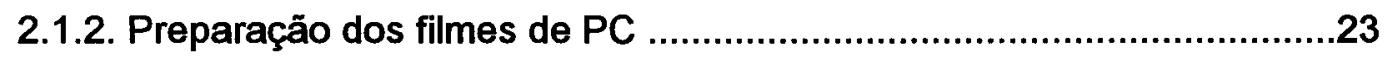

2.1.3. Síntese da Polianilina sobre os substratos poliméricos ........................24

2.1.3.1. Destilação da Anilina ...........................................................24

2.1.3.2. Sintese dos Compósitos PET/PANI e PC/PANI ........................24

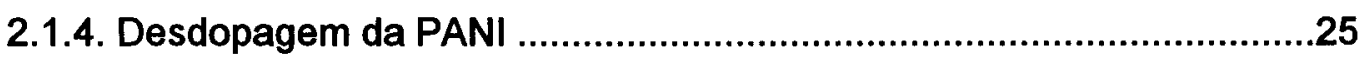

2.1.5. Redopagem da PANI (com ácidos e por Descarga Corona)................25 
2.1.6. Tratamento Térmico dos Compósitos

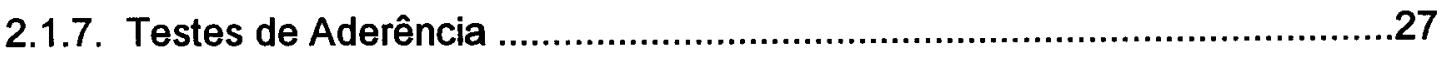

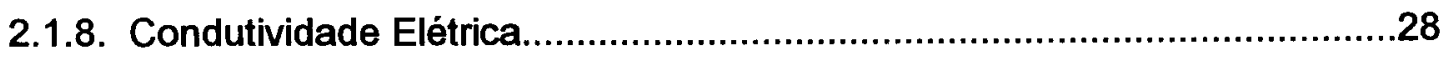

2.1.9. Espectroscopia de Foto-elétrons excitados por Raios X (XPS) ...............29

2.1.10. Espectroscopia de Absorção de Luz na região do Ultravioleta e Visível (UV-vis). .30

2.1.11Espectroscopia de Infravermelho com Transformada de Fourier (FTIR) .....30

2.1.12.Espectroscopia Raman Ressonante..............................................30

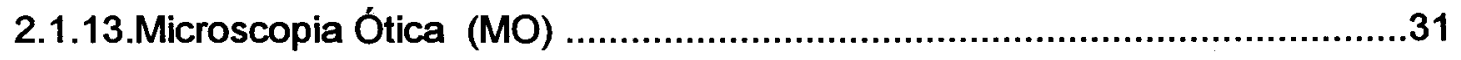

2.1.14.Microscopia Eletrônica de Varredura (MEV) ..........................................31

2.1.15. Microscopia de Força Atômica (AFM) ..................................................31

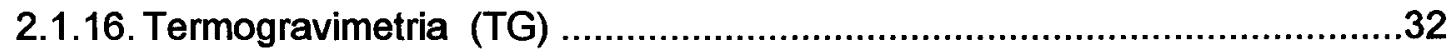

2.1.17. Estabilidade da dopagem da PANI

(análise de imagem com softwares)............................................32

Capítulo III - RESULTADOS E DISCUSSÕES …..............................................37

3.1. CARACTERIZAÇÃO E MORFOLOGIA DOS COMPÓSITOS PET/PANI, PC/PANI e

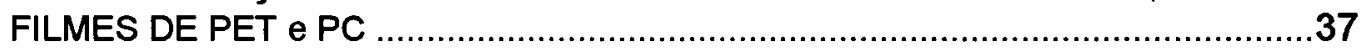

3.1.1. Espectroscopia no Infravermelho com Transformada de Fourier (FTIR).....37

3.1.2. Espectroscopia Raman Ressonante............................................45

3.1.3. Espectroscopia de Foto-elétrons excitados por Raios-X (XPS) ….........49

3.1.4. Espectroscopia de absorção de luz na região do Ultravioleta e Visível (UV-vis) ......................................................................................57

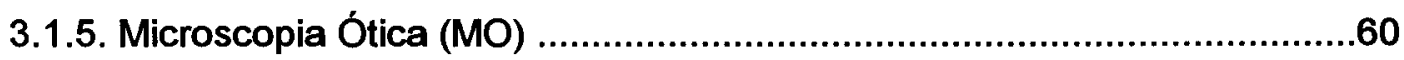

3.1.6. Microscopia Eletrônica de Varredura (MEV) .....................................63

3.1.7. Microscopia de Força Atômica (AFM)..............................................71

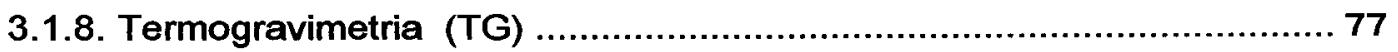


3.2. EFEITO DO TRATAMENTO TÉRMICO NA POLIANILINA DEPOSITADA NOS SUBSTRATOS POLIMÉRICOS.

3.2.1. Efeito do tratamento térmico na eficiência da dopagem da PANI em compósitos PET/PANI e PC/PANI.

3.2.2. Efeitos da Redopagem da PANI depositada sobre o PET - dopada com $\mathrm{HCl}$ (em diferentes concentrações)

3.2.3. Solubilidade da PANI em diferentes Solventes Orgânicos à Temperatura Ambiente .98

3.3. ESTUDO DA ESTABILIDADE DA DOPAGEM DA PANI (análise de imagens por softwares).

Capitulo IV - CONCLUSÕES .110

TRABALHOS FUTUROS .113

REFERÊNCIAS BIBLIOGRÁFICAS 
LISTA DE FIGURAS

\section{Capítulo I - REVISÃO BIBLIOGRÁFICA}

Figura 1.1: Alguns polímeros condutores

Figura 1.2: Condutividade elétrica de alguns materiais em $\mathrm{S} / \mathrm{cm}$

Figura 1.3: Fórmula geral da PANI. Onde: (y) é a espécie reduzida e $(1-y)$ é a

espécie oxidada.

Figura 1.4: Fórmula estrutural da pernigranilina..............................................

Figura 1.5: Estrutura da leucoesmeraldina...................................................... 8

Figura 1.6: Fórmula estrutural da base de esmeraldina........................................

Figura 1.7: Esquema de formação da banda de condução polarônica na polianilina. Onde: $\mathrm{EB}=$ base de esmeraldina; $\mathrm{ES}=$ sal de hidrocloreto

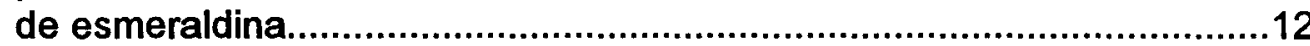

Figura 1.8: Síntese do PET (Terylene) ..........................................................14

Figura 1.9: Reação de obtenção do policarbonato por transesterificação..................17

\section{Capitulo II - PROCEDIMENTO EXPERIMENTAL}

Figura 2.1: Fórmula estrutural do monômero do PET............................................23

Figura 2.2: Fórmula estrutural do monômero do PC...............................................23

Figura 2.3: Triodo de corona. Onde: $\quad V_{c}=$ fonte de tensão; $\quad R=$ resistência; $C_{p}=$ controlador de potência; $T=$ termopar; $C_{t}=$ controlador de temperatura; $d_{1}=$ distância ponta-grade; $\quad d_{2}=$ distância grade-plano coletor.

Figura 2.4: Máscara para dopagem controlada da PANI.......................................33

Figura 2.5: Imagem digitalizada, com resolução espacial de 250 ppi e 24 bits, de PANI dopada na região central da imagem. As amostras (a), (c) e (e) foram obtidas logo após realizada a dopagem. As imagens (b), (d) e (f) são as últimas imagens obtidas (após $712 \mathrm{~h}$ de observação). As amostras foram dopadas com: descarga corona negativa em (a) e (b); descarga corona positiva em (c) e (d); vapores de $\mathrm{HCl}$ concentrado em (e) e (f).

Figura 2.6: Imagem digital ( 250 ppi e 8 bits) com aplicação do filtro THRESHOLD na cor verde-esmeralda, com a finalidade de destacar na imagem a área de dopagem da PANI.

Figura 2.7: Imagem digital (250 ppi e 8 bits) binarizada da porção que foi dopada da PANI

\section{Capitulo III - RESULTADOS E DISCUSSÕES}

Figura 3.1: Espectro de FTIR da PANI desdopada (PANI/EB) com $\mathrm{NH}_{4} \mathrm{OH} 0,1 \mathrm{M} \ldots . .38$

Figura 3.2: Espectro de FTIR da PANI dopada com $\mathrm{HCl} 1 \mathrm{M}(\mathrm{PANI} / \mathrm{HCl})$. .38 
Figura 3.3: Espectro de FTIR da PANI dopada com TFA 1M................................39

Figura 3.4: Espectro de FTIR da PANI dopada com TSA 1M................................39

Figura 3.5: Espectro de FTIR da PANI dopada com descarga corona positiva (PANI/DC(+)) ............................................................................40

Figura 3.6: Espectro de FTIR da PANI dopada com descarga corona negativa (PANI/DC(-)) ................................................................................40

Figura 3.7: Espectro de FTIR de filme de PET. ....................................................43

Figura 3.8: Espectro de FTIR de filme de PC..............................................44

Figura 3.9: Espectro Raman da PANI desdopada com $\mathrm{NH}_{4} \mathrm{OH} 0,1 \mathrm{M}$ (PET/PANI-EB) $\left(\lambda_{\text {exc. }}=632,8 \mathrm{~nm}\right)$.

Figura 3.10: Espectro Raman da PANI dopada com HCl 1M (PET/PANI-HCl)

$\left(\lambda_{\text {exc. }}=632,8 \mathrm{~nm}\right)$

Figura 3.11: Espectro Raman da PANI dopada com descarga corona positiva $($ PET/PANI-DC $(+))\left(\lambda_{\text {exc. }}=632,8 \mathrm{~nm}\right)$.

Figura 3.12: Espectros Raman da PANI dopada com HCl $1 \mathrm{M}(\mathrm{PET} / \mathrm{PANI}-\mathrm{HCl}) ;$ descarga corona negativa (PET/PANI-DC(-)) e da PANI dopada com descarga corona positiva (PET/PANI-DC $(+)),\left(\lambda_{\text {exc. }}=632,8 \mathrm{~nm}\right)$.

Figura 3.13: Espectro de XPS do nivel $1 \mathrm{~s}$ do $\mathrm{C}$ do PET (puro)

Figura 3.14: Espectro de XPS do nível $1 \mathrm{~s}$ do $\mathrm{C}$ do PET tratado termicamente por 2 horas, à $200^{\circ} \mathrm{C}$.

Figura 3.15: Valores percentuais dos elementos químicos presentes nas superfícies das amostras de PANI. Onde: $E B$ = PANI desdopada; $\mathrm{HCl} 1 \mathrm{M}=$ PANI dopada com $\mathrm{HCl} 1 \mathrm{M} ; \mathrm{DC}(+)=$ PANI dopada com descarga corona positiva; $\mathrm{DC}(-)=\mathrm{PANI}$ dopada com descarga corona negativa.

Figura 3.16: Espectros de XPS do N (1 s) da PANI desdopada (a); PANI dopada com: (b) $\mathrm{HCl} \mathrm{1M;} \mathrm{(c)} \mathrm{descarga} \mathrm{corona} \mathrm{positiva;} \mathrm{(d)} \mathrm{descarga}$ corona negativa; Espectros de XPS do C (1s) da PANI desdopada (e); PANI dopada com: (f) $\mathrm{HCl} 1 \mathrm{M}$; (g) descarga corona positiva; (h) descarga corona negativa.

Figura 3.17: Espectro de UV-vis da PANI, onde: a - desdopada em $\mathrm{NH}_{4} \mathrm{OH}$ $0,1 \mathrm{M}$ e da PANI dopada com: $\mathrm{b}-\mathrm{HCl} 1 \mathrm{M}, \mathrm{c}-\mathrm{TSA} 1 \mathrm{M}$, e-descarga corona positiva, $f$ - descarga corona negativa 
Figura 3.18: Fotomicrografias de $M O$ de compósitos PET/PANI, onde observa-se a superfície da PANI dopada com: (a) $\mathrm{HCl} 1 \mathrm{M}(400 \mathrm{x})$, (b) $\mathrm{HCl} 1 \mathrm{M}$ $(1.000 \mathrm{x})$, (c) descarga corona positiva (400 x), (d) descarga corona positiva $(1.000 \mathrm{x}), \quad$ (e) descarga corona negativa $(400 \mathrm{x})$, (f) descarga corona negativa $(1.000 \mathrm{x})$.

Figura 3.19: Fotomicrografias de MEV de filmes de PET/PANI-desdopada em

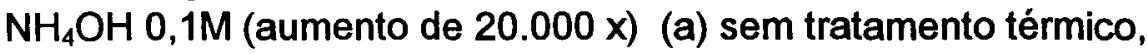
(b) com tratamento térmico $\left(2 \mathrm{~h}, 200^{\circ} \mathrm{C}\right)$; Fotomicrografias de MEV de filmes de PC/PANI-desdopada em $\mathrm{NH}_{4} \mathrm{OH} \mathrm{0,1M}$ (aumento de $20.000 \mathrm{x}$ ) (a) sem tratamento térmico,

(b) com tratamento térmico $\left(2 \mathrm{~h}, 200^{\circ} \mathrm{C}\right)$ .63

Figura 3.20: Fotomicrografias de MEV de filmes de PET/PANI-dopada em $\mathrm{HCl} 1 \mathrm{M}$ (aumento de $20.000 \mathrm{x}$ ): (a) sem tratamento térmico, (b) com tratamento térmico $\left(2 \mathrm{~h}, 200^{\circ} \mathrm{C}\right)$; fotomicrografias de filmes de PC/PANI-dopada em HCl 1M (aumento de 20.000 x): (c) sem tratamento térmico, (d) com tratamento térmico $\left(2 \mathrm{~h}, 200^{\circ} \mathrm{C}\right)$

Figura 3.21: Fotomicrografias de MEV de filmes de PET/PANI-dopada em TFA 1M (aumento de $20.000 \mathrm{x}$ ): (a) sem tratamento térmico, (b) com tratamento térmico $\left(2 \mathrm{~h}, 200^{\circ} \mathrm{C}\right)$; Fotomicrografias de filmes de PC/PANI-dopada em TFA $1 \mathrm{M}$ (aumento de $20.000 \mathrm{x}$ ): (c) sem tratamento térmico, (d) com tratamento térmico $\left(2 \mathrm{~h}, 200^{\circ} \mathrm{C}\right)$

Figura 3.22: Fotomicrografias de MEV de filmes de PET/PANI-dopada em TSA 1M (aumento de $20.000 \mathrm{x}$ ): (a) sem tratamento térmico, (b) com tratamento térmico $\left(2 \mathrm{~h}, 200^{\circ} \mathrm{C}\right)$; Fotomicrografias de filmes de PC/PANI-dopada em TSA $1 \mathrm{M}$ (aumento de $20.000 \mathrm{x}$ ): (c) sem tratamento térmico, (d) com tratamento térmico $\left(2 \mathrm{~h}, 200^{\circ} \mathrm{C}\right)$

Figura 3.23:Fotomicrografias de MEV de filmes de PET/PANI-dopados em cada face, com descarga corona negativa $(t=45 \mathrm{~min}, i=10 \mu \mathrm{A}$, $d_{\text {ponta grade }}=18 \mathrm{~mm}, d_{\text {grade amostra }}=6 \mathrm{~mm}$ ): (a) aumento de $2.000 \mathrm{x}$, aumento de 20.000x; fotomicrografias de MEV de filmes de PET/PANI-dopada em cada face, com descarga corona positiva $\left(t=2 \mathrm{~h} ; i=20 \mu \mathrm{A}, d_{\text {ponta grado }}=18 \mathrm{~mm}, d_{\text {grade amostra }}=6 \mathrm{~mm}\right)$ : (c)aumento de $2.000 x$, (d)aumento de $20.000 x$.

Figura 3.24: Fotomicrografias de MEV de filmes de PET (aumento de 2.000x):

a) sem tratamento térmico,(b)com tratamento térmico $\left(2 \mathrm{~h}, 200^{\circ} \mathrm{C}\right)$; Fotomicrografias de MEV de filmes de PC,(aumento de 2.000x) (b)sem tratamento térmico,(c)com tratamento térmico $\left(2 \mathrm{~h}, 200^{\circ} \mathrm{C}\right)$..... .68 
Figura 3.25: Fotomicrografias de MEV de compósitos que foram esticados até a ruptura: (a) PET/PANI (aumento de 2.000x); (b) PC/PANI (aumento de 2.000x); (c) PET/PANI (aumento de 20.000x); (d) PC/PANI (aumento de 20.000x).

Figura 3.26: Imagens de AFM da topografia da superfície da PANI (modo nãocontato), onde: (a)amostra dopada com $\mathrm{Hcl} 1 \mathrm{M}$, (b) desdopada e (c)redopada com descarga corona.

Figura 3.27: Imagem de AFM e perfil de uma linha vertical da superfície da PANI (desdopada) depositada sobre PET, apresentando o comprimento (em y) de um grão.

Figura 3.28: Imagem de AFM e perfil de uma linha vertical da superfície da PANI (desdopada) depositada sobre PET, apresentando o comprimento (em $x)$ de um grão.

Figura 3.29: Curvas de TGA de filmes de (a) PC; (b) PC/PANI (desdopada); PC/PANI dopada com: (c) HCl 1M; (d) TFA 1M; (e) TSA 1M.

Figura 3.30: Curvas de TGA de filmes de (a) PET; (b) PET/PANI (desdopada); PET/PANI dopada com: (c) HCl 1M; (d) TFA 1M; (e) TSA 1M.

Figura 3.31: Curvas de TGA da PANI (a) desdopada; dopada em: (b) TFA 1M;

(c) $\mathrm{HCl} 1 \mathrm{M}$ e (d) TSA $1 \mathrm{M}$.

Figura 3.32: Representação da fórmula estrutural da PANI dopada com (a) ácido clorídrico $(\mathrm{HCl} 1 \mathrm{M})$, (b) ácido trifluoracético (TFA 1M) e (c) ácido $p$ toluenosulfônico (TSA 1M).

Figura 3.33: Fotomicrografias de MEV de filmes de PET/PANI, onde observa-se a superficie da PANI (aumento de $2.000 \mathrm{x}$ ):

(a) originalmente obtida na forma dopada em $\mathrm{HCl} 1 \mathrm{M}$;

(b) desdopada em $\mathrm{NH}_{4} \mathrm{OH} 0,1 \mathrm{M}$

Figura 3.34: Fotomicrografias de MEV de compósitos de PET/PANI dopados em $\mathrm{HCl}$ (aumento de $20.000 \mathrm{x}$ ), nas concentrações: (a) 1M; redopados: (b) $1 \mathrm{M}$; (c) $0,001 \mathrm{M} \mathrm{e}$ (d) $0,0001 \mathrm{M}$.

Figura 3.35: Fotomicrografias de MO de PET/PANI (aumento de 400x):

(a)desdopada (b)obtida na forma dopada em $\mathrm{HCl} 1 \mathrm{M}$,

(c)redopada em $\mathrm{HCl} 0,001 \mathrm{M} \mathrm{e}$ (d) redopada em $\mathrm{HCl} 0,0001 \mathrm{M}$. 96

Figura 3.36: Espectros de absorção de Ultravioleta-visível de compósitos de PET/PANI, com os valores dos seus picos máximos de absorção:

(a) dopado com $\mathrm{Hcl} 1 \mathrm{M}(870 \mathrm{~nm})$; redopados em:

(b) $\mathrm{HCl}-(830 \mathrm{~nm}) ;(\mathrm{c}) \mathrm{HCl}-(680 \mathrm{~nm})$;

(d) tratado termicamente $\left(200^{\circ} \mathrm{C}, 2 \mathrm{~h}\right)$ e redopado em $\mathrm{HCl} 1 \mathrm{M}$ -

$(835 \mathrm{~nm})$. 
Figura 3.37: Espectros de UV-vis de PET/PANI em diversos tempos de imersão (t) em NMP: (A) PET/PANI-EB (desdopada), onde:
a) antes da imersão; b) $t=1 \mathrm{~min}$;
(B) PET/PANI-HCI
(dopada em $\mathrm{HCl} 1 \mathrm{M}$ ), onde: a) antes da imersão;
b) $\mathrm{t}=1 \mathrm{~min}$;

c) $t=2 \min , d) t=3 \min , e) t=4 \min , f$ ) $t=19 \min$.

Figura 3.38: Espectros de UV-vis de PET/PANI em diversos tempos de imersão (t) em NMP: (A) PET/PANI-DC(-) (dopada com descarga corona negativa) e (B) PET/PANI-DC $(+)$ (dopada com descarga corona positiva), onde:

a) antes da imersão; b) $t=1 \mathrm{~min} ; c) t=1 \mathrm{~h}$. 100

Figura 3.39: Espectros de UV-vis de PET/PANI em diversos tempos de imersão (t) em DMF: (A) PET/PANI-EB (desdopada), onde: a) antes da imersão; b) $t=1 \mathrm{~min}$, (B) PET/PANI-HCl (dopada em $\mathrm{HCl} 1 \mathrm{M}$ ), onde: a) antes da imersão; b) $t=1 \mathrm{~min}$, c) $t=2 \min , d) t=3 \min , e) t=18 \min$.

Figura 3.40: Espectros de UV-vis de PET/PANI em diversos tempos de imersão (t) em DMF: (A) PET/PANI-DC(-) (dopada por descarga corona negativa) e (B) PET/PANI-DC(+) (dopada por descarga corona positiva), onde: a) antes da imersão; b) $t=1 \mathrm{~min}$;

c) $t=2 \min ; d) t=12 \min$. 101

Figura 3.41: Espectros de UV-vis de PET/PANI em diversos tempos de imersão ( $t$ ) em m-cresol: (A) PET/PANI- $\mathrm{HCl} 1 \mathrm{M}$, onde:
a) antes da imersão;
b) $t=1 \mathrm{~min}$;
c) $\mathrm{t}=2 \mathrm{~min}$

d) $\mathrm{t}=17 \mathrm{~min}$; (B) PET/PANI-DC(-) (descarga corona negativa)

e (C) PET/PANI-DC(+) (descarga corona positiva), onde:

antes da imersão; $b$ ) $t=1$ min; c) $t=2$ min;d) $t=17$ min;

e ) $\mathrm{t}=47 \mathrm{~min}$. .102

Figura 3.42: Espectros de UV-vis de PET/PANI em diversos tempos de imersão (t) em $\mathrm{CHCl}_{3}$, (A) PET/PANI-EB (desdopada) e

(B) PET/PANI- $\mathrm{HCl}$ (dopada em $\mathrm{HCl} 1 \mathrm{M}$ ), onde: a) antes da imersão, b) $\mathrm{t}=1 \mathrm{~min}, \mathrm{c}) \mathrm{t}=16 \mathrm{~min}, \quad$ d) $\mathrm{t}=61 \mathrm{~min}$ 103

Figura 3.43: Espectros de UV-vis de PET/PANI em diversos tempos de imersão (t) em $\mathrm{CHCl}_{3}$, (A) PET/PANI-DC(+) (dopada com descarga corona positiva) e (B) PET/PANI-DC(-) (dopada com descarga corona negativa), onde: a) antes da imersão;

b) $t=1 \min ; c) t=2 \min , d) t=22 \min , e) t=82 \min$ .104

Figura 3.44: Área de dopagem (\%) da PANI versus tempo de observação (horas), onde: (a) amostras dopadas por descarga corona negativa (N), (b) dopagem por descarga corona positiva $(P)$ e (c) dopagem com $\mathrm{HCl}$ concentrado (vapor) (A). 


\section{LISTA DE TABELAS}

\section{Capítulo III - RESULTADOS E DISCUSSÕES}

Tabela l: Valores de absorção de Infravermelho em número de onda e vibração correspondente, onde: $\quad(E B)=$ PANI desdopada; $(\mathrm{HCl})=$ PANI dopada com $\mathrm{HCl} \mathrm{1M;} \mathrm{(TFA)} \mathrm{=} \mathrm{PANI} \mathrm{dopada} \mathrm{com} \mathrm{TFA} \mathrm{1M;} \quad($ TSA $)=$ dopada com TSA 1M; $\quad$ (CP) = PANI dopada com descarga corona positiva; $(\mathrm{CN})=$ PANI dopada com descarga corona negativa.......................41

Tabela II: Valores de energia de ligação (eV), intensidade, \% de área gaussiana (oriundo da deconvolução dos picos) e grupos químicos do espectro de XPS do $\mathrm{C}(1 \mathrm{~s})$ das amostras de PET/PANI. Onde: $\mathrm{HCl}=$ PET/PANI dopada com $\mathrm{HCl} 1 \mathrm{M}$; $\quad \mathrm{EB}=\mathrm{PET} / \mathrm{PANI}$ desdopada; $\quad \mathrm{DC}(+)=\mathrm{PET} / \mathrm{PANI}$ dopada com descarga corona positiva e $\mathrm{DC}(-)=$ PET/PANI dopada com descarga corona negativa.

Tabela III: Valores de energia de ligação $(\mathrm{eV})$, intensidade, \% de área gaussiana (oriundo da deconvolução dos picos) e grupos químicos do espectro de XPS do $\mathrm{N}(1 \mathrm{~s})$ das amostras de PET/PANI. Onde: $\mathrm{HCl}=\mathrm{PET} / \mathrm{PANI}$ dopada com HCI 1M; EB = PET/PANI desdopada; $\quad \mathrm{DC}(+)=$ PET/PANI dopada com descarga corona positiva e $\mathrm{DC}(-)=$ PET/PANI dopada com descarga corona negativa.

Tabela IV: Valores de absorbância ótica da PANI desdopada, dopada com $\mathrm{HCl} 1 \mathrm{M}$, TSA $1 \mathrm{M}$, TFA $1 \mathrm{M}$, descarga corona positiva $(\mathrm{DC}(+)) e$ descarga corona negativa (DC(-)).

Tabela V: Valores das dimensões de alguns grãos da PANI depositada sobre o PET. Onde: $\mathrm{PANI} / \mathrm{HCl} 1 \mathrm{M}=\mathrm{PANI}$ dopada com $\mathrm{HCl} 1 \mathrm{M}$;

PANI/EB = PANI desdopada; $\mathrm{PANI} / \mathrm{DC}(-)$ = PANI dopada com descarga corona negativa.

Tabela VI: Compósitos de PET/PANI dopados com: HCl 1M; TFA 1M; TSA 1M; desdopados (EB), sem tratamento térmico e com tratamento térmico (TT) à $200{ }^{\circ} \mathrm{C}$ durante $2 \mathrm{~h}$.Valores de aderência e condutividade elétrica... 83

Tabela VIl:Compósitos de PC/PANI dopados com: HCl 1M; TFA 1M; TSA 1M; desdopados (EB), sem tratamento térmico e com tratamento térmico (TT) à $200^{\circ} \mathrm{C}$ durante $2 \mathrm{~h}$. Valores de aderência e condutividade elétrica...84

Tabela VIII: Valores de Aderência e Condutividade Elétrica em compósitos PET/PANI e PC/PANI - dopante $\mathrm{HCl} 1 \mathrm{M}$ (antes e após tratamento térmico em diferentes tempos e temperaturas). .86

Tabela IX: Valores de Aderência e Condutividade Elétrica em compósitos PET/PANI e PC/PANI - dopante TFA 1M (antes e após tratamento térmico em diferentes tempos e temperaturas). 
Tabela X: Valores de Aderência e Condutividade Elétrica em compósitos PET/PANI e PC/PANI - dopante TSA 1M (antes e após tratamento térmico em diferentes tempos e temperaturas).

Tabela XI: Redopagem da PANI com HCl $1 \mathrm{M}$ (05 ciclos) alternados com desdopagem usando $\mathrm{NH}_{4} \mathrm{OH} 0,1 \mathrm{M}$.

Tabela XII: Redopagem da PANI com HCl 0,01M (05 ciclos) alternados com desdopagem usando $\mathrm{NH}_{4} \mathrm{OH} 0,1 \mathrm{M}$. 


\section{RESUMO}

Compósitos formados por polímeros condutores depositados sobre substratos flexíveis, tais como plásticos ou elastômeros, têm sido estudados na última década, porque combinam as propriedades de ambos os materiais que thes deram origem, formando novos materiais condutores de eletricidade, transparentes, flexiveis, resistentes e de baixo custo. Neste trabalho, foram obtidos filmes de polianilina (PANI) obtida pela síntese química diluída à temperatura ambiente, depositados sobre filmes de policarbonato de bisfenol-A $(P C)$ e poli(tereftalato de etileno) (PET). Os compósitos foram desdopados com $\mathrm{NH}_{4} \mathrm{OH} 0,1 \mathrm{M}$ e redopados com ácido clorídrico $(\mathrm{HCl} 1 \mathrm{M})$, ácido trifluoracético (TFA 1M), ácido ptoluenosulfônico (TSA $1 \mathrm{M}$ ), descarga corona negativa e positiva. Esses materiais foram caracterizados por espectroscopia no infravermelho com transformada de Fourier (FTIR), espectroscopia Raman Ressonante, espectroscopia de foto-elétrons excitados por raios-X (XPS), espectroscopia de luz na região do ultravioleta e visível (UV-vis), microscopia ótica (MO), microscopia eletrônica de varredura (MEV), microscopia de força atômica (AFM), termogravimetria (TG), testes de aderência (ASTM D-3359-B), medidas de condutividade elétrica, testes de redopagem e de solubilidade. A condutividade elétrica dos compósitos dopados com ácidos foi da ordem de $2 \mathrm{~S} / \mathrm{cm}$ e a dos dopados com descarga corona foi em torno de 0,3 $\mathrm{S} / \mathrm{cm}$. Quando esses materiais sofreram tratamento térmico observou-se que a aderência da PANI ao substrato aumentou e que a condutividade elétrica diminuiu. Os estudos da morfologia da PANI sobre os substratos revelaram morfologia do tipo granular, sendo que o tamanho e altura dos grãos parecem também serem influenciados pelo tipo de dopagem, sendo maiores os grãos de amostras dopadas com $\mathrm{HCl} 1 \mathrm{M}$. Foi aplicado um novo software desenvolvido na Embrapa Instrumentação Agropecuária para observar a estabilidade da dopagem na PANI. Com este software foram testadas amostras dopadas com descarga corona positiva e negativa e dopadas com ácido clorídrico e observou-se que a dopagem das amostras dopadas com descarga corona é mais estável do que as dopadas com o ácido. 


\begin{abstract}
Composites made of conducting polymers deposited onto flexible substrates, as plastics or elastomers, have been studied in the last decade, since the properties from both components lead to new electrically conducting materials, which are transparents, flexibles and with low cost. In this work, polyaniline (PANI) films, synthezised by the chemical synthesis at room temperature and deposited onto bisphenol-A polycarbonate (PC) and poly(ethylene terephthalate) (PET), were obtained. The composites were dedoped with $\mathrm{NH}_{4} \mathrm{OH} 0,1 \mathrm{M}$ and redoped with $\mathrm{HCl}$ $1 \mathrm{M}$, trifluoracetic acid (TFA 1M), p-toluenesulfonic acid (TSA 1M), negative and positive corona discharge. These materials were characterized by Fourier Transform Infrared Spectroscopy (FTIR), Raman spectroscopy, X-rays photo-electron spectroscopy (XPS), ultraviolet and visible absorption spectroscopy (UV-vis), optical microscopy, scanning electron microscopy (SEM), atomic force microscopy (AFM), termogravimetric analysis (TGA), adherence tests (ASTM D-3359-B), electrical conductivity measurements, redoping tests and solubility tests. The electrical conductivity of the composites doped with acids is around $2 \mathrm{~S} / \mathrm{cm}$ and those doped with corona discharge $\sim 0,3 \mathrm{~S} / \mathrm{cm}$. When these materials were thermally treated it was observed that the PANI adherence onto the substrate was increased and the electrical conductivity was decreased. The studies of the morphology of the PANI onto the substrates revealed granular morphology. It seems that the size and the height of the grains can be influenced by the dopant, been greater the grains of the samples doped with the $\mathrm{HCl} 1 \mathrm{M}$. A new software developed by Embrapa Instrumentação Agropecuária was applied to observe the stability of the PANI doped with positive and negative corona discharge and samples doped with $\mathrm{HCl}$. It was observed that the doping with corona discharge is more stable than the samples doped with protonic acids.
\end{abstract}




\section{INTRODUÇÃO}

Os polímeros condutores intrínsecos formam uma classe de materiais orgânicos que tem sido estudada extensivamente desde 1977 [1], devido ao interesse científico em suas propriedades e inúmeras aplicações tecnológicas [2]. Desde a década de 90 , está ocorrendo um interesse crescente das indústrias (Allied-Signal, BASF, IBM, Toyota, General Motors, entre outras) na comercialização desses materiais [2,3]. O Prêmio Nobel de Química do ano 2000 foi entregue aos descobridores dos polímeros condutores intrinsecos (A. G. Mac Diarmid (EUA), A. Heeger (EUA) e H. Shirakawa (Japão)).

A polianilina (PANI) é um polímero condutor que tem a capacidade de ser dopada e desdopada reversivelmente por ácidos e bases diluídos usuais [4,5], sendo usada em inúmeras aplicações, tais como: separação de gases [6], dispositivos micro-eletrônicos [2], baterias recarregáveis [3], sensores [7], mostradores [3], etc.

O entendimento da mudança de morfologia que a PANI sofre durante o processo de dopagem e desdopagem, por exemplo, é importante visando futuras aplicações, pois isto altera as suas propriedades (condutividade elétrica, aderência, solubilidade, etc).

O objetivo deste trabalho foi estudar o efeito de diferentes condiçס̃es de dopagem nas propriedades de compósitos de polianilina. Foram obtidos compósitos de PANI depositada sobre filmes de policarbonato de bisfenol-A (PC) e poli(tereftalato de etileno) (PET). Os substratos poliméricos e a PANI foram analisados separadamente e na forma de compósito. Os compósitos foram inicialmente desdopados com $\mathrm{NH}_{4} \mathrm{OH} 0,1 \mathrm{M}$ e redopados com $\mathrm{HCl} 1 \mathrm{M}$, ácido trifluoracético (TFA 1M), ácido p-toluenosulfônico (TSA 1M), descarga corona negativa e positiva. A caracterização dos compósitos foi feita por microscopia 
ótica (MO), microscopia eletrônica de varredura (MEV), microscopia de força atômica (AFM), espectroscopia de luz na região do ultravioleta e visivel (UV-vis), espectroscopia no infravermelho com transformada de Fourier (FTIR), espectroscopia Raman, e espectroscopia de fotoelétrons excitados por raios-X (XPS). A estabilidade do dopante foi monitorada por análise das imagens da área de dopagem que foram ampliadas (40x), digitalizadas e analisadas através de um programa computacional apropriado. A estabilidade da PANI foi avaliada por: testes de solubilidade, testes de aderência, medidas de condutividade elétrica, tratamentos térmicos e termogravimetria (TG). 


\section{Capítulo I - REVISÃO BIBLIOGRÁFICA}

\subsection{Polímeros Condutores Intrínsecos}

Os polímeros condutores intrínsecos formam uma nova classe de materiais porque apresentam comportamento redox reversível e a incomum combinação de propriedades dos metais (propriedades eletrônicas, elétricas e óticas) e dos plásticos (propriedades mecânicas e processabilidade). Em vista de tais características são também denominados de "Metais Sintéticos" [4,8]. A pesquisa nesta área é altamente interdisciplinar porque envolve o trabalho conjunto de profissionais de diferentes especialidades, tais como: químicos, engenheiros elétricos, físicos, engenheiros de materiais; na busca do: controle das propriedades elétricas e mecânicas destes polímeros [8]. A principal qualidade dos polímeros condutores intrínsecos é a possibilidade de poderem mudar, reversivelmente, do estado isolante ao estado condutor. Esta passagem pode ser repetida até $10^{4}$ vezes, dependendo da eficiência coulômbica do polímero [9]. Todos esses materiais contém grandes sistemas $\pi$ conjugados compostos por ligações simples e duplas altemadas ao longo da cadeia polimérica.

O primeiro polimero condutor intrínseco foi descoberto em 1977 por A. G. MacDiarmid, A. Heeger e H. Shirakawa e consistia na dopagem com iodo do poliacetileno, que até então se apresentava no estado isolante (Prêmio Nobel de Química do ano 2000). A produção do poliacetileno é feita pela polimerização do acetileno $\left(\mathrm{C}_{2} \mathrm{H}_{2}\right)$, produzindo filmes plásticos que são formados por dois isômeros: cis e trans. O isômero trans é o mais estável termodinamicamente [10]. A dopagem desse material também pode ser feita por outras substâncias, tais como: $\mathrm{Br}^{-}, \mathrm{AsF}_{5}^{-}$(doadoras de elétrons) e $\mathrm{Na}^{+}, \mathrm{K}^{+}$(receptoras de elétrons).

Atualmente, o poliacetileno ainda é o polímero que alcançou a maior condutividade elétrica, na ordem de $10^{4} \mathrm{~S} / \mathrm{cm}$ (semelhante ao cobre). Porém, devido a sua instabilidade térmica e ambiental, insolubilidade e infusibilidade, outros 
polímeros têm sido pesquisados, com o propósito de se obter propriedades interessantes para aplicações tecnológicas [9].

A seguir são apresentadas as estruturas químicas do poliacetileno e de alguns polímeros condutores que surgiram na década de 80 .

polipirrol

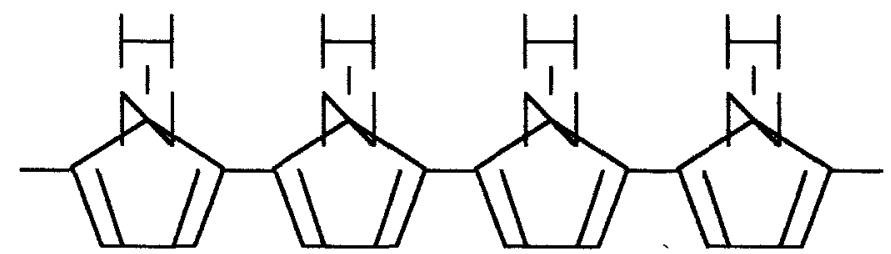

politiofeno

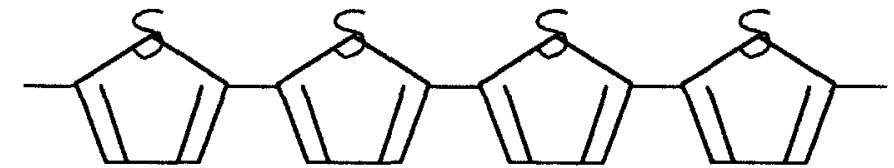

polianilina

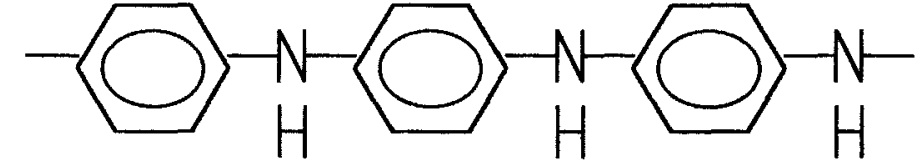

poli(trans-acetileno)

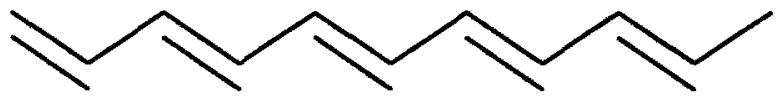

Figura 1.1: Alguns polímeros condutores [9].

Dos polimeros citados na figura anterior, apenas o polipirrol e a PANI possuem qualidades interessantes, como por exemplo, muito boa estabilidade química ambiental e baixo custo de síntese, para serem usados na confecção de baterias. Em 1987, a empresa Bridgestone começou a comercializar baterias feitas de cátodo de polianilina e ânodo de lítio. As baterias a base de PANI representam a primeira aplicaçăo industrial dos polimeros intrinsicamente condutores. Existem baterias de PANI-lítio que resistem a mais de 1.000 ciclos de carga/descarga e sua vida média pode ultrapassar 5 anos [9].

Os politiofenos demonstram ser materiais mais interessantes para serem utilizados como dispositivos eletrocrômicos (materiais que mudam de cor reversivelmente sob ação de um potencial elétrico externo) porque possuem longo tempo de vida, boa memória óptica e rápido tempo de resposta. Esses materiais 
são utilizados para fazer "janelas inteligentes" (que evitam o excesso de luminosidade no verão) e pára-brisas de automóveis [9].

Existem diversas outras aplicações para polímeros condutores, como por exemplo: dispositivos eletrônicos (junção pn, junção Schottky, transistores de efeito de campo e células fotovoltaicas), sensores (de grandezas mecânicas e eletroquímicas), revestimentos antiestáticos e blindagem contra interferência eletromagnética; membranas de troca iônica, entre outras [3].

Na figura 1.2. podemos observar a comparação dos valores de condutividade elétrica $(\mathrm{em} \mathrm{S} / \mathrm{cm}$ ) de alguns polímeros condutores (dependendo do grau de dopagem) em relação aos metais, semicondutores e isolantes. 


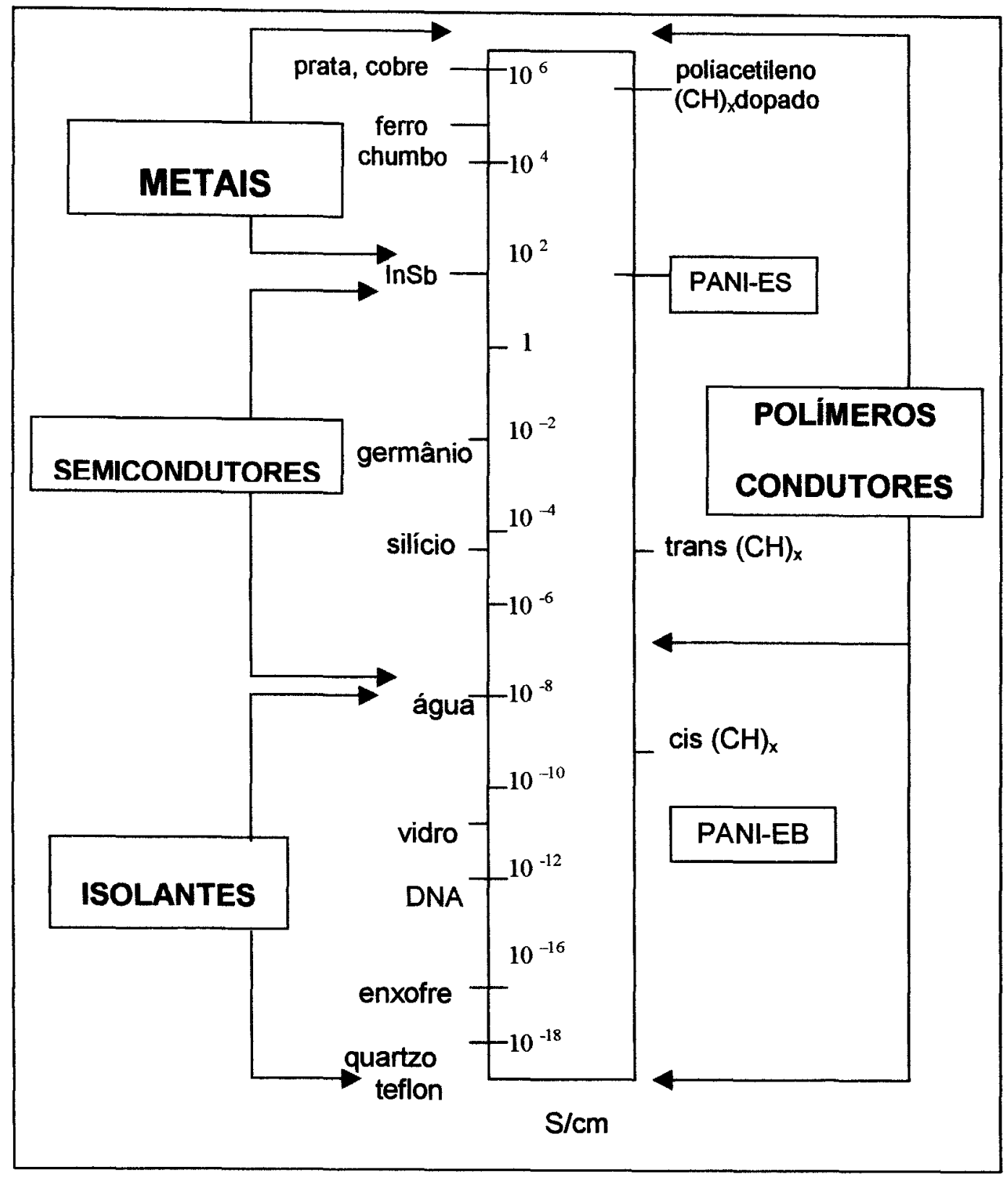

Figura 1.2.: Condutividade Elétrica de alguns materiais em S/cm [11]

A polianilina (PANI-EB/ base de esmeraldina) se apresenta na forma isolante $\left(\sim 10^{-10} \mathrm{~S} / \mathrm{cm}\right)$, sendo que após dopagem passa ao estado condutor (PANIES/ sal de esmeraldina) com condutividade elétrica em torno de $10^{-7}$ até $10^{2} \mathrm{~S} / \mathrm{cm}$, ou mais. Devido as propriedades únicas apresentadas por estes sistemas [10,12], a pesquisa dos polímeros condutores desperta um grande interesse tecnológico. 


\subsection{Polianilina (PANI)}

A PANI forma uma nova classe de polimeros condutores, porque pode ser dopada por protonação sem que haja variação no número de elétrons da sua cadeia polimérica, a qual é constituída por ligaçōes simples e duplas alternadas, onde os elétrons são removidos ou adicionados rapidamente, sem destruir as ligações químicas [9]. A PANI e seus derivados constituem um grupo de polímeros que podem possuir 1.000 meros ou mais.

A composição química na forma de base (não dopada) é apresentada abaixo.

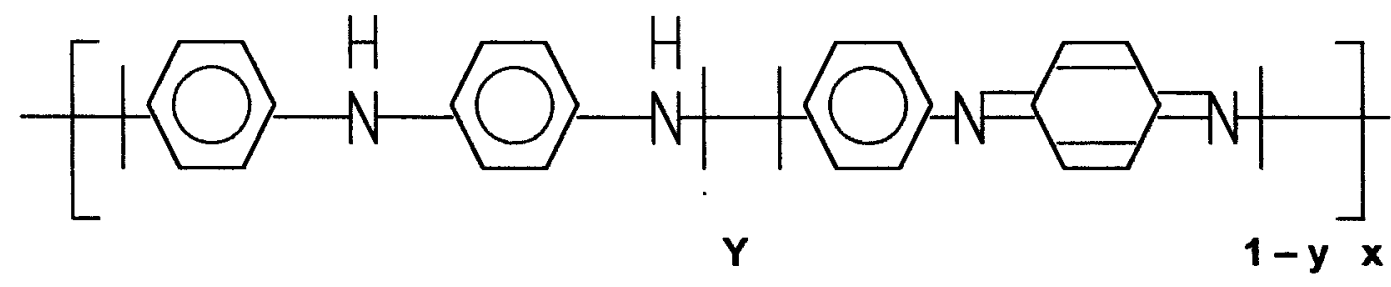

Figura 1.3: Fórmula geral da PANI

Onde: $(y)$ é a espécie reduzida e $(1-y)$ é a espécie oxidada [3].

O coeficiente $(y)$ pode variar de 1 (polímero totalmente reduzido, possuindo apenas nitrogênios amina) até zero (polímero totalmente oxidado, possuindo apenas nitrogênios imina) [3]. A PANI possui alguns estados de oxidação $[13,14,15,16]$ tendo em vista que "y " varia de zero a 1 . O estado de oxidaçăo da PANI está relacionado a quantidade de elétrons adicionados ou removidos do sistema $\pi$ da cadeia polimérica. O grau de oxidação é definido pela proporçăo de anéis quinóides formados no processo de oxidação, ou seja, quando há a remoção de hidrogênios dos sítios aminas da cadeia polimérica [3]. A pernigranilina é a espécie mais oxidada de PANI. Apresenta interessantes propriedades óticas devido à presença de muitos anéis quinóides. Em ácido sulfúrico concentrado 
possui coloração violeta [17]. A seguir está representada a fórmula estrutural da pernigranilina.

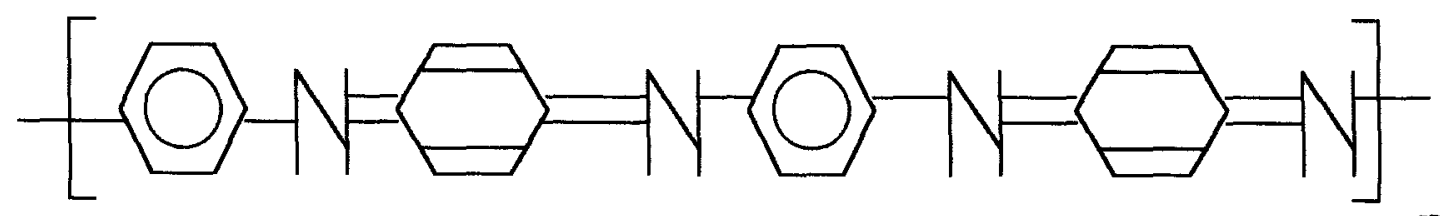

n

Figura 1.4: Fórmula estrutural da pernigranilina [17].

A leucoesmeraldina é a espécie mais reduzida da PANI, e aparece em forma de pó amarelo-pálido. Apresenta condutividade elétrica em tomo de $10^{-10}$ $\mathrm{S} / \mathrm{cm}$, por isso é isolante [18].

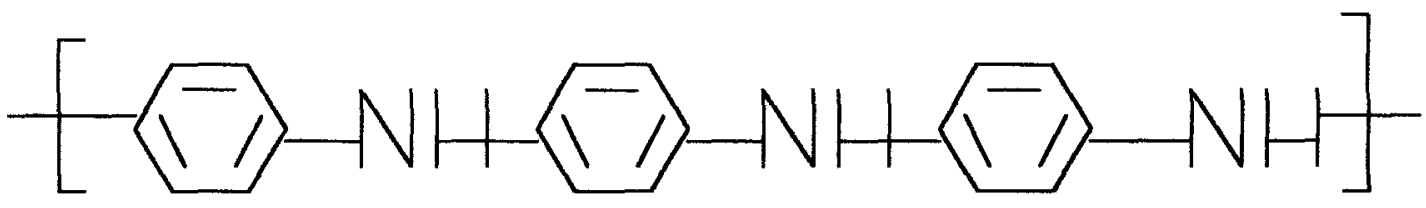

Figura 1.5: Estrutura da leucoesmeraldina [18].

A base de esmeraldina é formada pela mesma quantidade de unidades reduzidas e unidades oxidadas. Manifesta-se como um pó azul-violáceo, solúvel em alguns solventes apolares e em ácido sulfúrico concentrado [17]. A seguir é apresentada sua fórmula estrutural.

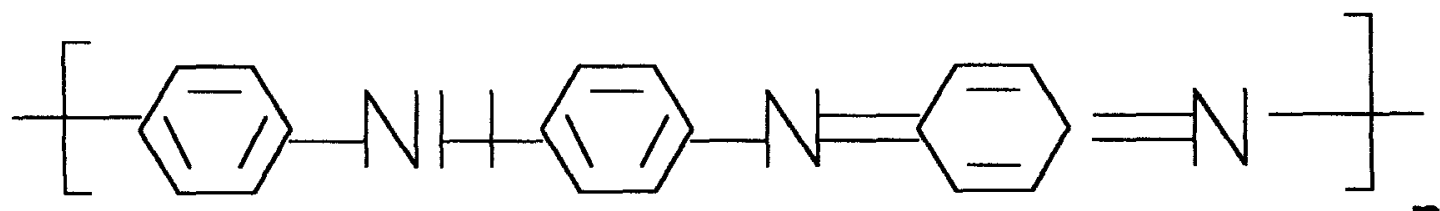

Figura 1.6: Fórmula estrutural da base de esmeraldina [17]. 
O sal de esmeraldina surge da protonação (dopagem) da base de esmeraldina com ácidos. A protonação ocorre nas unidades iminas, preferencialmente, podendo ocorrer também nos nitrogênios dos grupos aminas [17]. O sal de esmeraldina possui muito boa estabilidade térmica e ambiente. Sua cor é verde escuro. O sal de esmeraldina é a forma mais condutora entre os estados de oxidação da PANI. Na forma de base, a condutividade elétrica é baixa $\left(\sim 10^{-10} \mathrm{~S} / \mathrm{cm}\right)$ mas, após dopagem, a condutividade tende a aumentar, podendo atingir valores entre $10^{-7}$ e $10^{2} \mathrm{~S} / \mathrm{cm}$, ou mais [11].

A primeira sintese da PANI foi feita em 1862 por H. Letheby da Faculdade do Hospital de Londres (Inglaterra). Letheby obteve a PANI por oxidação anódica em ácido sulfúrico [19]. A descoberta de que a PANI poderia conduzir corrente elétrica só foi ocorrer, aproximadamente, 120 anos mais tarde [4] e desde então, inúmeros são os trabalhos na busca de entendimento do mecanismo de síntese da PANI, de como ocorre o fenômeno da condutividade elétrica e de diferentes formas de sintetizar a PANI com o objetivo de produzir polianilinas cada vez mais condutoras, estáveis termicamente e processáveis.

Devido ao fato da PANI ser um polímero condutor de baixo custo, com muito boa estabilidade térmica e ambiente, fácil dopagem e desdopagem, de rápida síntese, além de outras interessantes propriedades, tomou-se o polímero condutor com o maior número de aplicações tecnológicas. Entre as aplicações da PANI, encontram-se: eletrodos para baterias recarregáveis [9]; capacitores [2]; dispositivos eletrônicos (junção pn, junção Schottky) [3]; diodos emissores de luz (LEDS) [3]; proteção contra corrosão para o aço [3]; recobrimento condutor para fibras têxteis (roupas anti-estáticas) [21]; embalagens antiestáticas [22]; sensores químicos [7]; células foto-voltáicas [9], etc. 


\subsection{SÍNTESE DA POLIANILINA}

As duas formas mais conhecidas e utilizadas para se obter PANI são a Síntese Eletroquímica e a Sintese Química. A seguir serão apresentadas as vantagens e desvantagens da utilização de cada uma delas.

A síntese eletroquímica da PANI consiste na oxidação anódica da anilina sobre eletrodo metálico em solução eletrolítica, produzindo filmes finos de PANI. Apresenta algumas vantagens com relação à sintese química, tais como: não é necessário extrair a PANI do meio reacional (a PANI é obtida diretamente na forma de filmes finos); dispensa o uso de oxidante e catalisador, a caracterização pode ser feita in situ por análises espectroscópicas, tais como, condutivimetria, espectroscopia de infravermelho, Espectroscopia Raman, etc [4,23,24,25].

A polimerização eletroquímica da anilina já foi explorada em diversos artigos, usando vários ácidos, como por exemplo: ácido sulfúrico [26], ácido clorídrico [27], ácido trifluoracético [28], ácido polivinilsulfônico [29], etc.

O tipo de eletrodo mais utilizado é o eletrodo de platina $[28,29,30]$. Outros tipos de eletrodos também foram usados, tais como: cobre [31], zinco [31], ferro [32], chumbo [31], paládio [31], cromo [31] , ouro [33] aço inox [34], etc.

A síntese química da PANI é obtida através de oxidação da anilina em meio ácido. Uma grande diversidade de agentes oxidantes (peróxido de hidrogênio [31], persulfato de amônio [35,36,37], dicromato de potássio [26] e diferentes ácidos têm sido usados, tais como: ácidos inorgânicos (ácido clorídrico [3,31,38], ácido sulfúrico [31], ácido fosfórico [39]) e ácidos orgânicos (ácido polivinil sulfônico [3], ácido p-tolueno sulfônico [39], ácido dodecilbenzeno sulfônico [40], etc. A concentração de anilina (monômero) usada na síntese varia de $0,01 \mathrm{M}$ a 2 M. A razäo molar de oxidante por monômero varia de 2 a 1 , sendo que pode haver degradação da PANI se uma quantidade grande de oxidante for usada. 
O persulfato de amônio é um dos agentes oxidantes mais usados, pois produz alto rendimento de PANI com alta condutividade elétrica [35].

Quanto às propriedades da PANI obtidas ao final do processo de sintese, vão depender do dopante e das condiçōes de síntese (agente oxidante, meio ácido, temperatura de síntese, etc) [41]. Escolhe-se as condições de síntese em função das propriedades da PANI que se quer obter. Por exemplo, polianilina obtida através de peróxido de hidrogênio como agente oxidante apresenta baixa condutividade elétrica [31]. Sínteses usando ácido fosfórico produzem PANI com alta estabilidade térmica [39]. Sínteses que usam ácido clorídrico produzem PANI com alto rendimento, em comparação com outros ácidos, por isso é um dos ácidos mais usados na síntese química [31]. Na produção de PANI em escala industrial, a síntese química é, sem dúvida, a melhor opção pois permite a obtenção de maior quantidade de PANI , e requer, em geral, menores custos [2].

\subsection{DOPAGEM E CONDUTIVIDADE ELÉTRICA}

A dopagem consiste na adição de prótons à cadeia do polímero, por um agente dopante, provocando despovoamento do sistema $\pi$, e induzindo aumento da condutividade elétrica [10]. Estes agentes dopantes (em geral, ácidos) são usados na proporção de até $50 \%$ em relação à massa molecular da PANI, sendo que quando a dopagem chega a $50 \%$ a PANI se torna paramagnética [42]. A seguir, o esquema da protonação (dopagem) e desprotonação (desdopagem) da PANI é apresentado. 


\section{ISOLANTE - EB}
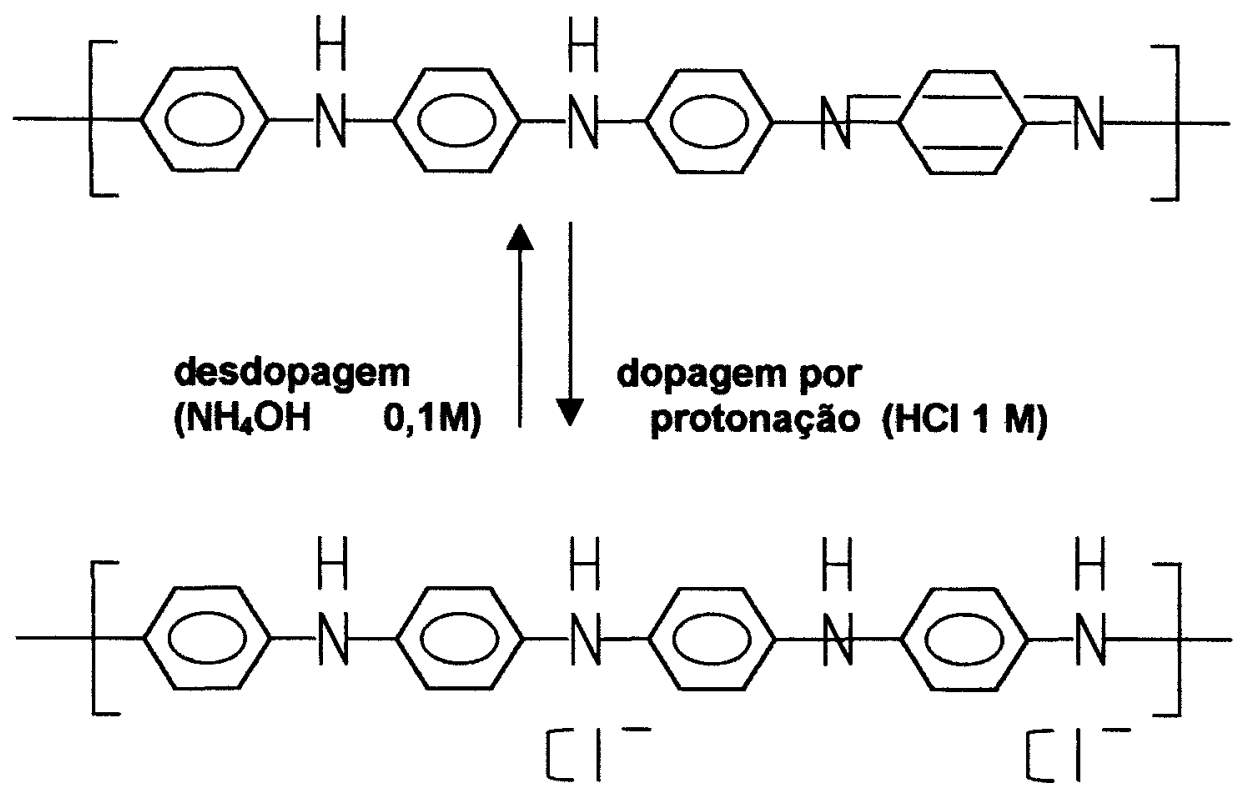

\section{CONDUTOR - ES}

Figura 1.7: Esquema de formação da banda de condução polarônica na polianilina. Onde: $E B=$ base de esmeraldina; $E S=$ sal de hidrocloreto de esmeraldina [3].

A base de esmeraldina (isolante) é protonada por ácidos (concentrados ou diluídos), originando o sal de esmeraldina (condutor). $\quad$ O processo inverso é a desprotonação da PANI, que é feito mediante imersão da mesma em solução aquosa de hidróxido de amônio, em geral, 0,1M [3 ]. A PANI dopada é formada por cátions de poli(semiquinona), originando a banda de condução polarônica, conforme figura anterior. $\quad \mathrm{Na}$ PANI a protonação ocorre com a formação de dominios protonados, originando "ilhas condutoras" imersas em regiōes não protonadas (isolantes) [4]. 
O tipo de agente dopante influencia de forma decisiva as propriedades e a morfologia da PANI $[3,11]$. O teor de água é uma das variáveis que mais influencia a condutividade elétrica da PANI, tanto na forma de sal de esmeraldina (protonada), quanto na forma de base de esmeraldina (não protonada) [31].

$\mathrm{Na}$ PANI o número de moléculas de água é igual ao número de ânions do dopante, e supõe-se que as moléculas de água estejam unidas ao polímero por ligações de Hidrogênio. O processo de exposição da amostra ao vácuo (perda de água e exposição ao vapor d'água/ganho de água) é facilmente reversivel [43]. Alguns estudos mostram que a PANI, tratada termicamente sob atmosfera inerte, apresenta condutividade elétrica um pouco melhor do que a PANI tratada ao ar. Por exemplo, a condutividade elétrica de amostras de PANI dopadas com ácido clorídrico, tratadas termicamente ao ar, diminui quando a temperatura ultrapassa $70^{\circ} \mathrm{C}$ (cerca de 1 ordem de grandeza), diminuindo a uma velocidade muito maior (em torno de 2 ordens de grandeza) após $150^{\circ} \mathrm{C}$, porém mantendo-se constante até $300^{\circ} \mathrm{C}$ quando tratadas termicamente sob atmosfera inerte. Supõe-se que as diferenças na condutividade da PANI após tratamento térmico se devam as alteraçōes na morfologia da PANI [44]. Baixas temperaturas de síntese $\left(0^{\circ} \mathrm{C}\right.$ até a temperatura ambiente) influem na massa molecular da PANI, com o aumento da massa molecular há o aumento da condutividade elétrica, segundo alguns autores $[27,38,39,43]$. Os dopantes mais utilizados são os ácidos inorgânicos e ácidos orgânicos, os mesmos usados na síntese química, conforme citados anteriormente, porém este tipo de dopagem pode causar problemas na indústria da micro-eletrônica, como migração do dopante para áreas não dopadas, por exemplo. A dopagem da PANI também pode ser feita por outros meios, tais como: exposição a raios-X [45], exposição a raios $\gamma$ [46], porém estes métodos são bastante caros, perigosos e pouco eficientes. Existe uma técnica recente de dopagem de PANI que consiste em expor a PANI (desdopada) à descarga corona $[47,48]$. Nesta 
técnica, submete-se a amostra a ser dopada à descarga elétrica estável, que é produzida próximo à extremidade metálica (ponta) do equipamento, que é submetida a alta tensão elétrica. Perto desta ponta metálica há produção de íons, moléculas excitadas e um vento elétrico (vento corona) que é produzido devido à transferência de momento mecânico, que ocorre durante o processo de colisão do gás. A descarga corona é um processo controlável porque os portadores positivos e negativos tem baixa mobilidade. Pode-se aplicar tensão elétrica positiva ou negativa, tendo-se daí os termos: descarga corona positiva e descarga corona negativa. Este método permite a dopagem da PANI a seco e a curtos intervalos de tempo, de forma a atingir niveis de condutividade na faixa do $10^{-10}$ a $10^{-1} \mathrm{~S} / \mathrm{cm}$.

\subsection{PET - Poli(tereftalato de etileno)}

O poli(tereftalato de etileno) pertence à classe dos polímeros conhecidos como poliésteres termoplásticos. Os filmes de PET são obtidos na indústria por polimerizaçăo em etapas, onde são utilizados catalisadores (óxidos metálicos, metais ou sais) a $275^{\circ} \mathrm{C}$, sob vácuo.

Na figura 1.8 é apresentada outra reação de obtenção de PET, que é feita a partir da reação do ácido tereftálico e do etileno glicol, formando como subproduto a água.
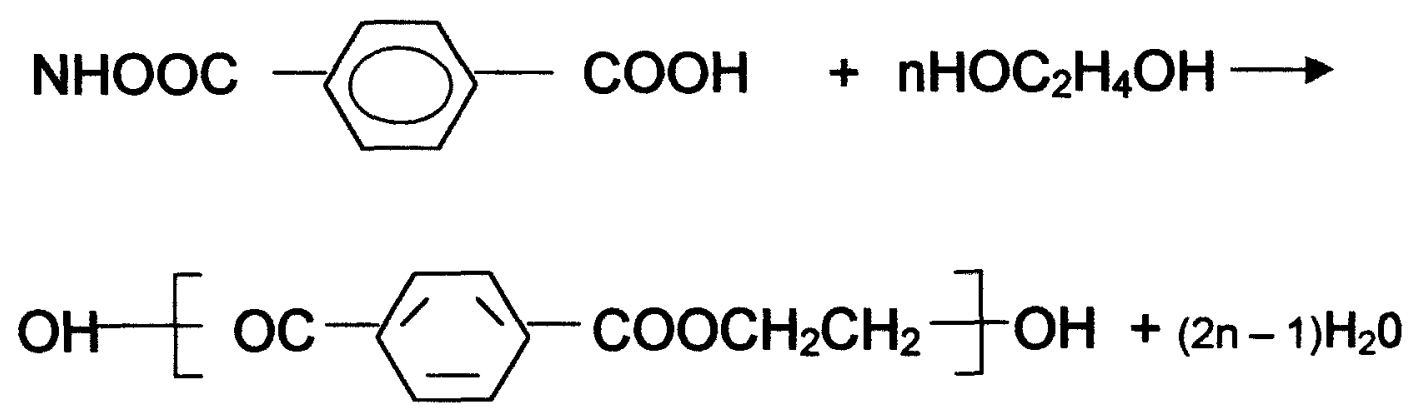

Figura 1.8: Síntese do PET (Terylene) [49]. 
O PET é obtido por extrusão e processado em espessuras que podem variar de 6 a $350 \mu \mathrm{m}$ e com vários graus de orientação uniaxial ou biaxial. Possui diversos nomes comerciais, tais como: Terphane (Rhodia-Ster), Mylar (DuPont), Melinex (ICI), Hostaphan (Kalle-Hoescht), Celanar (Celanese Plastics), etc. Existem mais de 30 fabricantes em nível mundial, sendo que no Brasil os mais conhecidos são a Rhodia-Ster e a DuPont. Os filmes de PET possuem alta resistência mecânica. Na forma cristalina, a temperaturas moderadas, o PET é em geral resistente a ácidos inorgânicos diluídos, sais não básicos, e a muitos compostos orgânicos. Contudo, são pouco resistentes a reagentes oxidantes e em particular a bases diluídas, as quais entram para o interior do polímero, quebrando os grupos éster, degradando o mesmo. O PET é praticamente inerte à água a temperatura ambiente, mas a temperatura acima de $150^{\circ} \mathrm{C}$ a água e a umidade atmosférica hidrolizam rapidamente os grupos éster a $\mathrm{OH}$ e $\mathrm{COOH}$, por essa razão - PET deve ser seco até reter no máximo 30 ppm de umidade, antes de ser processado [50].

\subsection{PC - (Policarbonato de Bisfenol-A)}

Os policarbonatos são classificados como poliésteres termoplásticos lineares derivados de compostos alifáticos ou aromáticos de um ácido carboxílico.

Existem algumas variedades de policarbonato, sendo que 0 mais utilizado na indústria é o policarbonato de bisfenol-A . Esta variedade possui transparência semelhante ao vidro, é auto-extingüivel à chama, apresenta propriedades mecânicas muito interessantes, possui alta resistência ao impacto a baixas temperaturas, baixa absorção de água $(\sim 0,5 \%)$, densidade de $1,20 \mathrm{~g} / \mathrm{cm}^{3}$ (na forma amorfa) e $1,30 \mathrm{~g} / \mathrm{cm}^{3}$ (na forma cristalina). Devido a suas propriedades, o PC possui muitas aplicações industriais, tais como: janelas de segurança, painéis 
de instrumentos, componentes do interior de aeronaves, capacetes de proteção, discos compactos, etc [51]. A cristalização do PC aromático depende da sua massa molecular, constituição química e dispersividade, por isso é considerado um polímero cristalizável, uma vez que o processo de cristalização é lento e o polímero termina se manufaturando num estado amorfo. A primeira sintese de policarbonato ocorreu em 1898, por Einhorn. A síntese consistiu na reação de sais alquílicos de hidroquinona e resorcinol em solução aquosa com fosgênio na presença de tolueno.

Em 1902 Bischoff e Hedenström obtiveram um policarbonato semelhante, através da síntese do resorcinol e hidroquinona com difenil carbonato. A primeira produção industrial de policarbonato foi feita pela G.E. Company, em 1956, e a técnica de polimerização foi descoberta por Schnell e tratava-se da síntese de um policarbonato aromático a partir do bisfenol [52]. A forma mais usual de obtenção de policarbonato é por processo de transesterificação. A reação consiste no aquecimento do bisfenol-A e do difenil carbonato até fundirem liberando fenol [53 ].

A seguir é apresentada a reação de polimerização por transesterificação do PC. 


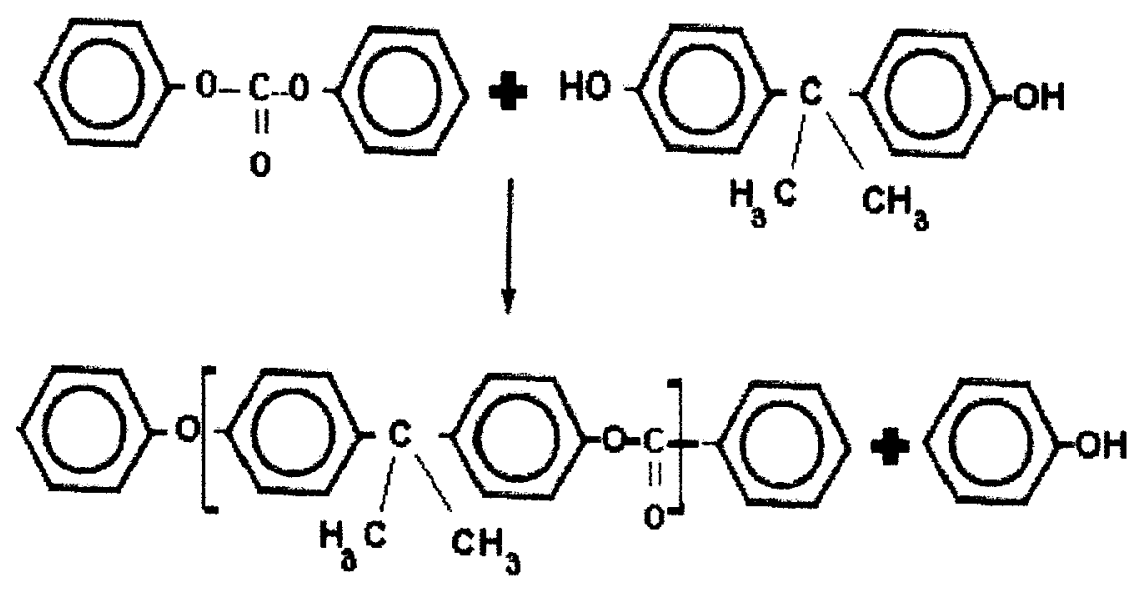

Figura 1.9: Reação de obtenção do policarbonato por transesterificação [53].

Obtém-se outros policarbonatos mediante a substituição de diferentes grupos no monômero (bisfenol - A). O policarbonato de bisfenol-A possui alto grau de rigidez devido à presença do grupo fenila e da carboxila na cadeia principal, sendo considerado, por esta razão, um dos poliésteres menos flexíveis [53].

\subsection{COMPÓSITOS DE POLIANILINA E POLÍMEROS CONVENCIONAIS}

Compósito é um novo material formado pela combinação de dois ou mais materiais quimicamente diferentes (formando duas ou mais fases distintas), sendo que o mesmo possui uma combinação das propriedades dos materiais que the deram origem[54]. O surgimento de novos compósitos poliméricos e as aplicações destes tende a aumentar cada vez mais, devido ao fato de que além das sínteses de novos polímeros, em geral, serem processos caros, existem inúmeros polímeros que já foram sintetizados e alguns ainda não foram sequer aplicados industrialmente. Nos dias atuais, há uma necessidade crescente de reciclar os polímeros existentes, bem como, produzir compósitos ou blendas destes polímeros, pois estas são iniciativas mais econômicas e menos poluentes. Os compósitos e blendas à base de polímeros condutores e polímeros convencionais 
começaram a surgir em publicações a partir dos anos 90 (PANI/PVA, polipirrol/poliestireno, politiofeno/PC, politiofeno/polestireno, etc) [2]. O objetivo principal da produção destes materiais foi porque eles possuem as propriedades elétricas e óticas dos polímeros condutores e a flexibilidade, leveza, durabilidade, resistência mecânica e transparência dos polímeros convencionais. Uma das vantagens da deposição de polímeros condutores em substratos (polímeros convencionais, vidros, elastômeros, etc) entre tantas outras citadas anteriormente, é que o polímero condutor estando espalhado sobre a superficie do substrato aumenta a sua superficie de contato, aumentando assim a sua capacidade de troca iônica, por exemplo, com outros meios. Toppare et al. [7,25] obtiveram compósitos de PC e PANI por síntese eletroquimica, transparentes, flexíveis e com boas propriedades mecânicas. Estes materiais estão sendo estudados como sensores de gases amônia e ácido clorídrico. A condutividade elétrica desses compósitos, dopados com ácido clorídrico, foi da ordem de $10^{-2} \mathrm{~S} / \mathrm{cm}$ e a da PANI pura em tomo de $10^{-1} \mathrm{~S} / \mathrm{cm}$. Quando utilizaram o ácido trifluoracético como dopante o valor da condutividade encontrada para o compósito e para a PANI pura foi de em torno de $10^{-2} \mathrm{~S} / \mathrm{cm}$. Segundo Toppare et al. [7], as vantagens de produzir esses compósitos está no fato de que além de possuírem valores de condutividade praticamente iguais aos da PANI pura, os compósitos se mostraram mais sensiveis quanto à detecção de gás amônia e de ácido clorídrico, em relação a amostras de PANI pura. Eles atribuem este fenômeno ao fato da PANI estar depositada na superfície do substrato, estando, assim, com uma área superficial maior para trocas com outras substâncias.

Im e Byun [55,56], obtiveram compósitos de filmes de nylon e polianilina, por sintese química à temperatura ambiente, por 2 horas, dopados com ácido cloridrico $(\mathrm{HCl})$, ácido benzenosulfônico (BSA), ácido sulfosalicílico (SSA) e ácido p-toluenosulfônico (TSA), tratados termicamente a diferentes 
temperaturas, sob ar atmosférico, obtendo condutividade elétrica máxima de 3,5 $\mathrm{x}$ $10^{-2} \mathrm{~S} / \mathrm{cm}$ para a PANI/nylon dopada com $\mathrm{HCl}$. Os autores atribuem os baixos valores de condutividade elétrica as prováveis ligações de Hidrogênio entre o substrato e a PANI, observado pelos deslocamentos nos espectros de Infravermelho (FTIR) e ultravioleta-visivel. Segundo os autores, a estabilidade térmica desses materiais dopados com ácidos orgânicos é maior do que a dos dopados com ácidos inorgânicos.

Li e Wan [57] obtiveram compósitos condutores de filmes de PET/PANI e de PET/polipirrol, cujas condutividades elétricas foram de $0,2 \mathrm{~S} / \mathrm{cm}$ e $0,10 \mathrm{~S} / \mathrm{cm}$, respectivamente.

Kulkarni (Americhem Inc.) [22] produziu compósitos de filmes de PET e polianilina, por sintese eletroquímica, com excelente transparência, resistência química à água, calor e solventes usuais de limpeza. $\mathrm{O}$ autor indicou o uso deste material para embalagens antiestáticas.

Neoh et al. [58] depositaram PANI sobre substratos de polietileno de baixa densidade (LDPE) observando que a espessura da PANI aumentava com o aumento do tempo de imersão no meio reacional da síntese da PANI e que a aderência da PANI em substratos de polímeros apolares como o polietileno é muito ruim, destacando quase todas as camadas de PANI do substrato no teste de despelamento. Porém após enxertarem a superfície do LDPE com monômeros vinílicos de ácido acrílico (AAC) ou n,n-dimetilacrilamida (DMAA) conseguiram tornar a PANI muito aderente ao LPDE, além do fato de que o DMAA e o AAC auxiliaram no processo de deposição da PANI sobre o substrato.

Trivedi e Dhawan [59] enxertaram polianilina condutora em chapas de vidro, lã de vidro e tecidos de nylon e após caracterização das propriedades elétricas e testes de interferência eletromagnética destes materiais, chegaram a conclusão de que os mesmos apresentam comportamento eletroquímico idêntico 
ao da polianilina eletrodepositada sintetizada pelo mesmo método e sugeriram uma provável aplicação como materiais anti-estáticos.

Buckley et al. [60] depositaram PANI sintetisada por sintese química e dopada com TSA $1 \mathrm{M}$ e $\mathrm{HCl} 1 \mathrm{M}$ em substratos de poli(metil metacrilato) - (PMMA) e testaram a resistência do depósito de PANI usando testes padrōes segundo normas da ASTM. Foi feito teste de tratamento térmico da seguinte maneira: expuseram amostras por 102 min à luz solar, jatos de spray de água e seguida de mais 18 min à luz solar (ASTM 500, método de teste 7.2). Testaram efeitos de maresia mediante a imersão em vapor de $\mathrm{NaCl}(5 \%)$ à $35^{\circ} \mathrm{C}$ (método da $\mathrm{ASTM} B$ 117). O teste de exposição à umidade foi feito à $38^{\circ} \mathrm{C}$ e $100 \%$ de umidade (ASTM D2247-87). Antes e após aplicado cada teste, as amostras foram monitoradas por medidas de condutividade elétrica e espectroscopia XPS. As amostras obtidas apresentaram condutividade elétrica em torno de 0,7 S/cm, logo após a síntese, sendo que após os testes de resistência (estabilidade), após um periodo de 8 dias, houve um pequeno decréscimo da condutividade elétrica. A espectroscopia XPS (ESCA) foi usada para determinar mudanças na composiçâo superficial após os testes e revelou, juntamente com medidas de condutividade elétrica que os filmes apresentaram uma queda no nivel de dopagem (protonação) e condutividade após tratamento térmico e teste de maresia, e quase nenhuma mudança após teste de exposição à umidade.

Heeger et al. [61] apresentaram um modelo para a construção de diodos emissores de luz (LEDS) de polianilina condutora e substrato de materiais transparentes e flexiveis, tais como vidro ou plásticos. As vantagens destes materiais são: baixo custo; podem ser fabricados à temperatura ambiente; flexiveis; transparentes, podendo ser vistos dos dois lados do material. Porém o problema está no fato de que a PANI é dopada com ácidos que ao volatizarem vão 
corroendo, com o passar do tempo, os metais que estão no equipamento. Futuramente deverão ser fabricadas com outros dopantes que sejam mais estáveis.

A empresa Allied-Signal vem produzindo alguns materiais compósitos que têm uso como indicadores de pressão e radiações. Um tipo de dispositivo indicador de radiação produzido por esta empresa é composto por um filme de PVC, que possui uma dispersão de PANI e é depositado sobre um adesivo. Quando a radiação atinge o $\mathrm{PVC}$, libera $\mathrm{HCl}$ que dopa a PANI, ativando o indicador, pela mudança de cor.

Além da Allied-Signal, outras empresas, como a Bridgestone e a Interlink Eletronics, estão iniciando a produção de materiais compósitos de polímeros condutores para fins semelhantes [9].

\subsection{IMAGEM DIGITAL}

Pode-se considerar uma imagem digital como sendo uma matriz do tipo $C(x, y)$, onde " $C$ " representa o nível da cor cinza para um dado ponto ou elemento da matriz, denominado de "pixel", ou também "elemento de imagem". Denominase de "resolução vertical" o número de linhas da matriz de "pixels" e de "resolução horizontal" o número de colunas. Quando é feito o produto das resoluçōes vertical e horizontal, obtém-se a resolução espacial, que é proporcional à quantidade de detalhes na imagem [62]. Devido à dificuldade de representar a imagem real com máxima resolução, como a imagem obtida pelo olho humano, utiliza-se a densidade de resolução de imagem, que é determinada em número de "pixels" por unidade de medida linear. São usadas o número de "pixels" por polegada americana, ppi "pixels per inch" e dpi "dots per inch". As imagens digitais são armazenadas na forma de 1, 4, 8 e 24 bits, resultando, respectivamente em 2, 16, 256 e 16.777.216 cores. Em geral, representa-se uma imagem 
digital de 8 bits em tons de cinza, com estes variando de 0 à 255 , sendo que 0 representa a cor preta e 255 , a cor branca. A esta caracteristica, ou seja, a resolução em cores denomina-se resolução em profundidade. Como cada computador apresenta uma capacidade de memória limitada, deve-se otimizar o uso trabalhando-se com o número máximo de cores que leve em conta a capacidade de armazenamento e processamento do computador e a quantidade de cores necessárias ao trabalho e mantendo a qualidade dos dados [63]. 
Capítulo II - PROCEDIMENTO EXPERIMENTAL

\subsection{Materiais e Métodos}

\subsubsection{Preparação dos filmes de PET - Poli(tereftalato de etileno)}

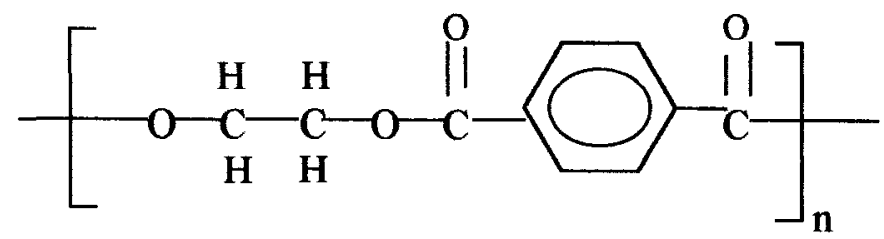

Figura 2.1: Fórmula estrutural do monômero do PET [64]

O filme de PET foi fornecido pela RHODIA - STER filmes Ltda, denominado Terphane 19.10, com espessura de $12 \mu \mathrm{m}$. Os filmes foram cortados nas dimensões de $2 \mathrm{~cm} \times 8 \mathrm{~cm}$, lavados com acetona, e secos ao ar, a temperatura ambiente por 1 hora. A preparação do PET foi feita na Embrapa Instrumentação Agropecuária.

\subsubsection{Preparação dos filmes de PC - Policarbonato de Bisfenol-A}

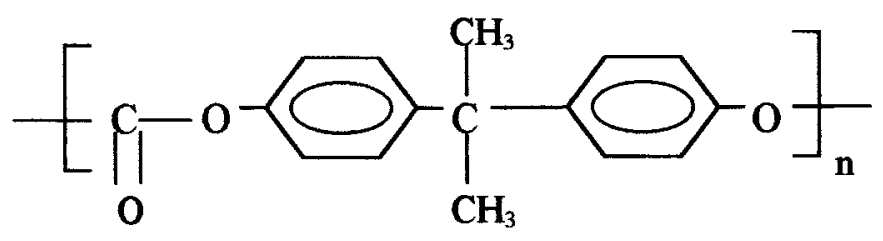

Figura 2.2: Fórmula estrutural do monômero do PC [53].

O PC (denominado LEXAN 4535) da COPLEN S.A., na forma de pó, foi doado pelo Prof. Dr. Luis A. Pessan da UFSCar/DeMa/Polimeros. O PC em pó foi 
seco em estufa sob vácuo, à $90^{\circ} \mathrm{C}$, durante 3 horas. A obtenção dos filmes de $\mathrm{PC}$ foi feita por termoprensagem nas seguintes condições: foi colocada em torno de $200 \mathrm{mg}$ de PC em pó entre as placas da prensa por 30 min de aquecimento (sem prensagem) e o sistema ficou assim por mais $30 \mathrm{~min}$ de resfriamento (com prensagem a $200 \mathrm{Kgf} / \mathrm{cm}^{2}$ ). Foram obtidos diversos filmes de PC (com cerca de $35 \mu \mathrm{m}$ de espessura) e os filmes foram cortados nas dimensões de $2 \mathrm{~cm} \times 8 \mathrm{~cm}$ e utilizados sem lavagem prévia. Foi utilizada a prensa manual com aquecimento e resfriamento do laboratório do Prof. Dr. Adhemar C. Rúvolo Filho do Instituto de Química da UFSCar.

\subsubsection{Síntese da Polianilina sobre os Substratos Poliméricos}

\subsubsection{Destilação da Anilina}

A anilina (Aldrich Chemical Co, Inc) foi destilada à $60^{\circ} \mathrm{C}$, sob vácuo, para eliminar produtos de oxidação e impurezas. A destilação da anilina foi feita no Laboratório de Polímeros do Instituto de Física/USP/São Carlos.

\subsubsection{Síntese dos compósitos PET/PANI e PC/PANI}

Foram dissolvidos $4 \mathrm{ml}$ de anilina destilada (monômero - 0,0548 mol) em $300 \mathrm{~mL}$ de $\mathrm{HCl} 1 \mathrm{M}$ (Merck) (solução A) e 2,87g de persulfato de amônio (Merck) (agente oxidante) $(0,0126 \mathrm{~mol})$ foram dissolvidos em $200 \mathrm{~mL}$ de $\mathrm{HCl} 1 \mathrm{M}$ (solução B). A solução $B$ foi adicionada à solução $A$ (gota à gota), durante 2 min. A este sistema foram adicionados os filmes de PC e PET, os quais estiveram imersos no recipiente reacional, sob agitação por 40 minutos, obtendo-se assim os compósitos PC/PANI e PET/PANI, pela deposição superficial da polianilina (PANI). Os compósitos foram secos ao ar, a temperatura ambiente, por 1 hora, a seguir foram secos em dessecador sob vácuo durante 24 horas. Desta maneira, a PANI foi obtida diretamente na forma dopada (com $\mathrm{HCl} 1 \mathrm{M}$ ), sendo desdopada com $\mathrm{NH}_{4} \mathrm{OH} \quad 0,1 \mathrm{M}$ e redopada novamente com diversos ácidos e/ou sob descarga 
corona. A sintese da polianilina foi feita na Embrapa Instrumentação Agropecuária.

\subsubsection{Desdopagem da Polianilina}

Alguns compósitos foram desdopados em solução de hidróxido de amônio $\left(\mathrm{NH}_{4} \mathrm{OH}\right) 0,1 \mathrm{M}$, durante 2 horas, e secos em dessecador sob vácuo dinâmico por 6 horas.

\subsubsection{Redopagem da Polianilina}

\section{I - Dopantes Químicos}

Alguns compósitos obtidos, após desdopagem, foram redopados em:

- ácido clorídrico (HCl) (Merck), nas seguintes concentrações:1 M; 0,01 M;

$0,001 \mathrm{M}$ e $0,0001 \mathrm{M}$

- ácido trifluoracético (TFA), $\mathrm{CF}_{3}-\mathrm{COOH}$, na concentração: $1 \mathrm{M}$ (FARMITALIA - Carlo Erba)

- ácido p-toluenosulfônico (TSA), $\mathrm{CH}_{3}-\left(\mathrm{C}_{6} \mathrm{H}_{4}\right)-\mathrm{SO}_{3} \mathrm{H}$, na concentração: $1 \mathrm{M}$ (Aldrich Chem. Co Inc.)

A redopagem dos compósitos ocorreu por imersão dos mesmos nas soluções ácidas citadas acima durante um tempo de 2 horas, a seguir os compósitos foram secos em dessecador sob vácuo em tomo de 6 horas (até apresentarem valores de condutividade elétrica constantes, indicando que estavam secos). As desdopagens e redopagens (com substâncias químicas) foram efetuadas na Embrapa Instrumentação Agropecuária.

\section{II - Dopagem por Descarga Corona}

Algumas amostras dos compósitos desdopados foram redopadas com Descarga Corona Positiva e Descarga Corona Negativa. O sistema de Descarga Corona é apresentado a seguir: 


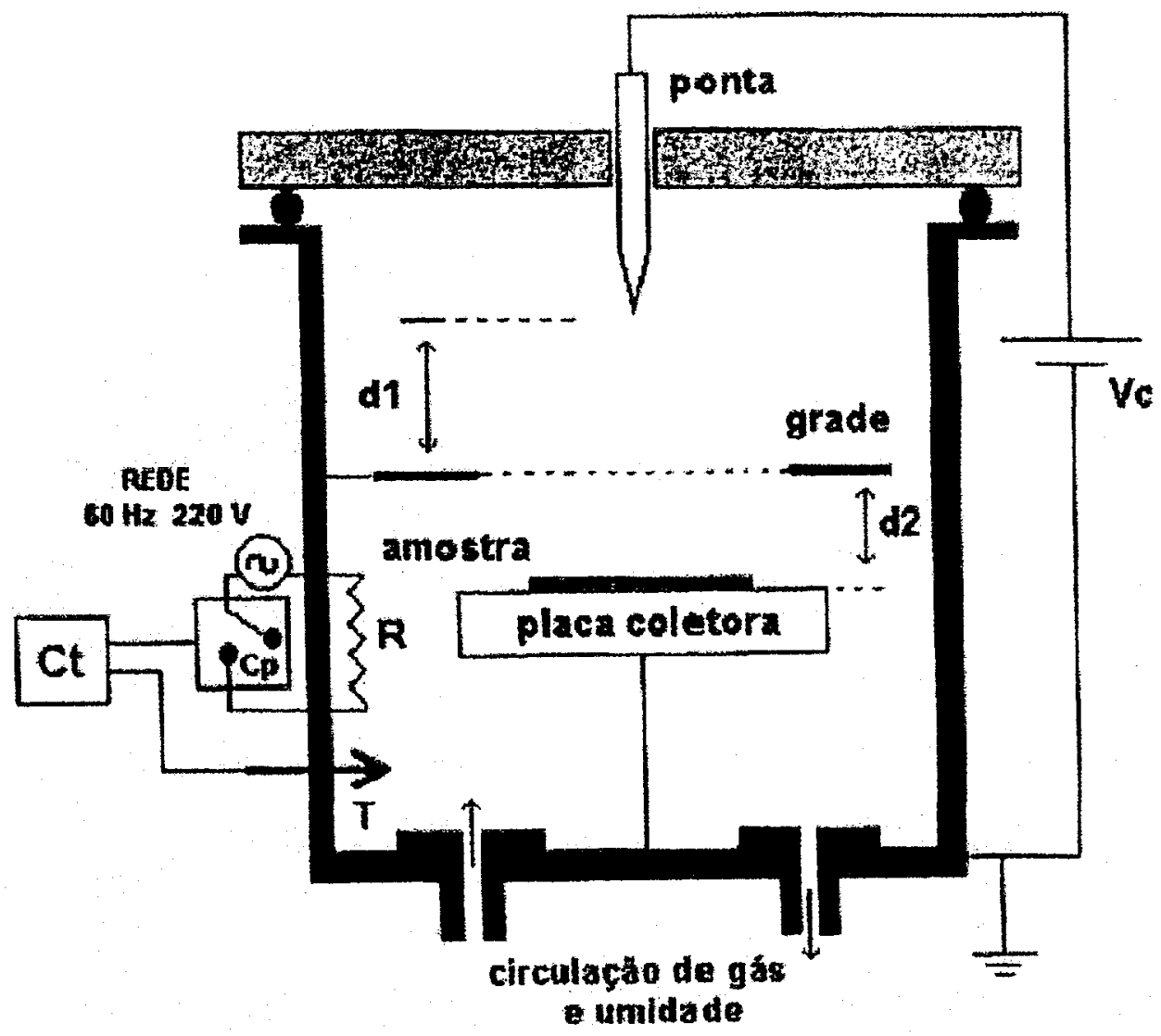

Figura 2.3: Triodo de Corona. Onde: $V_{c}=$ fonte de tensão; $R=$ resistência; $C_{p}=$ controlador de potência; $\mathbf{T}=$ termopar; $\mathbf{C}_{t}=$ controlador de temperatura; $\mathbf{d}_{\mathbf{1}}=$ distância ponta-grade e $d_{2}=$ distância grade-plano coletor [64].

Este sistema é conhecido como Triodo de Corona. O sistema possui uma câmara com controle de gás, temperatura e umidade, e é constituído de uma ponta e uma grade metálicas e um plano coletor. Pode-se mover a ponta na direção vertical (conforme a figura anterior, $d_{1}=$ distância ponta-grade).

Aplica-se alta tensão com fonte de corrente controlada na ponta.

A distância $d_{2}$ corresponde à distância que separa a grade e o plano coletor, sendo regulada pelo operador, também podendo variar na vertical. Para que não haja a deposição de íons ou surgimento de alto campo elétrico na amostra que está sendo dopada, os quais provocariam ruptura dielétrica na mesma, liga-se a grade metálica ao fio terra. A fonte de tensão usada é Bertan, modelo 225, de 0 
à $\sim 30 \mathrm{kV}$, que fornece tensão positiva e negativa. As condições otimizadas de dopagem por descarga corona foram: descarga corona negativa $(\mathrm{t}=45$ minutos; $i=10 \mu \mathrm{A} ; \mathrm{d}_{\text {ponta-grade }}=18 \mathrm{~mm}$ e $\mathrm{d}_{\text {grade-amostra }}=6 \mathrm{~mm}$ ); descarga corona positiva $\left(\mathrm{t}=2 \mathrm{~h} ; \mathrm{i}=20 \mu \mathrm{A} ; \mathrm{d}_{\text {ponta-grade }}=18 \mathrm{~mm}\right.$ e $\left.\mathrm{d}_{\text {grade-amostra }}=6 \mathrm{~mm}\right) . \quad$ As dopagens por descarga corona foram feitas no Laboratório de Polímeros do Instituto de Física da USPISão Carlos, pelo aluno de Mestrado do Curso de Física da USP/São Carlos, Silmar Antônio Travain, sob orientação do Prof.Dr. José Alberto Giacometti.

\subsubsection{Tratamento térmico dos Compósitos}

Submetemos a tratamento térmico algumas amostras de compósitos dopados em meio ácido (em todas as diferentes condições, mencionadas anteriormente), amostras desdopadas, amostras de PC e PET . As condições foram: tempo $(1 / 2 \mathrm{~h}, 1 \mathrm{~h}, 2 \mathrm{~h} \mathrm{e} 4 \mathrm{~h})$ e temperatura $\left(50^{\circ} \mathrm{C}, 100^{\circ} \mathrm{C}, 130^{\circ} \mathrm{C}, 180^{\circ} \mathrm{C} \mathrm{e}\right.$ $\left.200^{\circ} \mathrm{C}\right)$. Foi utilizada a mufla EDGCON 3 P (EDG - Equipamentos a Controles Ltda), da Embrapa Instrumentação Agropecuária.

\subsubsection{Testes de Aderência}

Foram submetidos a testes de aderência os compósitos de PC/PANI e PET/PANI desdopados, dopados com os ácidos TFA $1 \mathrm{M}$, TSA $1 \mathrm{M} \mathrm{e} \mathrm{HCl}$ $(0,01 M, 0,001 M, 0,0001 M$ e $1 M)$, amostras desdopadas e amostras dopadas e tratadas termicamente. Os testes seguiram a norma técnica ASTM D 3359, método de teste $B$ [65]. Esta norma só pode ser usada em materiais que estejam revestidos com uma camada fina $(<125 \mu \mathrm{m}) . \quad O$ teste consiste em fazer 06 cortes horizontais e 06 cortes verticais na amostra, sendo que a distância entre cada corte deve ser de $2 \mathrm{~mm}$. Os cortes devem ser feitos com um instrumento de corte "pouco" afiado, para evitar que corte o substrato, corta-se apenas a camada de revestimento (no presente caso, a polianilina). 
A seguir, deve-se limpar a superfície cortada com uma escova muito macia, para retirar qualquer resíduo de corte da camada externa, sem riscá-la. Por fim, fixa-se fita adesiva sobre os cortes firmemente, sem deixar bolhas, esperase 60 segundos, e remove-se a fita rapidamente, em um ângulo o mais próximo possível de $180^{\circ}$. Examina-se a superfície após a remoção da fita adesiva, e a mesma é classificada de acordo com o número percentual de área de camada removida, por exemplo: $0 \%$ - nenhuma parte foi removida (5 B), $5 \%$ de área removida (4 B), 5 a $15 \%$ de área removida (3 B), 15 a $35 \%$ de área removida (2 B), 35 a $65 \%$ (1 B) e maior do que $65 \%(0 \mathrm{~B})$. Os testes de aderência foram realizados na Embrapa Instrumentação Agropecuária.

\subsubsection{Condutividade Elétrica}

As medidas de condutividade elétrica dos compósitos obtidos e dopados, foram feitas utilizando-se o Método de Quatro Pontas [66].

Este método consiste em colocar a amostra (filme) em um sistema constituído por quatro contatos elétricos eqüidistantes, mantidos sob pressão na superfície da amostra. Aplica-se corrente elétrica (10 $\mathrm{nA}$ a $1 \mathrm{~mA}$ ) entre os contatos das extremidades da amostra e mede-se a diferença de potencial que é gerada entre os contatos internos.

Utiliza-se a equação: [66]

$$
\sigma=i . C / V . w
$$

Onde: $\boldsymbol{i}=$ corrente elétrica aplicada

$\mathbf{V}=$ diferença de potencial elétrico medida

$\mathbf{w}=$ espessura da polianilina (depositada sobre o substrato)

$C=$ constante (depende da largura, comprimento, espessura da amostra e da distância entre os contatos elétricos). 
O valor da espessura da polianilina $\mathbf{w}$ foi medido através da técnica de Microscopia de Força Atômica (AFM).

O equipamento utilizado pertence ao Grupo de Polímeros do Instituto de Física/USP/São Carlos e trata-se de uma fonte de corrente programável Keithley, modelo 224, acoplada a um eletrômetro programável Keithley, modelo 617.

\subsubsection{Espectroscopia de Foto-elétrons excitados por Raios-X (XPS)}

Foram analisadas por XPS algumas amostras de PET (sem tratamento), PET (tratado termicamente em mufla, à $200^{\circ} \mathrm{C}$ por 2 horas), PET/PANI dopada em $\mathrm{HCl} 1 \mathrm{M}$, PET/PANI dopada por descarga corona positiva, PET/PANI dopada por descarga corona negativa e PET/PANI desdopada com $\mathrm{NH}_{4} \mathrm{OH} 0,1 \mathrm{M}$.

O objetivo das análises foi a caracterização qualitativa e quantitativa dos elementos quimicos das superficies das amostras, bem como os grupos químicos, pois esta técnica dá a composição química de uma área com espessura máxima de $10 \mathrm{~nm}$. O equipamento utilizado foi o espectrômetro Perkin Elmer PHI 5400 , usando uma fonte de $\mathrm{Mg} \mathrm{k \alpha}$. A fonte de Raios-X funcionou com uma potência de $300 \mathrm{~W}$. A pressão na câmara de análise foi mantida à $10^{-8}$ mbar durante as medidas. Para compensar os efeitos de carga superficiais, todas as energias de ligação foram referenciadas ao pico de carbono neutro C 1 à $284,6 \mathrm{eV}$.

A composição química foi determinada pela deconvolução dos picos do $\mathrm{C}$ 1s e do $\mathrm{N}$ 1s e foi dada a área percentual dos mesmos, bem como o valor percentual dos elementos $\mathrm{C}, \mathrm{N}$ e $\mathrm{O}$ das amostras. Os espectros foram obtidos com ângulo de $45^{\circ}$. As análises foram feitas pelos alunos Adriana Martin e Leonardo Patemo (alunos de Doutorado DeMa/UFSCar, orientados pelo Dr. Luiz H.C.Mattoso/Embrapa Instrumentação Agropecuária), na Universidade de Wisconsin, EUA sob a co-orientação do Dr. Ferencz Denes. 


\subsubsection{Espectroscopia de absorção de luz na região do Ultravioleta e Visível (UV-vis)}

Foram analisados por UV-vis, todos os tipos de compósitos obtidos na forma dopada (nos diferentes ácidos) e por descarga corona, desdopados, bem como, os filmes que foram imersos em diferentes solventes orgânicos (para avaliar a estabilidade da dopagem da PANI). Esta técnica permite observar, através da absorção de luz pela amostra em diferentes comprimentos de onda, o quanto uma amostra pode estar dopada em relação à outra. Com esta técnica detectam-se as transições eletrônicas da polianilina dopada e desdopada. Utilizou-se um espectrometro da marca Hitachi, modelo UV-U-200, acoplado a microcomputador, pertencente ao Laboratório de Polímeros do Instituto de Física/USP/São Carlos.

\subsubsection{Espectroscopia no Infravermelho com Transformada de Fourier (FTIR)}

Esta técnica foi utilizada para. caracterizar a estrutura química da polianilina desdopada, dopada em diferentes condições de ácidos e sob descarga corona, bem como a estrutura química do PC e do PET. As análises foram feitas com o espectrometro de Infravermelho PERKIN-ELMER, software usado:spectrum - 1000, da Embrapa Instrumentação Agropecuária.

\subsubsection{Espectroscopia Raman Ressonante}

Foram analisadas por esta técnica amostras de PET, PANI (desdopada)/PET, PANI(dopada com HCl 1 M)/PET, e compósitos de PET/PANI dopados com descarga corona positiva e negativa. O principal objetivo foi o de observar se havia alguma diferença química entre as amostras dopadas com descarga corona. As análises foram feitas pela Prof .Dr'. Márcia Temperini, no Instituto de Química da USP/São Paulo. Foi usado o equipamento Renishaw 
Raman Imaging Microscope (System 3000), contendo microscópio Olympus e detector CCD (Wright, $600 \times 400$ pixels), resfriado por Peltier.

\subsubsection{Microscopia Ótica (MO)}

Foi observada a morfologia de amostras de compósitos em um microscópio ótico Olympus, modelo $\mathrm{BH}$, acoplado à uma câmera fotográfica Olympus, modelo C-35 A, da Embrapa Instrumentação Agropecuária. As amostras foram observadas sobre lâminas de vidro. Foram feitas observaçōes nos aumentos de $400 x$ e $1.000 x$, a seguir as imagens selecionadas foram fotografadas.

\subsubsection{Microscopia Eletrônica de Varredura (MEV)}

Utilizou-se esta técnica para avaliar a morfologia da polianilina sobre os substratos (desdopada, dopada em diferentes condições e com tratamentos térmicos). Também foi observada a morfologia dos substratos PC e PET, com e sem tratamento térmico. Foi utilizado um microscópio eletrônico de varredura computadorizado da marca Zeiss, modelo DSM 960, usando-se feixe de elétrons com energia de 10 a $25 \mathrm{kV}$, e amplificações de 2.000 e 20.000 vezes. As amostras foram coladas nas bordas com tinta prata condutora em suportes apropriados para análise de MEV. A seguir, foi depositada uma camada fina de ouro $(20 \mathrm{~nm})$ sobre este filme, com a utilização de um Sputter Coater (plasma de argônio), marca Balzers, modelo SCD 50.

\subsubsection{Microscopia de Força Atômica (AFM)}

Esta técnica foi usada para avaliar a morfologia da polianilina depositada sobre o PET, uma vez que permite observar uma superfície com mais detalhes do que a técnica citada no item anterior (MEV). Foi utilizado um microscópio de força atômica Topometrix, modelo Discovery TMX 2010. 
As imagens foram coletadas pelo Dr. Paulo S. P. Herrmann Jr, na Embrapa Intrumentação Agropecuária. Obteve-se as imagens usando-se pontas de varredura de dióxido de silício com constante de mola de $45 \mathrm{~N} / \mathrm{m}$ e com freqüência de varredura na faixa de 0,5 a 2 Hertz para o modo não contato.

\subsubsection{Termogravimetria (TG)}

Foram efetuadas análises de termogravimetria para verificar se havia influência da polianilina na estabilidade térmica do compósito, variando o tipo de dopante e na forma desdopada (os termogramas formam feitos para todos os tipos de compósitos obtidos e para o PET e PC). As análises foram feitas no CCDMUFSCar, no termoanalisador $N E T Z S C H$, modelo TG 209, com varredura de 30 à $700^{\circ} \mathrm{C}$, taxa de aquecimento de $10^{\circ} \mathrm{C}$ por minuto, usando nitrogênio como gás de arraste.

\subsubsection{Estabilidade da dopagem da PANI (análise de imagens com softwares)}

Este estudo foi efetuado em amostras de compósitos de PET/PANI obtidas pela síntese química diluída à temperatura ambiente da PANI. As amostras foram desdopadas com $\mathrm{NH}_{4} \mathrm{OH}$ (Merck) 0,1M e redopadas com descarga corona positiva e negativa (conforme itens 2.1 .4 e 2.1.5), outra amostra foi redopada sob vapores de $\mathrm{HCl}$ (Merck), em capela, por um tempo de $\sim 10$ segundos. A redopagem foi feita apenas em uma área retangular $(1 \mathrm{~mm} \times 2,5 \mathrm{~mm}$ ) em cada corpo de prova (foram usados 3 corpos de prova para cada tipo de amostra). O controle do tamanho da área de dopagem foi feito com auxilio de uma máscara de chapa fina de cobre, revestida com polietileno, vazada no interior, possuindo as seguintes dimensões externas: $10 \mathrm{~mm} \times 15 \mathrm{~mm}$ e as medidas da abertura central eram de $1 \mathrm{~mm} \times 2,5 \mathrm{~mm}$ (conforme figura 2.4). 
A máscara foi elaborada no Laboratório de Micro-eletrônica do Instituto de Física da USP/São Carlos.

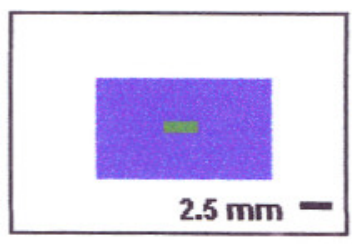

Figura 2.4: Máscara para dopagem controlada da PANI.

A amostra desdopada (azul) foi fixa à máscara com fita adesiva e após dopagem e remoção da máscara, a região dopada, à vista desarmada, parecia estar na forma retangular (conforme figura anterior), independentemente do tipo de dopante usado. Imediatamente foi feita a captura das imagens (digitalização). Este processo pode ser realizado de algumas formas. No presente trabalho, as imagens foram digitalizadas em 24 bits, com resolução espacial de 250 ppi, usando um microscópio estereoscópio com zoom ocular de $10 \mathrm{x}$ de aumento, lente de $4 \mathrm{x}$, modelo XTB WILD, acoplado a uma telecâmera Color CCD-LG (SAMSUNG), conectada a um computador padrão (PC) equipado com 64 MB de memória RAM e processador Pentium de $100 \mathrm{MHz}$. Foram coletadas logo após a dopagem, 9 imagens, ou seja: usou-se 3 corpos de prova para cada tipo de dopagem (descarga corona negativa, descarga corona positiva e vapores de $\mathrm{HCl}$ concentrado). A seguir, as imagens foram coletadas em intervalos de horas $(0,25 h, 0,75 h, 2 h, 4 h$, $16 \mathrm{~h}, 40 \mathrm{~h}, 112 \mathrm{~h}, 232 \mathrm{~h}, 472 \mathrm{~h}$ e $712 \mathrm{~h}$ ), em um período total de aproximadamente 1 mês de observação. O número total de imagens digitalizadas foi de 90 imagens, que por sua vez, posteriormente, sofreram pré-processamento e binarização (cada uma das 90 imagens), totalizando 270 imagens durante este estudo.

As condições ambientais foram (em ambiente controlado por ar-condicionado): umidade relativa do ar em torno de $50 \%$ e temperatura ambiente em 
torno de $25^{\circ} \mathrm{C}$. Após a captura das imagens, através da telecâmera, as imagens foram visualizadas com auxílio de um programa computacional denominado kdl v.1.0 (kit de desenvolvimento laboratorial), desenvolvido na Embrapa Instrumentação Agropecuária. Na figura a seguir, pode-se ver a primeira (inicial) e a última imagem (após 712 horas), obtida pelo microscópio, de cada tipo de amostra dopada com os diferentes dopantes.
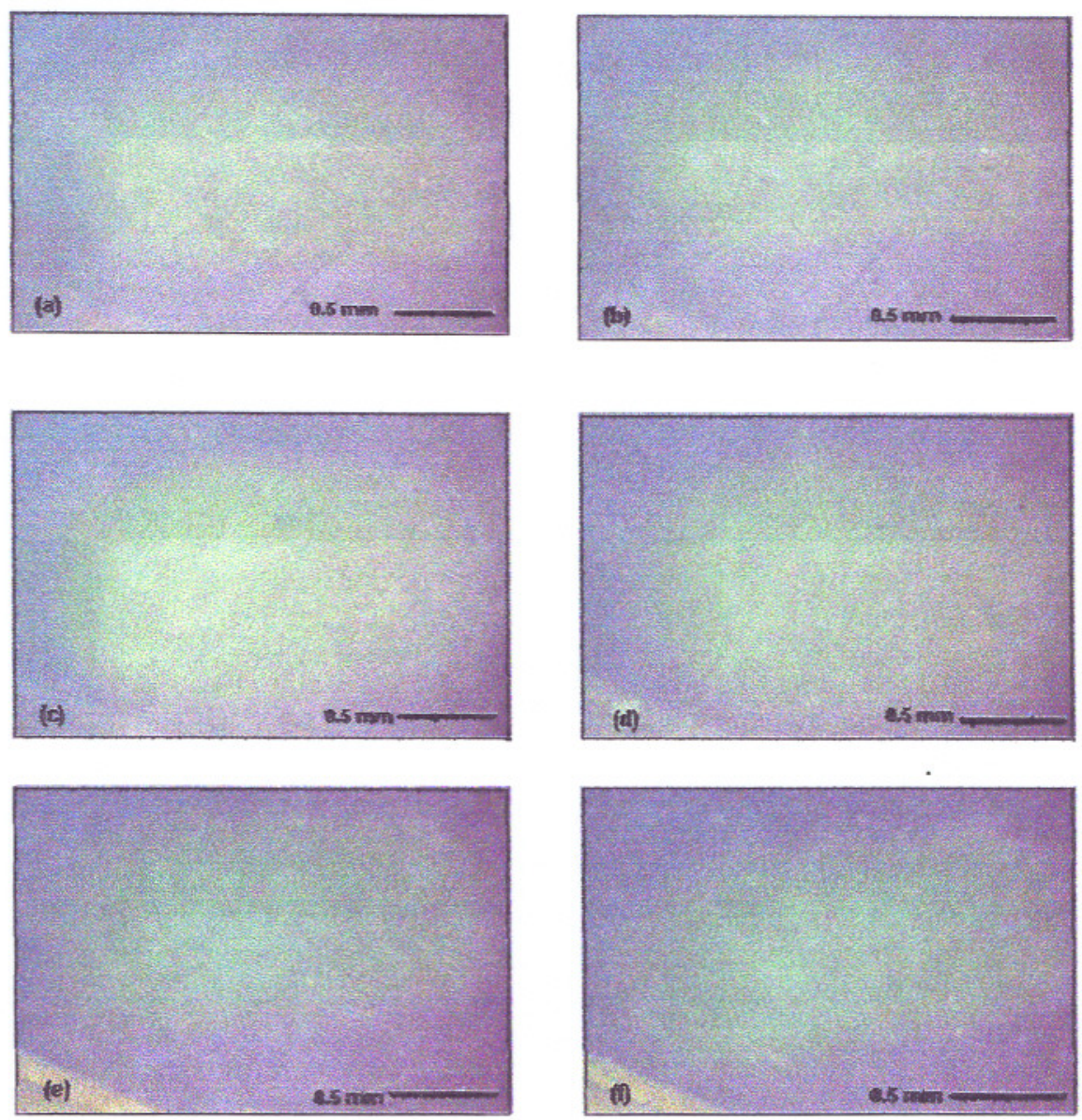

Figura 2.5: Imagem digitalizada, com resolução espacial de 250 ppi e 24 bits, de PANI dopada na região central da imagem. As amostras (a), (c) e (e) foram obtidas logo após realizada a dopagem. As imagens (b), (d) e (f) são as últimas imagens obtidas (após $712 \mathrm{~h}$ de observação). As amostras foram dopadas por: descarga corona negativa em (a) e (b); descarga corona positiva em (c) e (d); vapores de $\mathrm{HCl}$ concentrado em (e) e (f).

Todas as amostras, independentemente do tipo de dopante, apresentaram a mesma tonalidade de verde, porém a imagem vista pelo microscópio não pareceu mais ser retangular como quando era observada à vista desarmada, mas 
apresentou aspecto elipsóide. As imagens digitalizadas passaram por préprocessamento que consistia na conversão de 24 bits para a resolução de 8 bits (256 cores) através do aplicativo Image Convert.exe, a fim de poder trabalhar com o sistema computacional SIARCS $3.0 \AA$, ambos desenvolvidos na Embrapa Instrumentação Agropecuária. Esta conversão é necessária, uma vez que o SIARCS 3.0 \& opera com 256 cores. Com este sistema pode-se selecionar apenas a área que se quer analisar da imagem. Também possui ferramentas de apresentação, edição e processamento de imagem digital, dentre os quais destacase o filtro denominado THRESHOLD, o qual foi usado neste trabalho. Usa-se este filtro para identificar os objetos de interesse de uma imagem e separá-los do resto, através da manipulação direta da tabela de cores da imagem. Portanto, nas imagens de cada figura procedia-se à separação da área desdopada da área dopada mediante aplicação do filtro. Esta operação foi feita com base na distribuição de cores da imagem, a região dopada possuía cor verde e a região desdopada, cor azul. Através da tabela de cores da imagem, no programa, era possivel fazer a escolha de todos os tons "degradés" entre as cores verde claro e escuro, para selecionar apenas a área dopada.

$\mathrm{Na}$ figura 2.6 pode-se visualizar o resultado para a faixa de cores.

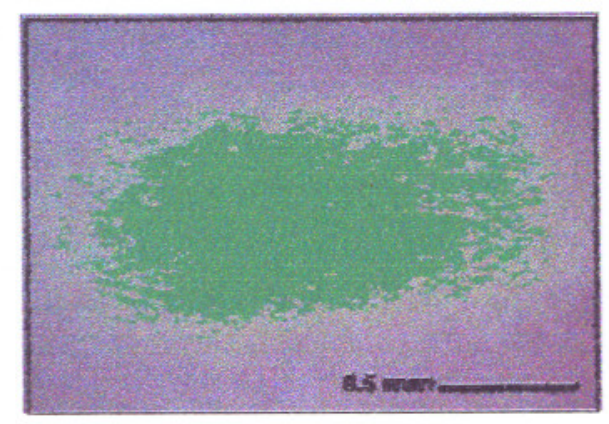

Figura 2.6: Imagem digital ( 250 ppi e 8 bits) com aplicação do filtro THRESHOLD na cor verde-esmeralda, com a finalidade de destacar na imagem a área de dopagem da PANI. 
A seguir foi feita (para cada imagem que foi pré-processada) a binarização das imagens, conforme figura 2.7. O processo de binarização da imagem consiste na transformação das cores originais da imagem, para as cores preto e branco, somente. Os pixels que representam a área de dopagem (área verde), são pintados de preto e o resto da imagem a porção não dopada (área azul), de branco.

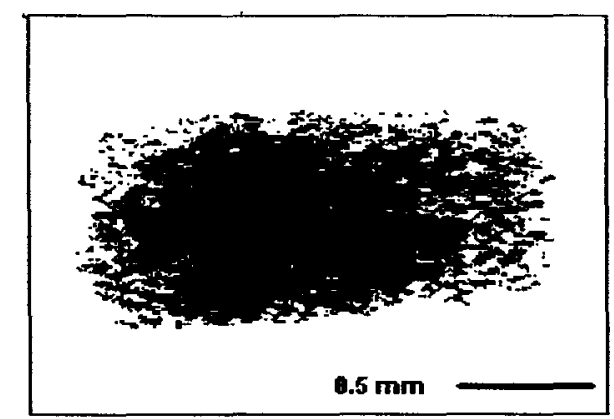

Figura 2.7: Imagem digital (250 ppi e 8 bits) binarizada da porção que foi dopada da PANI.

Após a binarização foi feita a contagem de pixels (quantificação da imagem). A imagem binarizada era salva com a extensão *.BMP e analisada, contado o número de pixels da região selecionada, bem como o seu percentual, automaticamente.

Os valores obtidos encontram-se abordados na forma de gráficos na seção de Resultados (item 3.3). 


\section{Capítulo III - RESULTADOS E DISCUSSÕES}

\subsection{Caracterização e Morfologia dos compósitos PET/PANI e PC/PANI}

\subsubsection{Espectroscopia no Infravermelho com Transformada de Fourier (FTIR)}

A técnica de Espectroscopia FTIR foi usada para caracterizar a PANI dopada depositada sobre PET e PC. Também foram analisados a PANI desdopada e os filmes puros de PC e PET. As camadas de PANI foram destacadas dos substratos por fricção com $\mathrm{KBr}$ em pó, desta forma a PANI e os substratos puderam ser analisados separadamente, uma vez que na forma de compósito foi impossivel caracterizá-los porque a PANI e os substratos possuem bandas em valores de número de onda muito próximos no espectro de Infravermelho. Os substratos poliméricos (PET e PC) foram analisados na forma de filmes. A PANI desdopada e a dopada nos diversos tipos de dopantes foi analisada da seguinte forma: a PANI na forma de pó foi misturada com $\mathrm{KBr}$ (em pó) à 1\%, e prensada, obtendo-se pastilhas que eram analisadas por FTIR. Esta técnica foi muito útil na diferenciação dos grupos químicos da PANI dopada nos diversos tipos de dopantes (ácido inorgânico, ácidos orgânicos e com descarga corona positiva e negativa), bem como dos substratos usados (PC e PET), permitindo uma análise qualitativa dos mesmos.

Adiante são apresentados os espectros da PANI na forma de base de esmeraldina (isolante) desdopada com $\mathrm{NH}_{4} \mathrm{OH} 0,1 \mathrm{M}$ e da PANI dopada com $\mathrm{HCl}$ $1 \mathrm{M}$. 


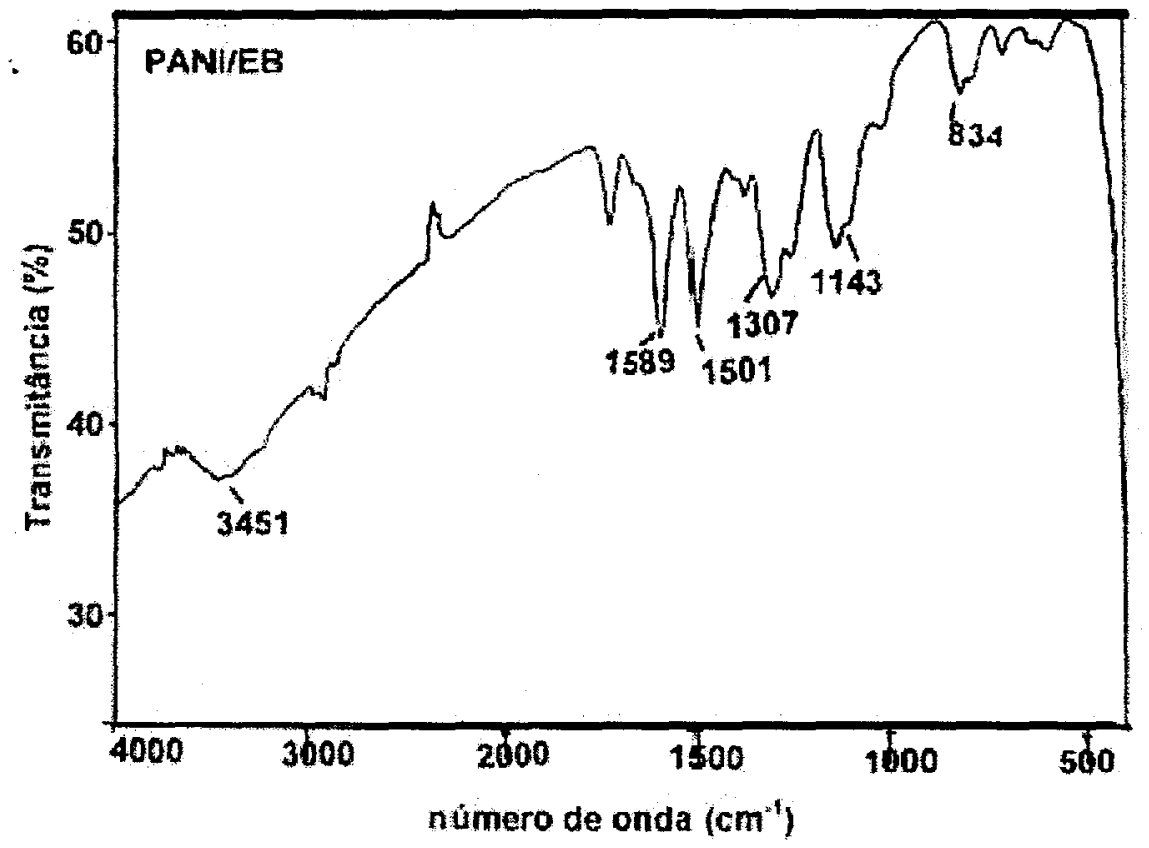

Figura 3.1: Espectro de FTIR da PANI desdopada (PANI/EB) com $\mathrm{NH}_{4} \mathrm{OH} \mathrm{0,1M}$.

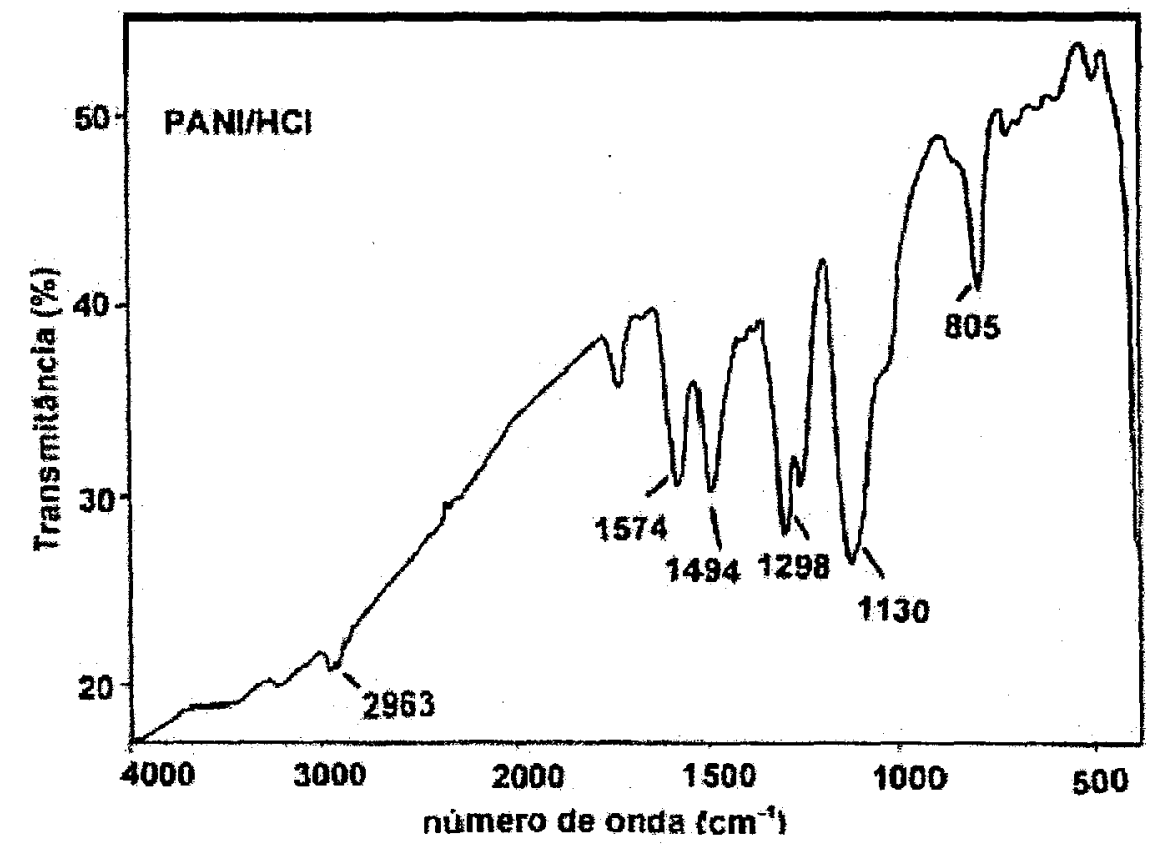

Figura 3.2: Espectro de FTIR da PANI dopada com $\mathrm{HCl} 1 \mathrm{M}(\mathrm{PANI} / \mathrm{HCl})$.

As figuras 3.3 e 3.4 apresentam, respectivamente, os espectros da PANI dopada com os ácidos orgânicos TFA 1M e TSA 1M. 


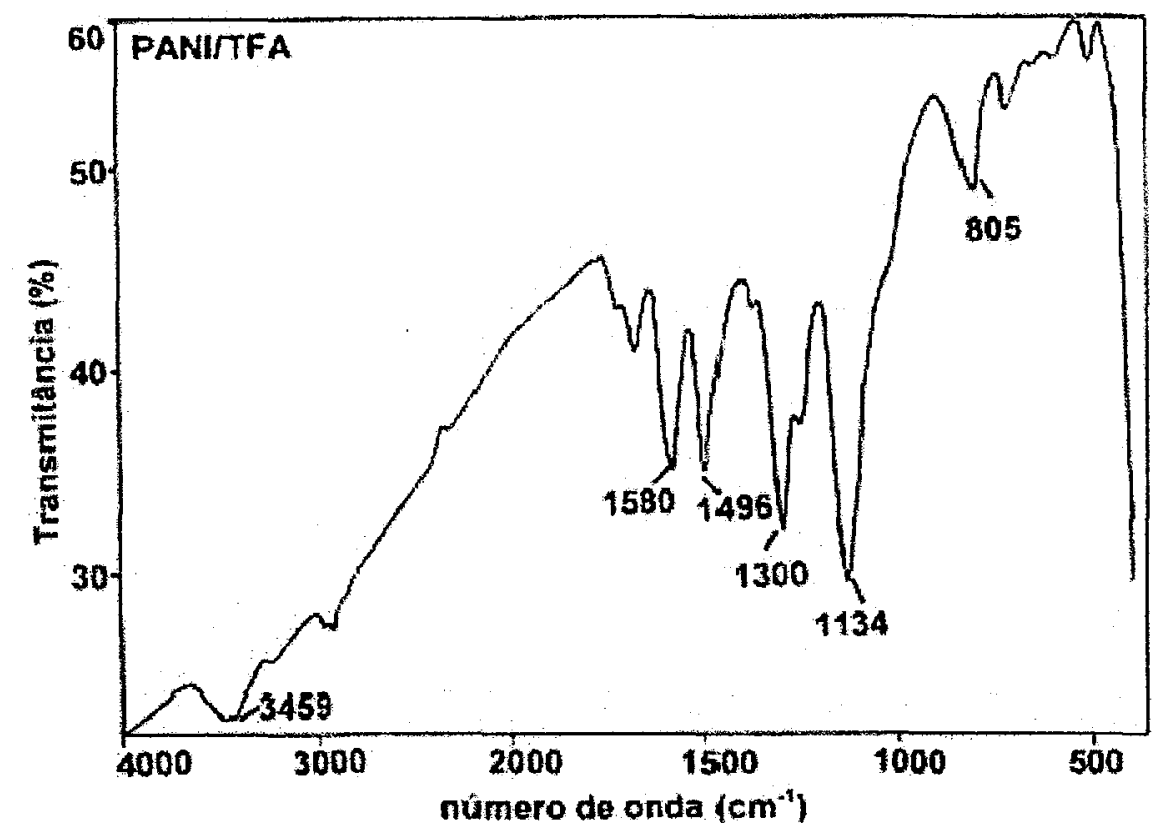

Figura 3.3: Espectro de FTIR da PANI dopada com TFA 1M.

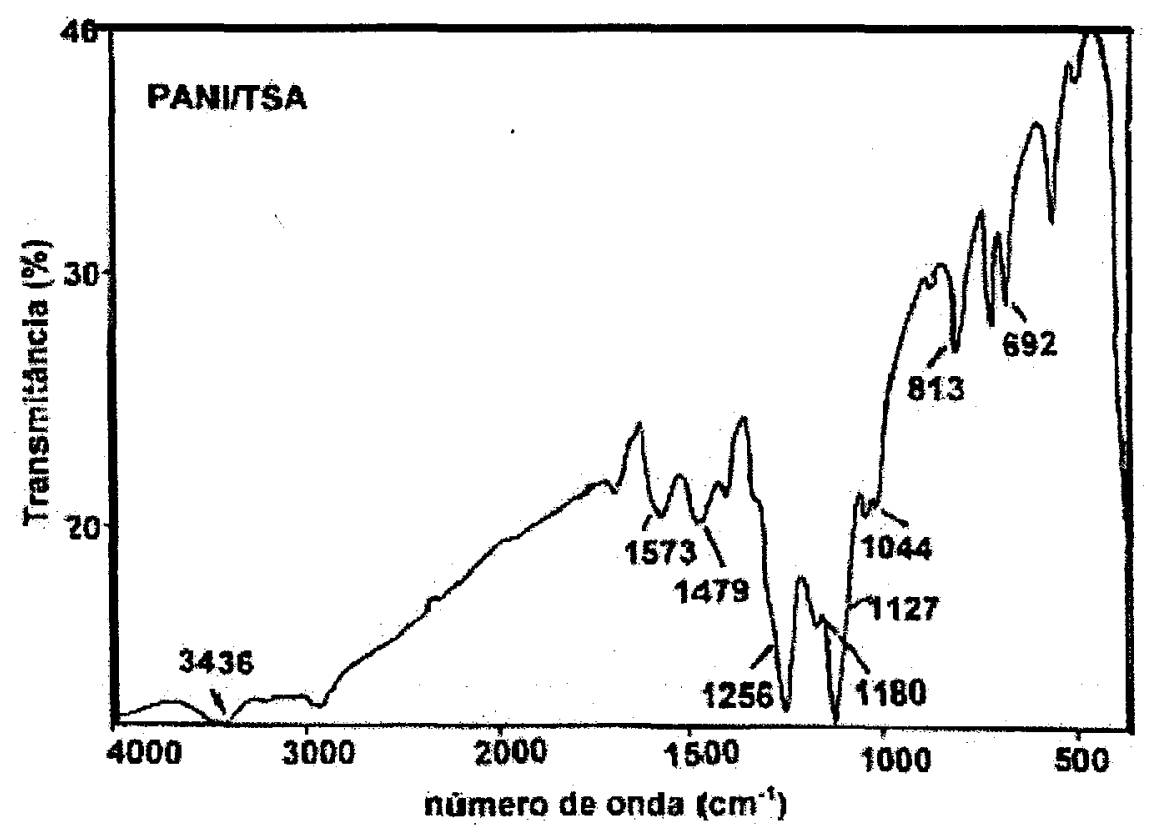

Figura 3.4: Espectro de FTIR da PANI dopada com TSA 1M.

As figuras 3.5 e 3.6 apresentam, respectivamente, os espectros de FTIR da PANI dopada com descarga corona positiva e descarga corona negativa. 


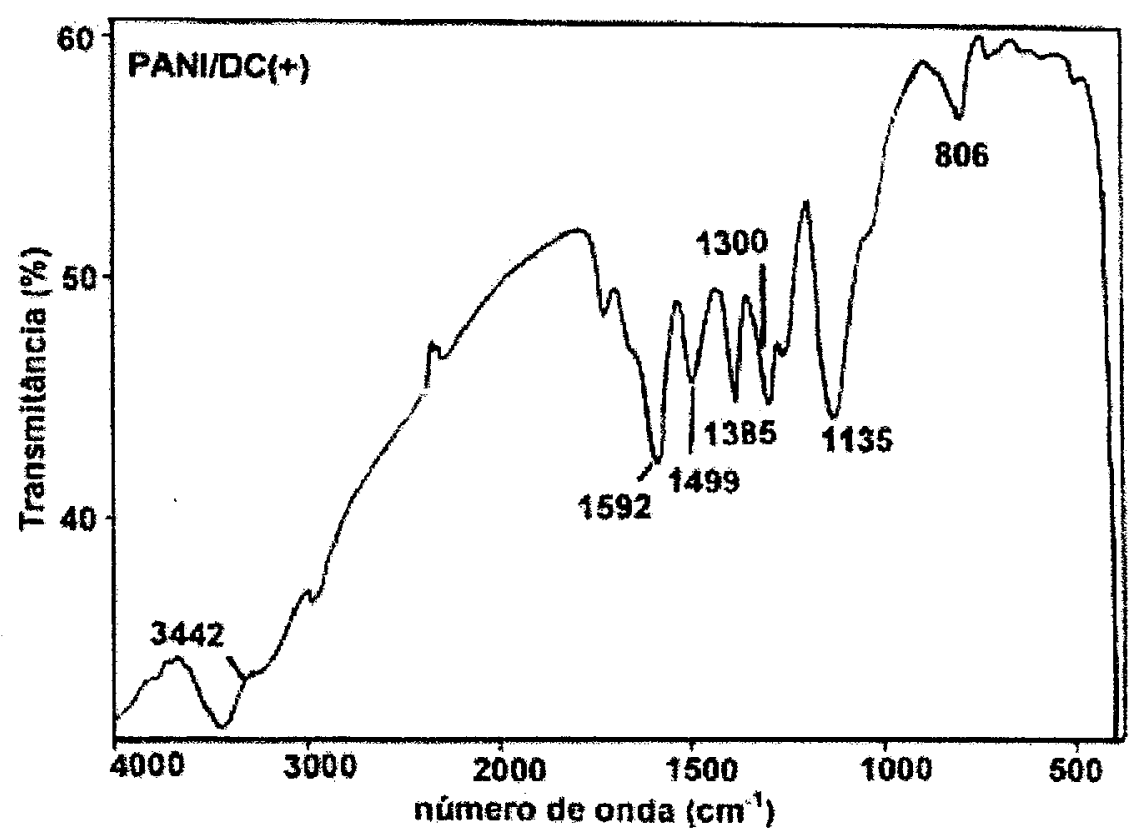

Figura 3.5: Espectro de FTIR da PANI dopada com descarga corona positiva (PANI/DC $(+)$ ).

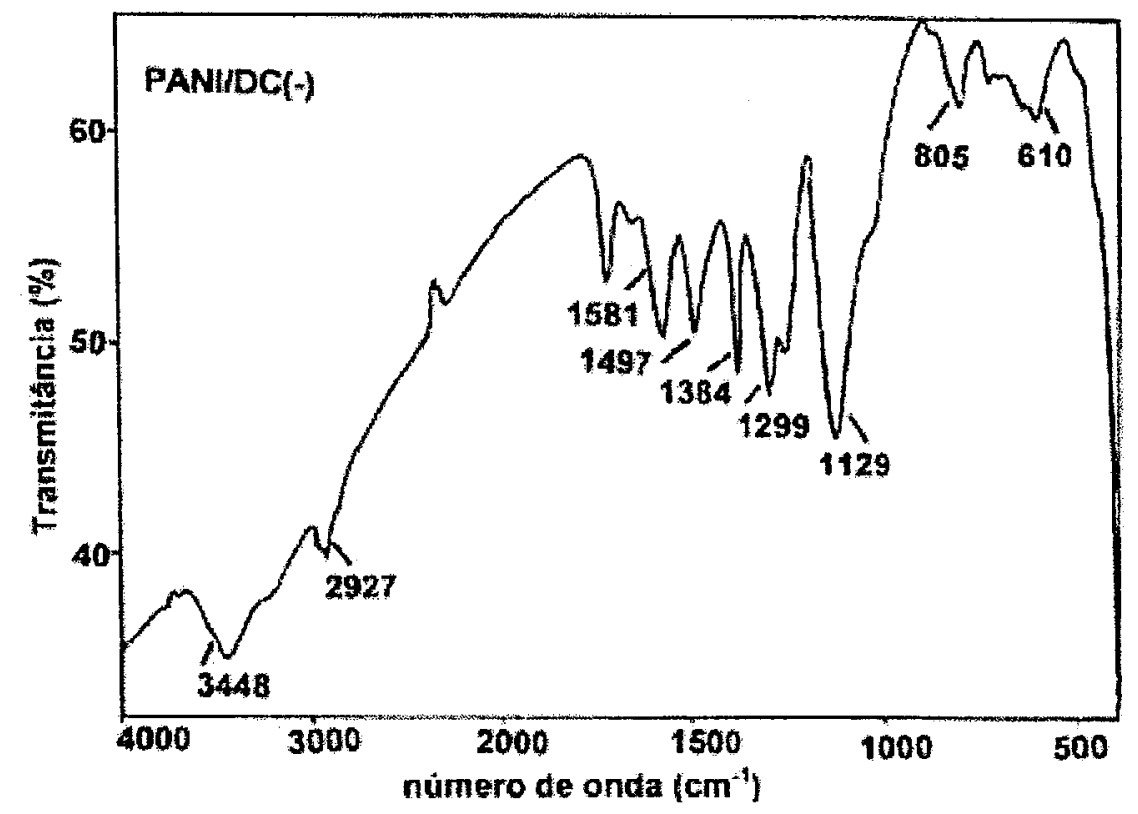

Figura 3.6: Espectro de FTIR da PANI dopada com descarga corona negativa (PANI/DC(-)). 
Na tabela I estão os valores dos picos da PANI dopada com $\mathrm{HCl} 1 \mathrm{M}$, TFA 1M, TSA 1M, descarga corona positiva, descarga corona negativa e da PANI desdopada, bem como o tipo de vibração associada ao pico.

Tabela I : Valores de absorção de Infravermelho em número de onda e vibração correspondente, onde: $\quad(E B)=$ PANI desdopada; $(\mathrm{HCl})=$ PANI dopada com $\mathrm{HCl}$ 1M; (TFA) = PANI dopada com TFA 1M; (TSA) = PANI dopada com TSA 1M; (CP) = PANI dopada com descarga corona positiva; $(\mathrm{CN})$ = PANI dopada com descarga corona negativa.

\begin{tabular}{|c|c|}
\hline Número de onda $\left(\mathrm{cm}^{-1}\right)$ & Vibração \\
\hline $3.100 \sim 3.500(E B, H C l, T F A, T S A, C P$ e $C N)$ & Estiramento $\mathrm{N}-\mathrm{H}$ \\
\hline $\begin{array}{l}1.589(\mathrm{~EB})-1.592(\mathrm{CP})-1.581(\mathrm{CN})-1.580(\mathrm{TFA})- \\
1.574(\mathrm{HCl})-1.573(\mathrm{TSA})\end{array}$ & Estiramento $\mathrm{N}=\mathrm{Q}=\mathrm{N}$ do anel quinóide \\
\hline $\begin{array}{l}1.501(\mathrm{~EB})-1.499(\mathrm{CP})-1.497(\mathrm{CN})-1.496(\mathrm{TFA})- \\
1.494(\mathrm{HCl})-1.479(\mathrm{TSA})\end{array}$ & Estiramento $\mathrm{N}-\mathrm{B}-\mathrm{N}$ do anel benzenóide \\
\hline $1.385(\mathrm{CP})$ e $1.384(\mathrm{CN})$ & Estiramento $\mathrm{Q}=\mathrm{N}-\mathrm{B}$ \\
\hline $\begin{array}{l}1.307(\mathrm{~EB})-1.300(\mathrm{CP})-1.300(\mathrm{TFA})-1.299(\mathrm{CN})- \\
1.298(\mathrm{HCl})-1.256(\mathrm{TSA})\end{array}$ & $\begin{array}{l}\text { Estiramento } \mathrm{C}-\mathrm{N} \text { das aminas aromáticas } \\
\text { secundárias }\end{array}$ \\
\hline $\begin{array}{l}1.143(\mathrm{~EB})-1.135(\mathrm{CP})-1.134(\mathrm{TFA})-1.130(\mathrm{HCl})- \\
1.129(\mathrm{CN})-1.127(\mathrm{TSA})\end{array}$ & Banda vibracional do $\mathrm{N}$ quinona \\
\hline $834(\mathrm{~EB})-813(\mathrm{TSA})-806(\mathrm{CP})-805(\mathrm{CN}, \mathrm{HCl}$ e TFA) & $\begin{array}{l}\text { Deformaçăo angular fora do plano } \mathrm{C}-\mathrm{H} \text { (anel } \\
1,4 \text { dissubstituído) }\end{array}$ \\
\hline
\end{tabular}

Observou-se que os valores obtidos experimentalmente são muito semelhantes aos encontrados na literatura $[25,34,39,58,67,68,69] . \quad$ Na faixa de número de onda que compreende 3.100 à $3.500 \mathrm{~cm}^{-1}$ ocorre o estiramento do grupo N-H. Esta banda aparece larga porque existem muitos desses grupos na amostra, então a banda é espalhada no espectro. Podem haver também bandas nesta faixa que ocorrem devido ao estiramento do grupo $\mathrm{O}-\mathrm{H}$, em conseqüência da umidade que contenha a amostra [39]. 
Segundo Trivedi e Dhawan [34] o fato dos valores de número de onda dos picos de FTIR da PANI na forma desdopada (EB) estarem deslocados para valores um pouco maiores do que os da PANI dopada (ES), ocorre devido a desprotonação do polímero porque há um aumento do número de anéis quinóides. As diferenças fundamentais nos espectros da PANI dopada e desdopada estão no fato de que próximo a $1.140 \mathrm{~cm}^{-1}$ existe um pico muito intenso na PANI na forma condutora (ES) que se deve a deslocalização de cargas originada por protonação. No estado isolante (EB) este pico é pouco intenso [34,39]. Não existem valores tabelados na literatura para o caso das amostras dopadas por descarga corona. Em $1.385 \mathrm{~cm}^{-1}$ aparece um pico de média intensidade para as amostras dopadas por descarga corona positiva e negativa, que algumas vezes aparece em polianilinas, sendo atribuído ao estiramento do grupo $Q=N-B$, onde: $Q=$ qrupo quinóide e $B=$ grupo benzenóide [55]. A maioria das bandas características dos dopantes ácidos da PANI se sobrepõem ao espectro da mesma, como é o caso do TSA e do TFA. Os ácidos orgânicos possuem muitos picos e bandas característicos que podem ser observados por FTIR. No caso da PANI dopada com TSA 1M há uma interação muito forte entre os grupos químicos da PANI e do TSA, fazendo com que no espectro de FTIR, os picos característicos do grupo sulfona (do TSA) interfiram um pouco nos picos dos grupos químicos da PANI, como se pode verificar na figura 3.4. Por exemplo, em $1.351 \mathrm{~cm} \mathrm{~cm}^{-1}$ aparece um ombro que corresponde à deformação axial assimétrica do grupo O-S-O, que interfere no pico característico do estiramento $\mathrm{C}-\mathrm{N}$ das aminas aromáticas secundárias $\left(1.256 \mathrm{~cm}^{-1}\right)$. Em $1.180 \mathrm{~cm}^{-1}$ há um pico referente à deformação axial simétrica do grupo O-S-O, que interfere na banda vibracional do " $\mathrm{N}$ " quinona $\left(1.127 \mathrm{~cm}^{-1}\right)$. Em $1.044 \mathrm{~cm}^{-1}$ há o estiramento da ligação $S=O$ do TSA. Na região de 692 à $813 \mathrm{~cm}^{-1}$ ocorrem deformações axiais do sistema S-O-C do TSA que interferem na defomação 
angular fora do plano do anel C-H (anel 1,4 dissubstituído) da PANI $\left(805 \mathrm{~cm}^{-1}\right)$ $[69,70]$.

A seguir, são apresentados os espectros de FTIR dos substratos PET e PC (figuras 3.7 e 3.8), analisados na forma de filmes, tal qual como foram usados na síntese dos compósitos.

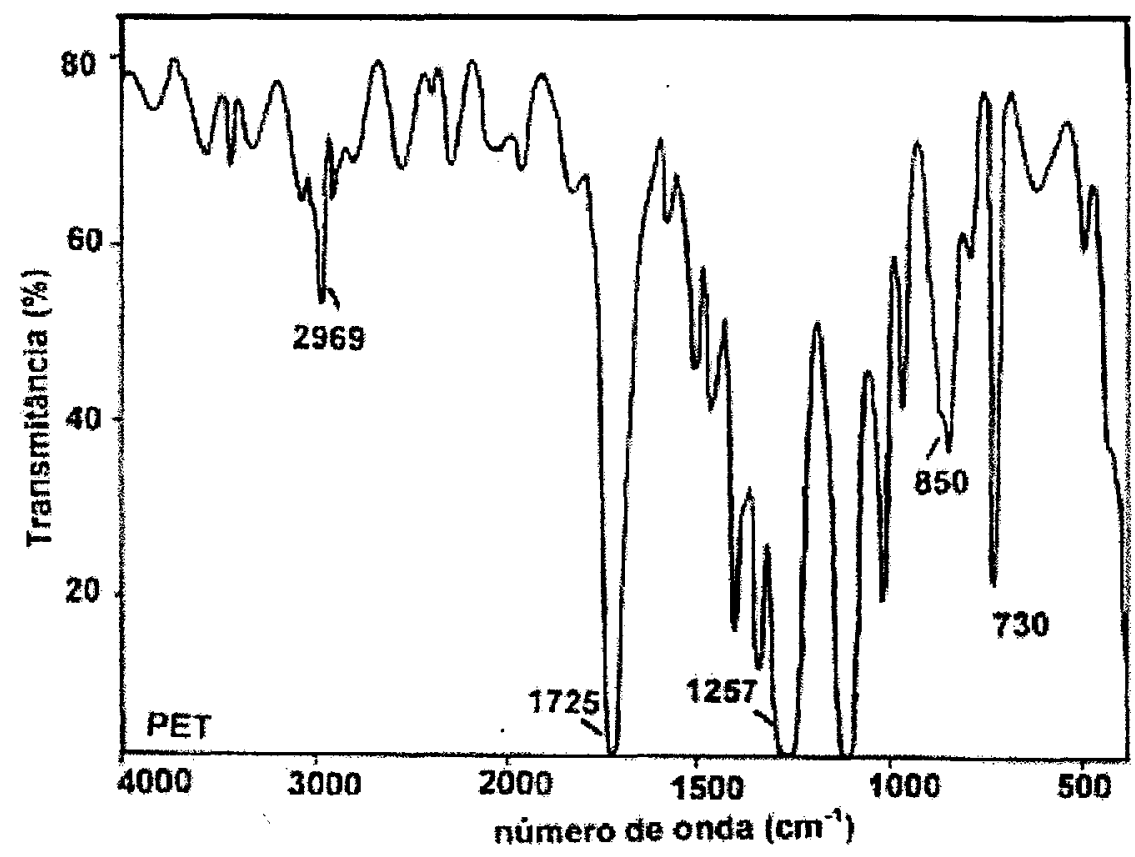

Figura 3.7: Espectro de FTIR de filme de PET.

Na figura 3.7 observa-se que na região de $3.050 \mathrm{~cm}^{-1}$ ocorre o estiramento do grupo $=\mathrm{C}-\mathrm{H}$ do anel benzênico. $\quad$ Em 2.969 e $2.860 \mathrm{~cm}^{-1}$ ocorre o estiramento assimétrico e simétrico, respectivamente, do grupo $\mathrm{CH}_{2}$ do etileno. Em $1.725 \mathrm{~cm}^{-1}$ há a deformação axial do grupo $\mathrm{C}=0$. Em 1.600 e $1.500 \mathrm{~cm}^{-1}$ ocorre o estiramento do esqueleto $C=C$ no plano do anel benzênico. Em $1.257 \mathrm{~cm}^{-1}$ há o estiramento do grupo O-C-O. $\quad E m 850 \mathrm{~cm}^{-1}$ há a substituição "para" do anel benzênico e em $730 \mathrm{~cm}^{-1}$ ocorre o estiramento do grupo éster $O=C-O[71,72]$. 


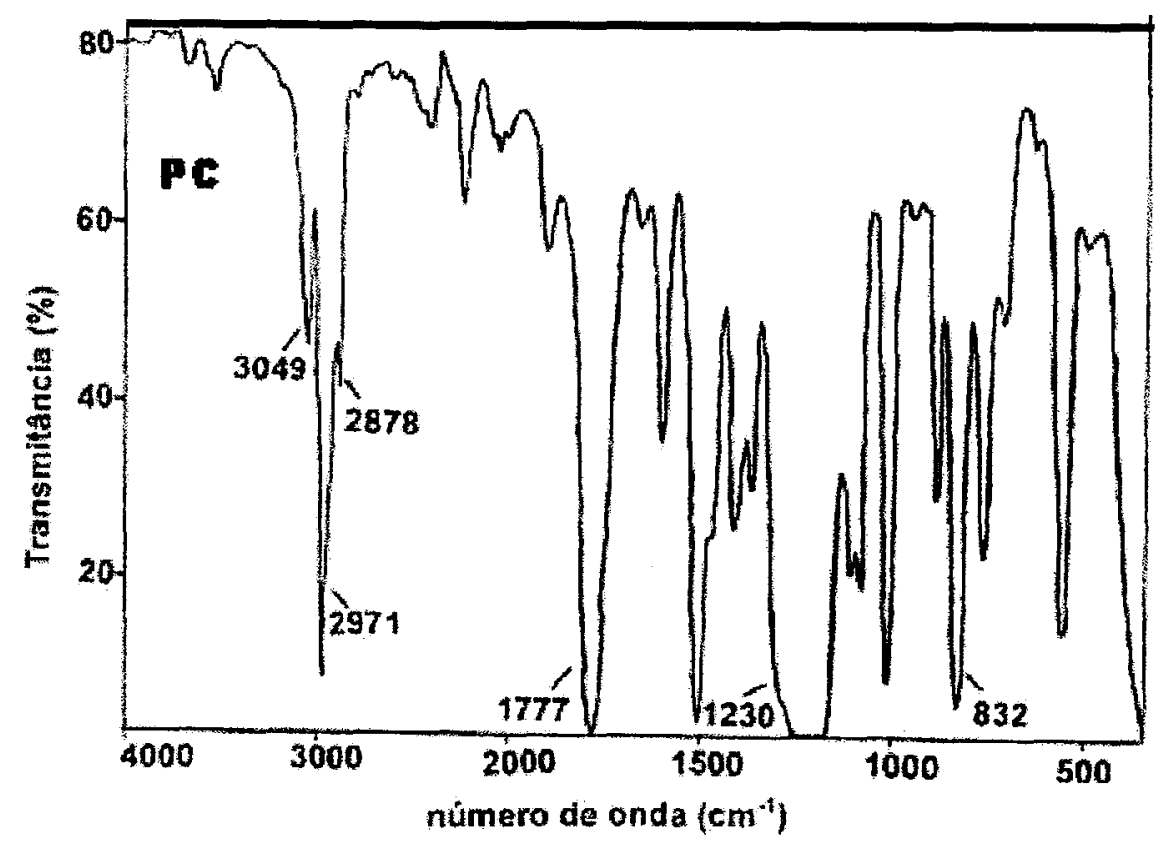

Figura 3.8: Espectro de FTIR de filme de PC.

O pico de $3.049 \mathrm{~cm}^{-1}$ corresponde a deformação axial do "C" aromático. Em 2.971 e $2.878 \mathrm{~cm}^{-1}$ há a deformação axial do "C" alifático. Em $1.777 \mathrm{~cm}^{-1}$ ocorre a deformação axial do grupo carbonila $(C=O)$. O dublete em 1.385 e 1.365 $\mathrm{cm}^{-1}$ corresponde ao $\mathrm{CH}_{3}$ geminado. $\quad \mathrm{Em} 1.230 \mathrm{~cm}^{-1}$ ocorre o estiramento do grupo carbonato (O-C-O). O pico $832 \mathrm{~cm}^{-1}$ corresponde a substituição "para" do anel benzênico $[73,74]$.

Com a técnica de FTIR foi possível caracterizar todos os tipos de PANI desdopada e dopadas, bem como seus substratos, sendo que os valores obtidos dos espectros são muito semelhantes aos encontrados na literatura. No caso das amostras dopadas com descarga corona, ainda não existem valores tabelados na literatura, mas observou-se que seus espectros de FTIR são muito semelhantes ao espectro da PANI dopada com $\mathrm{HCl} 1 \mathrm{M}$. 


\subsubsection{Espectroscopia Raman Ressonante}

Esta técnica foi usada para caracterizar os grupos químicos que constituem a estrutura química da PANI na forma desdopada e dopada com $\mathrm{HCl}$ $1 \mathrm{M}$, descarga corona negativa e positiva. O principal objetivo foi verificar se existe diferença entre a estrutura química da PANI dopada com descarga corona positiva e negativa. A PANI na forma de compósitos com PET foi analisada por Raman. As figuras 3.9 e 3.10 apresentam, respectivamente, os espectros Raman das amostras de PET/PANI desdopadas e dopadas. As bandas do PET são desconsideradas e analisadas apenas as referentes à PANI.

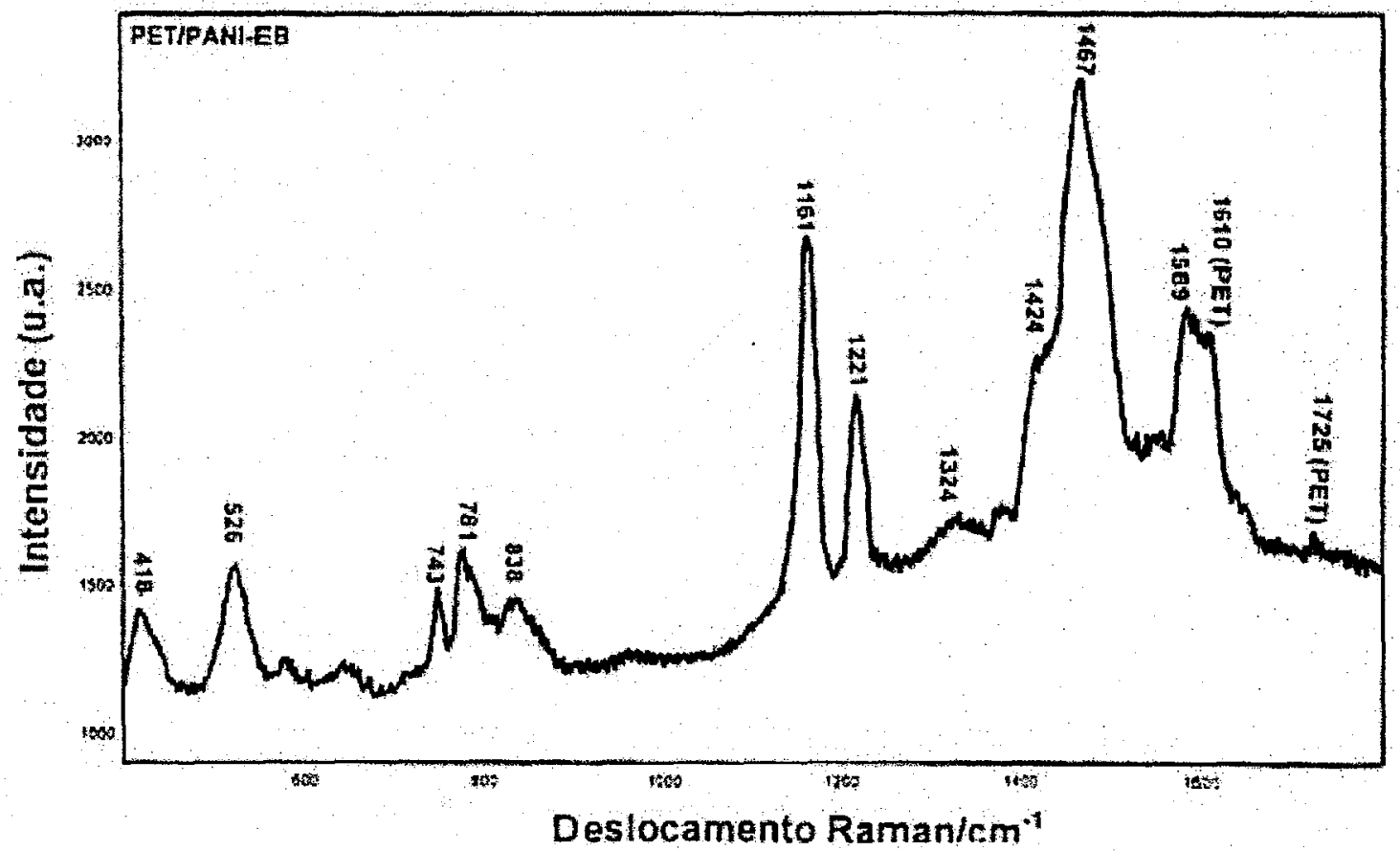

Figura 3.9: Espectro Raman da PANI desdopada com $\mathrm{NH}_{4} \mathrm{OH} 0,1 \mathrm{M}$ (PET/PANIEB) $\left(\lambda_{\text {exc. }}=632,8 \mathrm{~nm}\right)$.

As bandas características da PANI desdopada são: em $1161 \mathrm{~cm}^{-1}$ (estiramento $\mathrm{C}-\mathrm{H}$ no plano do anel quinônico); em $1221 \mathrm{~cm}^{-1}$ (estiramento $\mathrm{C}-\mathrm{N}$ entre anel benzênico e " $N$ "); $1467 \mathrm{~cm}^{-1}$ (estiramento $\mathrm{C}=\mathrm{N}$ do anel quinônico) e 1589 $\mathrm{cm}^{-1}$ (estiramento $\mathrm{C}=\mathrm{C}$ do anel quinônico). Os valores encontrados estão de 
acordo com a literatura $[13,75,76]$ Abaixo, o espectro Raman da PANI dopada com $\mathrm{HCl} 1 \mathrm{M}$.

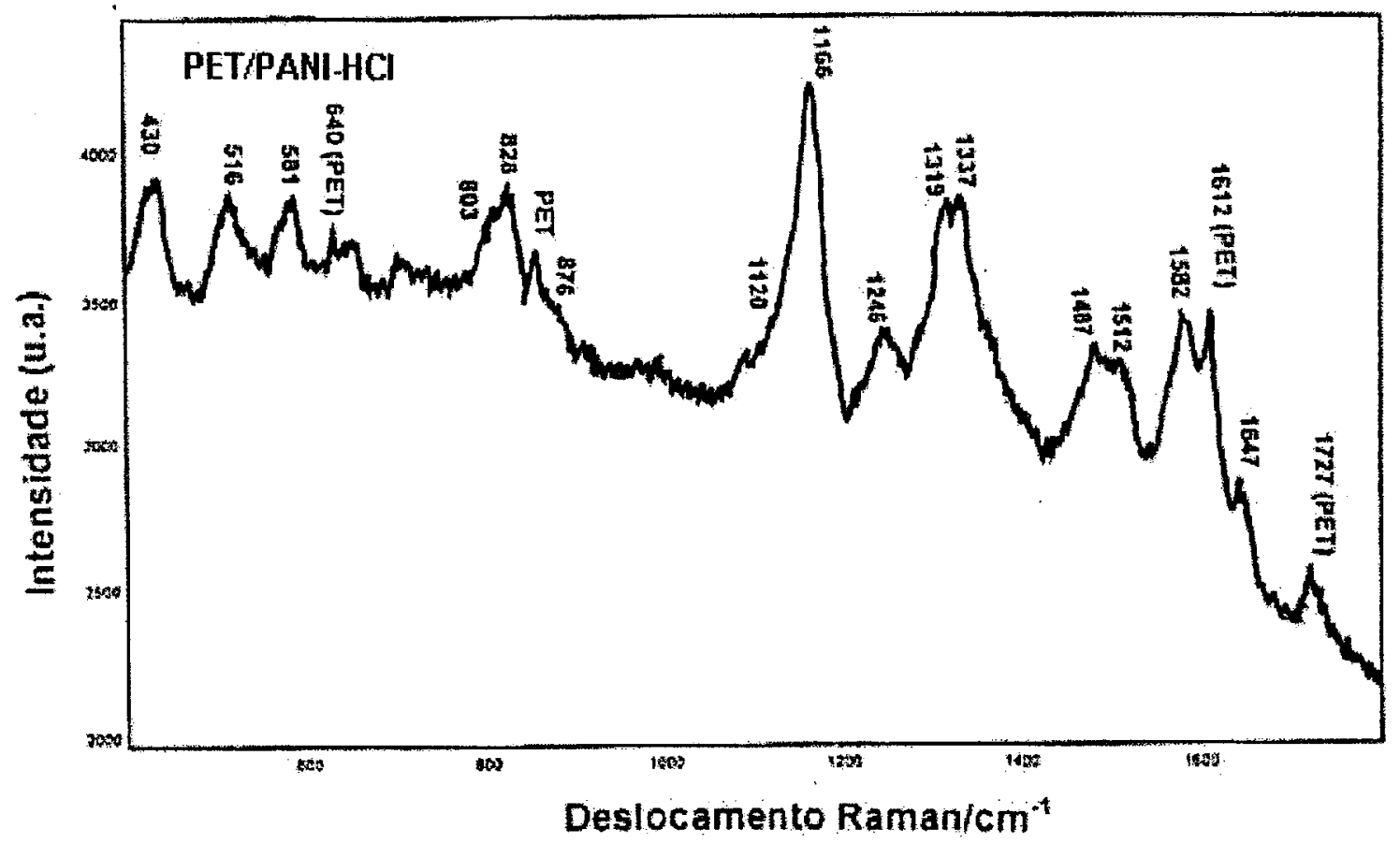

Figura 3.10: Espectro Raman da PANI dopada com $\mathrm{HCl} 1 \mathrm{M}$ (PET/PANI-HCl) $\left(\lambda_{\text {exc. }}=632,8 \mathrm{~nm}\right)$.

Na figura 3.10 observa-se as seguintes bandas Raman características da PANI dopada com HCl 1M: $1166 \mathrm{~cm}^{-1}$ (vibração $\mathrm{C}-\mathrm{H}$ do anel quinônico); 1337 $\mathrm{cm}^{-1}$ (estiramento $\mathrm{C}=\mathrm{N}$ da estrutura semiquinônica); $1487 \mathrm{~cm}^{-1}$ (estiramento $\mathrm{N}-\mathrm{H}$ do $\mathrm{B}-\mathrm{NH}-\mathrm{B}$ ) e em $1582 \mathrm{~cm}^{-1}$ (estiramento $\mathrm{C}=\mathrm{C}$ do anel benzenóide). Estes valores são praticamente idênticos aos resultados obtidos por Cochet et al. [75] quando a PANI foi sintetizada por síntese química e dopada com vapores de $\mathrm{HCl}$.

Na figura 3.11 encontra-se o espectro Raman da PANI dopada com descarga corona positiva. 


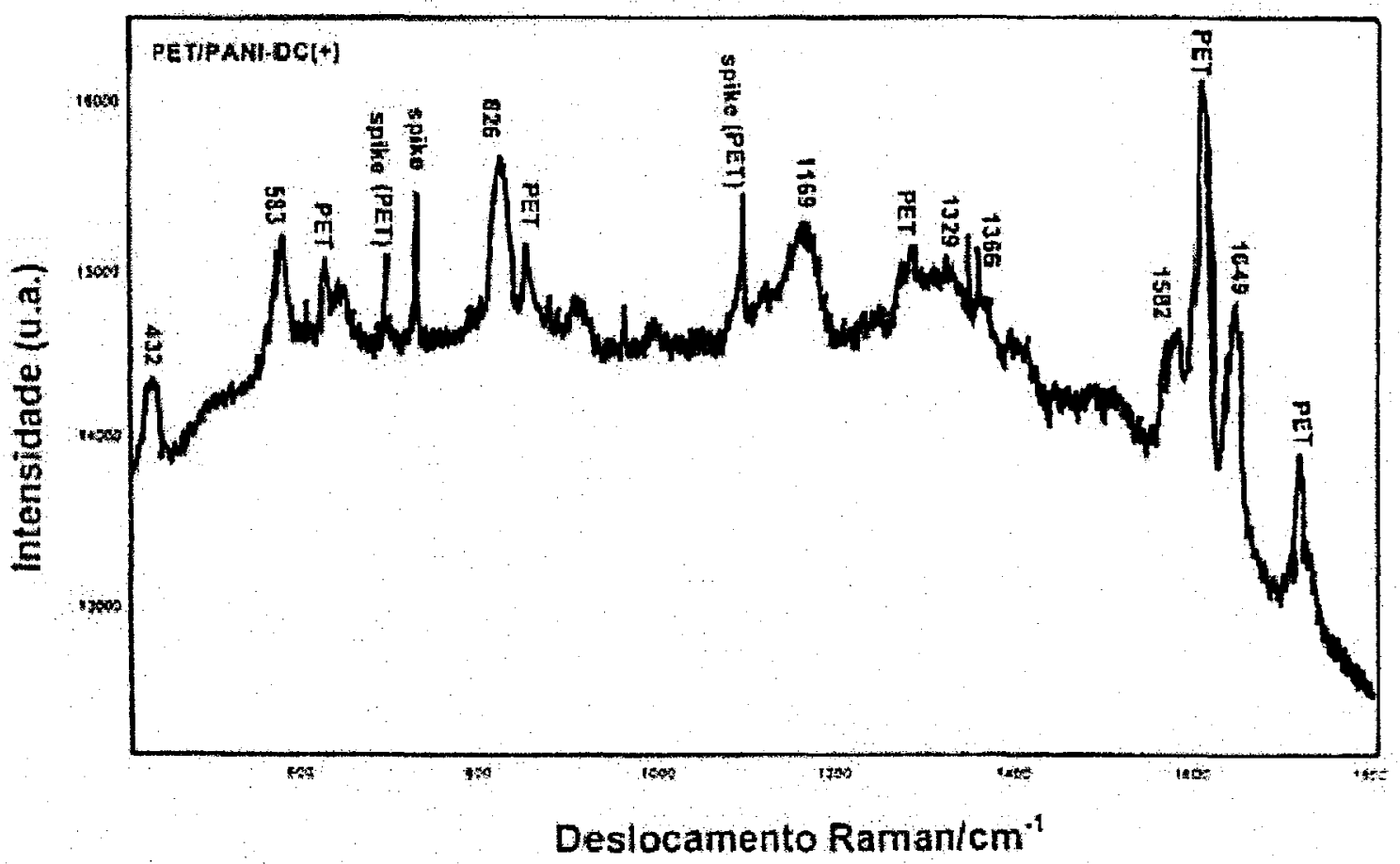

Figura 3.11: Espectro Raman da PANI dopada com descarga corona positiva $($ PET/PANI-DC $(+)) \quad\left(\lambda_{\text {exc. }}=632,8 \mathrm{~nm}\right)$.

$\mathrm{Na}$ literatura ainda não existem valores de deslocamento Raman tabelados para PANI dopada com descarga corona. Os valores de deslocamento Raman da PANI dopada com descarga corona positiva são, praticamente, os mesmos valores da PANI dopada com $\mathrm{HCl} 1 \mathrm{M}$, sendo que no caso da PANI dopada com $\mathrm{HCl} 1 \mathrm{M}$ as bandas são mais intensas podendo ser indício de que o filme de PANI dopada com $\mathrm{HCl} 1 \mathrm{M}$ é mais espesso do que o dopado com descarga corona positiva. O mesmo se pode verificar no espectro da PANI dopada com descarga corona negativa que é apresentado na figura 3.12, juntamente com os espectros da PANI dopada com descarga corona positiva, e dopada com $\mathrm{HCl} 1 \mathrm{M}$. 


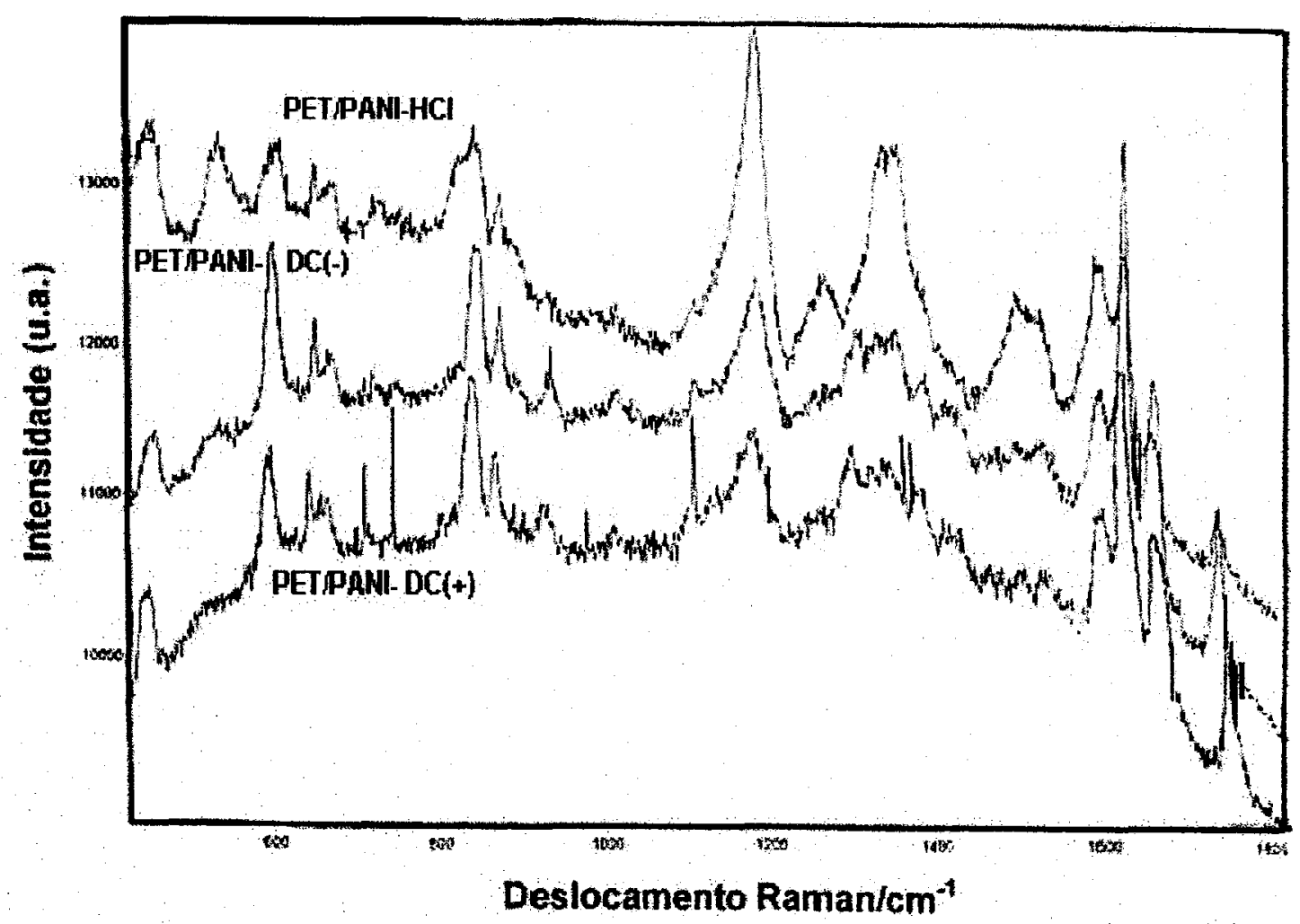

Figura 3.12: Espectros Raman da PANI dopada com HCl 1M (PET/PANI-HCl); descarga corona negativa (PET/PANI-DC(-) e da PANI dopada com descarga corona positiva (PET/PANI-DC $(+),\left(\lambda_{\text {exc. }}=632,8 \mathrm{~nm}\right)$.

$\mathrm{Na}$ figura 3.12 observa-se que as bandas Raman da PANI dopada com descarga corona negativa aparecem nas mesmas posições da PANI dopada com descarga corona positiva e reodopada com $\mathrm{HCl} 1 \mathrm{M}$. Conclui-se que não se pode detectar diferenças entre os grupos químicos da PANI dopada nos 3 tipos de dopagens. A única diferença visivel está entre a espessura dos filmes da PANI depositada sobre o PET, que no caso das amostras dopadas com $\mathrm{HCl} 1 \mathrm{M}$, as camadas da PANI são mais espessas. Observamos que não houve ligações cruzadas ou oxidação da superfície através da faixa de deslocamento Raman.

A espectroscopia Raman foi bastante útil na determinação da mudança dos segmentos quinóides da PANI-EB (desdopada - isolante) em semiquinóides na PANI-ES (dopada - condutora), indicando, desta forma, que todas as amostras dopadas estão no mesmo estado de oxidação e dopagem. 


\subsubsection{Espectroscopia de Foto-elétrons excitados por Raios-X (XPS)}

A análise por XPS é, nos dias atuais, uma das mais poderosas ferramentas para a determinação da constituição química dos elementos presentes em um material, no estudo de superfícies para profundidades menores do que $10 \mathrm{~nm}$. Neste trabalho, usou-se XPS para a determinação dos grupos químicos que constituem a PANI dopada com $\mathrm{HCl} 1 \mathrm{M}$, e com descarga corona negativa e positiva, a PANI desdopada, o PET (puro) e PET tratado termicamente.

Este item foi dividido em duas partes: A e B. Na parte A é apresentada a análise por XPS da superfície do PET (puro) e do PET que sofreu tratamento térmico à $200^{\circ} \mathrm{C}$ e 2 horas. Na parte B é apresentada a análise da constituição química da superfície da PANI desdopada e dopada (com $\mathrm{HCl} 1 \mathrm{M}$, descarga corona negativa e positiva).

\section{A) Análise da superfície do PET}

O objetivo destas análises foi verificar se ocorreu mudança na constituição química do PET após tratamento térmico, uma vez que no item 3.1.6 (fotomicrografias de MEV) conforme será apresentado adiante, foram observados cristais de formato hexagonal após o tratamento térmico do PET.

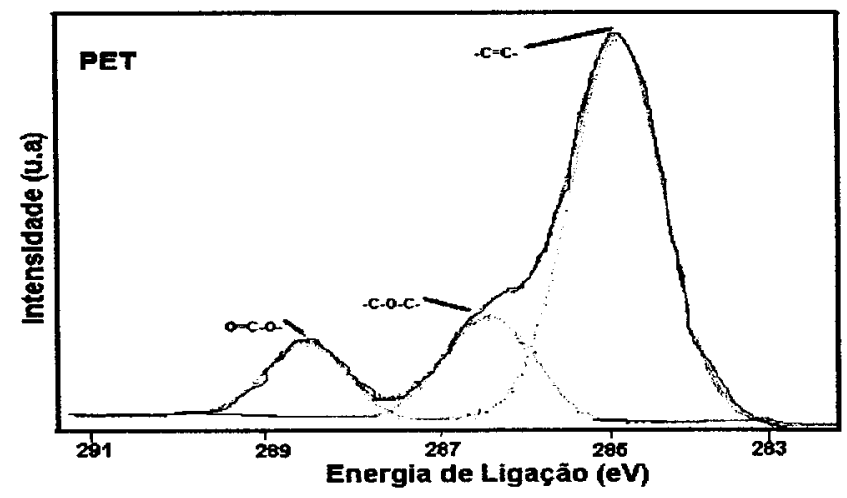

Figura 3.13: Espectro de XPS do nivel $1 \mathrm{~s}$ do $\mathrm{C}$ do PET (puro). 
$\mathrm{Na}$ figura 3.13 os valores de energia de ligação $284,6 \mathrm{eV} ; 286,3 \mathrm{eV}$ e $288,8 \mathrm{eV}$, correspondem aos carbonos na forma $-\mathrm{C}=\mathrm{C}-$, $-\mathrm{C}-\mathrm{O}-\mathrm{C}-$ e $\mathrm{O}=\mathrm{C}-\mathrm{O}-$, respectivamente $[78,79]$.

$\mathrm{Na}$ figura 3.14 é apresentado o espectro do PET após tratamento térmico.

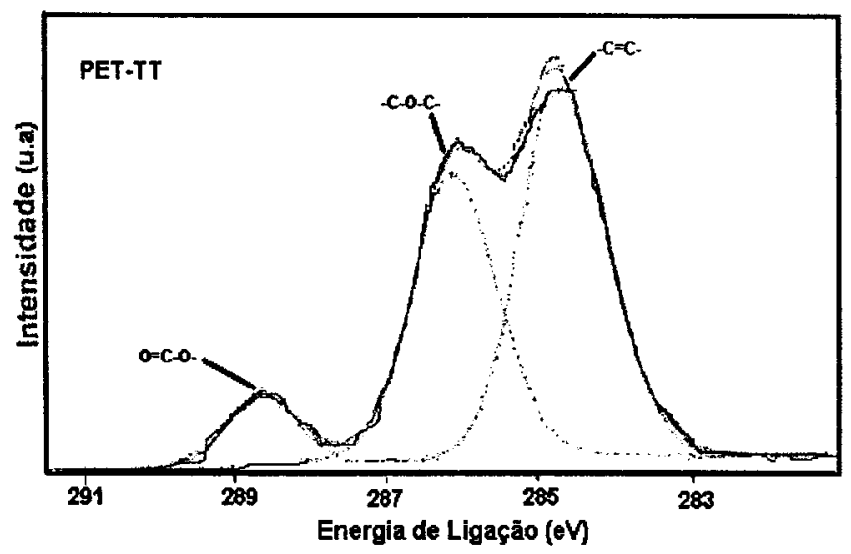

Figura 3.14: Espectro de XPS do nível $1 \mathrm{~s}$ do $\mathrm{C}$ do PET tratado termicamente por 2 horas, à $200^{\circ} \mathrm{C}$.

Os valores de energia de ligaçãa $284,6 \mathrm{eV}, 286,1 \mathrm{eV}$ e $288,7 \mathrm{eV}$, correspondem aos carbonos na forma $-\mathrm{C}=\mathrm{C}-, \mathrm{C}-\mathrm{O}-\mathrm{C}$ e $\mathrm{O}=\mathrm{C}-\mathrm{O}$, respectivamente $[78,79]$, sendo que neste caso, há um brusco aumento de intensidade do pico do C $1 \mathrm{~s}$ correspondente ao grupo $\mathrm{C}-\mathrm{O}-\mathrm{C}$. Isto indica que o PET pode ter incorporado $\mathrm{O}_{2}$ do ar e sofrido oxidação superficial, devido ao fato do aquecimento ter sido feito em presença de oxigênio atmosférico. Como não foram observados outros elementos químicos nos espectros, supõe-se que os cristais que foram observados nas fotomicrografias de MEV (item 3.1.6) sejam uma segunda fase do PET que cristaliza após tratamento térmico nessas condiçōes. 


\section{A) Análise da superfície da PANI}

Foram feitos espectros de XPS de amostras de PANI desdopada, PANI dopada com $\mathrm{HCl} 1 \mathrm{M}$, dopada com descarga corona negativa e positiva.

Na figura 3.15 vê-se os valores percentuais de cada elemento químico presente nas amostras de PANI desdopada e dopadas.

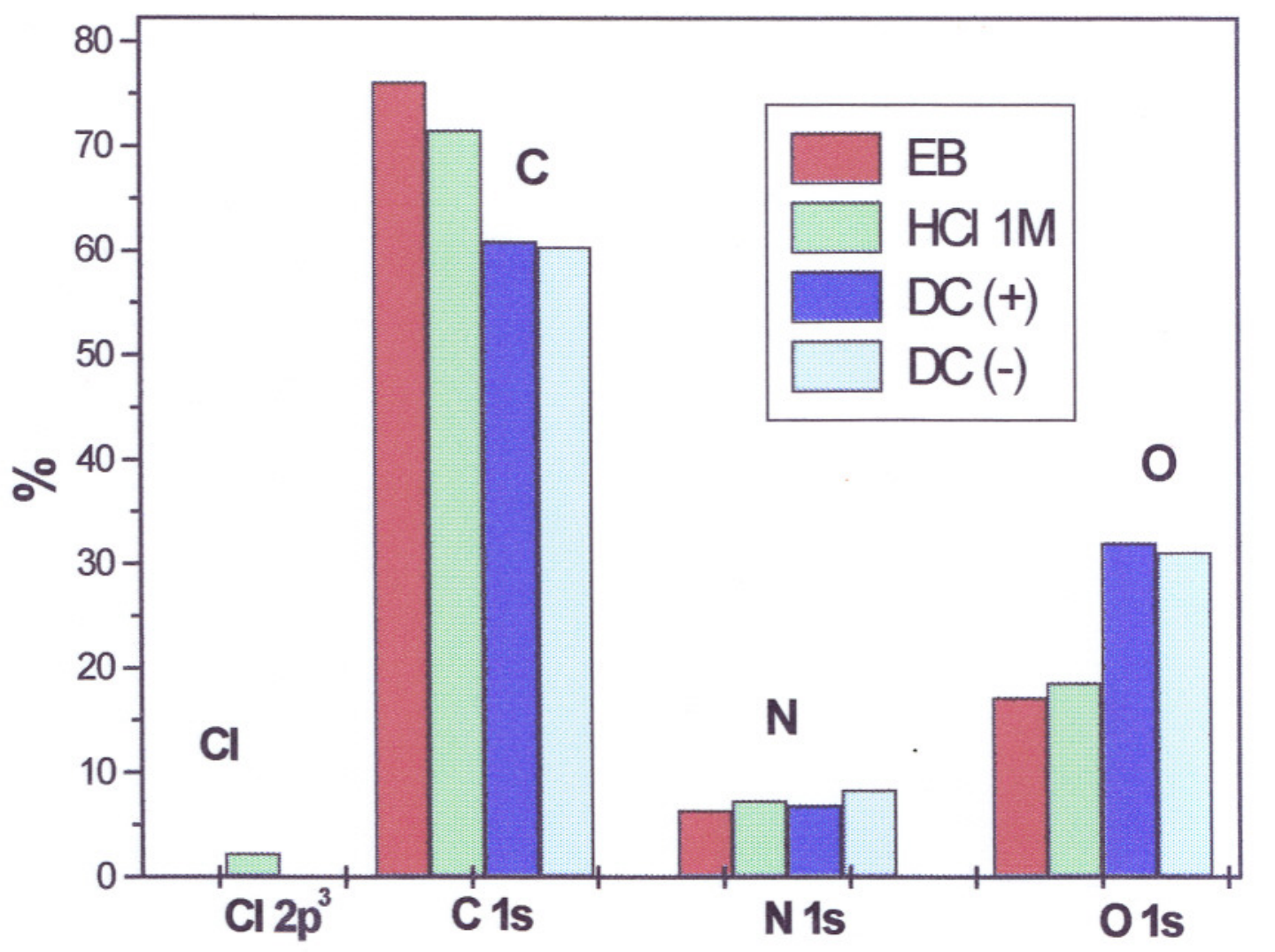

Figura 3.15: Valores percentuais dos elementos químicos presentes nas superfícies das amostras de PANI. Onde: $\mathrm{EB}=\mathrm{PANI}$ desdopada; $\mathrm{HCl} 1 \mathrm{M}=$ PANI dopada com $\mathrm{HCl} 1 \mathrm{M}$; $\mathrm{DC}(+)$ = PANI dopada com descarga corona positiva; $\mathrm{DC}(-)=$ PANI dopada com descarga corona negativa.

A contribuição dos dopantes pode ser vista na figura 3.15 , como por exemplo a PANI dopada com $\mathrm{HCl} 1 \mathrm{M}$ possui $2,3 \%$ de Cloro $\left(\mathrm{Cl} 2 \mathrm{p}^{3}\right)$. As amostras dopadas com descarga corona possuem maior quantidade de Oxigênio $(\mathrm{O} 1 \mathrm{~s})$ e a amostra dopada com descarga corona negativa possui maior quantidade de 
Nitrogênio ( $N$ 1s) $(8,4 \%)$ do que as demais. Segundo Job et al. [47] a descarga corona positiva produz íons protônicos (agregados de $\mathrm{H}_{2} \mathrm{O}$ carregados eletricamente) que protonam a superfície da polianilina. A descarga corona negativa leva a formaçăo de substâncias ácidas neutras (tais como $\mathrm{HNO}_{2}, \mathrm{HNO}_{3}$, etc) que se dissociam na superficie da polianilina, protonando a mesma. Esses íons se originam do Nitrogênio do ar, combinado com a umidade do ar da cámara de descarga corona, que săo produzidos com a emissão da descarga elétrica, consistentes com o aumento da percentagem de Nitrogênio nas amostras dopadas com descarga corona negativa e o aumento percentual de oxigénio nas amostras dopadas por descarga corona negativa e positiva observadas nas análises e por XPS.

Na figura 3.16 pode-se ver os espectros de XPS da deconvoluçăo dos picos do C (1s) e do N (1s) da PANI desdopada, dopada com descarga corona negativa, positiva e com $\mathrm{HCl} 1 \mathrm{M}$. 


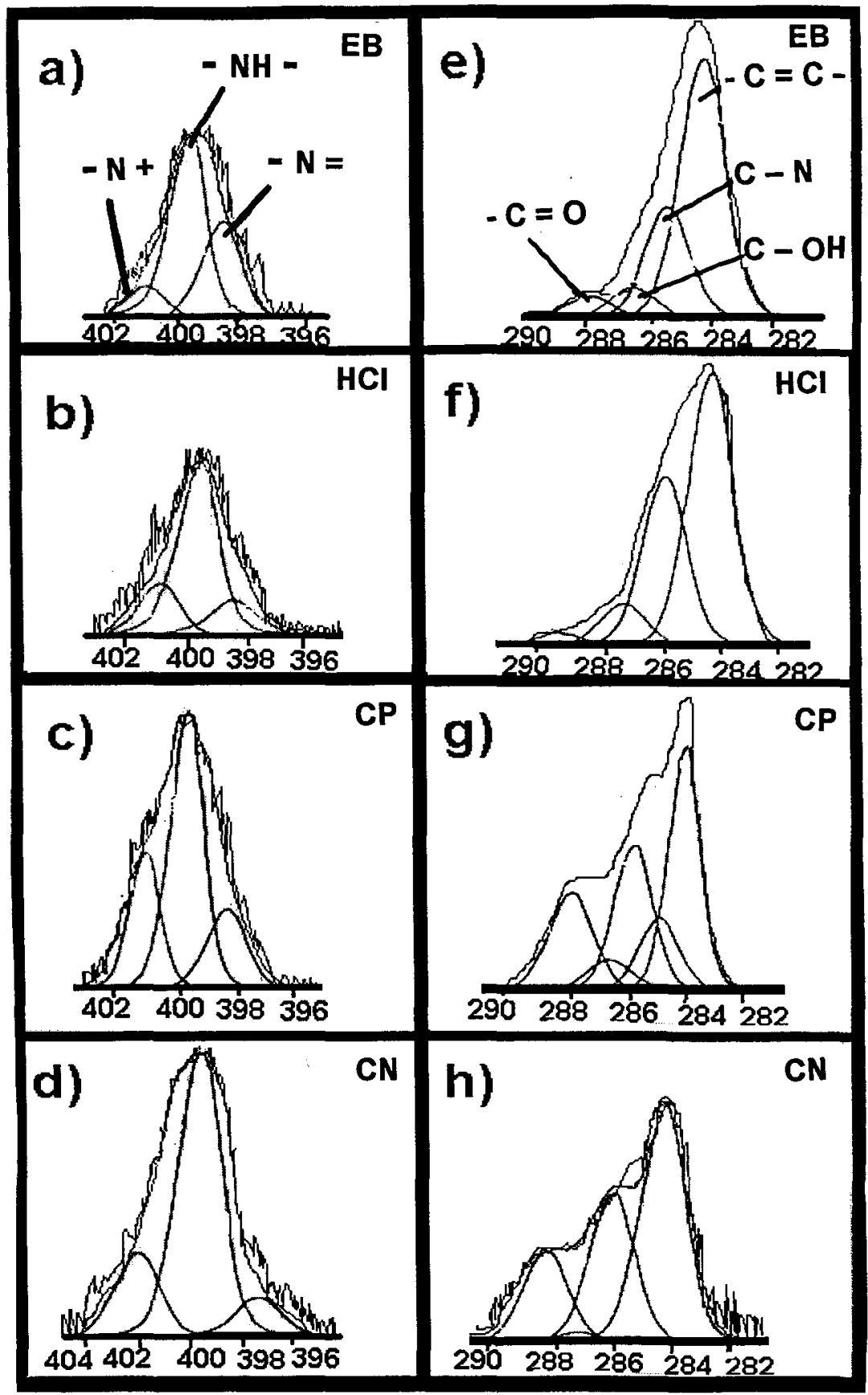

Energia de Ligação (eV)

Figura 3.16: Espectros de XPS do N (1s) da PANI desdopada (a); PANI dopada com: (b) $\mathrm{HCl} \mathrm{1M;} \mathrm{(c)} \mathrm{descarga} \mathrm{corona} \mathrm{positiva;} \mathrm{(d)} \mathrm{descarga} \mathrm{corona} \mathrm{negativa;} \mathrm{Espectros} \mathrm{de}$ XPS do C (1s) da PANI desdopada (e); PANI dopada com: (f) HCl 1M; (g) descarga corona positiva; (h) descarga corona negativa. 
A seguir, as tabelas II e III ilustram os valores de energia de ligação e grupo químico correspondente de cada uma das amostras analisadas.

Tabela II: Valores de energia de ligação $(\mathrm{eV})$, intensidade, \% de área gaussiana (oriundo da deconvolução dos picos) e grupos químicos do espectro de XPS do $\mathrm{C}$ (1s) das amostras de PET/PANI. Onde: $\mathrm{HCl}=\mathrm{PET} / \mathrm{PANI}$ dopada com $\mathrm{HCl}$ $1 \mathrm{M} ; \mathrm{EB}=\mathrm{PET} / \mathrm{PANI}$ desdopada; $\mathrm{DC}(+)$ = PET/PANI dopada com descarga corona positiva e DC $(-)=$ PET/PANI dopada com descarga corona negativa.

\begin{tabular}{|l|c|c|c|c|l|}
\hline AMOSTRA & INTENSIDADE & $\mathrm{eV}$ & $\begin{array}{l}\text { \%área } \\
\text { gaussiana }\end{array}$ & Grupo químico & referência \\
\hline EB & 323 & 284,7 & 60,6 & $-\mathrm{C}=\mathrm{C}-$ & {$[77,78,79]$} \\
\hline & 139 & 285,8 & 26,1 & $-\mathrm{C}-\mathrm{N}$ & {$[58,77]$} \\
\hline & 41 & 286,9 & 7,7 & $-\mathrm{C}-\mathrm{O}-\mathrm{H}$ & {$[77]$} \\
\hline & 30 & 288,3 & 5,6 & $-\mathrm{C}=\mathrm{O}$ & {$[77]$} \\
\hline $\mathrm{HCl}$ & & & & & \\
\hline & 392 & 284,6 & 54,7 & $-\mathrm{C}=\mathrm{C}-$ & {$[77,78,79]$} \\
\hline & 242 & 286,1 & 33,8 & $-\mathrm{C}-\mathrm{N}$ & {$[58,77]$} \\
\hline & 60 & 287,4 & 8,4 & $-\mathrm{C}-\mathrm{O}-\mathrm{H}$ & {$[77]$} \\
\hline & 22 & 289,5 & 3,1 & O=C-O & {$[58,77]$} \\
\hline $\mathrm{DC}(+)$ & & & & & \\
\hline & 404 & 284,6 & 35,5 & $-\mathrm{C}=\mathrm{C}-$ & {$[77,78,79]$} \\
\hline & 122 & 285,4 & 13,3 & $-\mathrm{C}-\mathrm{N}$ & {$[58,77]$} \\
\hline & 239 & 286,2 & 25,2 & $-\mathrm{C}-\mathrm{N}$ & {$[58,77]$} \\
\hline & 52 & 287,0 & 6,4 & $-\mathrm{C}-\mathrm{O}-\mathrm{H}$ & {$[77]$} \\
\hline & 162 & 288,2 & 19,6 & $-\mathrm{C}=\mathrm{O}$ & {$[77]$} \\
\hline $\mathrm{DC}(-)$ & 1238 & 284,6 & 48,5 & $-\mathrm{C}=\mathrm{C}-$ & {$[77,78,79]$} \\
\hline & 784 & 286,2 & 30,7 & $-\mathrm{C}-\mathrm{N}$ & {$[58,77]$} \\
\hline & 54 & 287,3 & 2,1 & $-\mathrm{C}-\mathrm{O}-\mathrm{H}$ & {$[77]$} \\
\hline & 475 & 288,3 & 18,6 & $-\mathrm{C}=\mathrm{O}$ & {$[77]$} \\
\hline
\end{tabular}


Tabela III: Valores de energia de ligação (eV), intensidade, \% de área gaussiana (oriundo da deconvolução dos picos) e grupos químicos do espectro de XPS do N (1s) das amostras de PET/PANI. Onde: $\mathrm{HCl}=\mathrm{PET} / \mathrm{PANI}$ dopada com $\mathrm{HCl}$ 1M; EB = $\mathrm{PET} / \mathrm{PANI}$ desdopada; $\mathrm{DC}(+)=\mathrm{PET} / \mathrm{PANI}$ dopada com descarga corona positiva e DC(-) = PET/PANI dopada com descarga corona negativa.

\begin{tabular}{|l|c|c|c|c|l|}
\hline AMOSTRA & INTENSIDADE & $\mathrm{eV}$ & $\begin{array}{c}\text { \%área } \\
\text { gaussiana }\end{array}$ & $\begin{array}{l}\text { Grupo } \\
\text { químico }\end{array}$ & referência \\
\hline EB & 35 & 398,2 & 31,6 & $-\mathrm{N}=$ & {$[70,15,78,79]$} \\
\hline & 66 & 399,3 & 58,4 & $-\mathrm{NH}-$ & {$[70,15,78,79]$} \\
\hline & 12 & 400,6 & 10,0 & $-\mathrm{N}+$ & {$[15,78]$} \\
\hline & & & & & \\
\hline $\mathrm{HCl}$ & 14 & 398,2 & 18,3 & $-\mathrm{N}=$ & {$[70,15,78,79]$} \\
\hline & 67 & 399,4 & 64,0 & $-\mathrm{NH}-$ & {$[70,15,78,79]$} \\
\hline & 20 & 400,6 & 17,7 & $-\mathrm{N}+$ & {$[15,78]$} \\
\hline & & & & & \\
\hline $\mathrm{DC}(+)$ & 28 & 398,7 & 18,7 & $-\mathrm{N}=$ & {$[70,15,78,79]$} \\
\hline & 96 & 400,0 & 56,8 & $-\mathrm{N}+$ & {$[15,78]$} \\
\hline & 47 & 401,4 & 24,5 & $-\mathrm{N}+$ & {$[15,78]$} \\
\hline & & & & & \\
\hline $\mathrm{DC}(-)$ & 46 & 398,1 & 9,6 & $-\mathrm{N}=$ & {$[70,15,78,79]$} \\
\hline & 120 & 400,0 & 69,7 & $-\mathrm{N}+$ & {$[15,78]$} \\
\hline & 402,0 & 20,7 & $-\mathrm{N}+$ & {$[15,78]$} \\
\hline
\end{tabular}

Os valores de energia de ligação e os grupos químicos característicos para os espectros de C (1s) e N (1s), apresentados nas tabelas II e III, estão de acordo com os valores encontrados na literatura para a PANI obtida por síntese química. Na tabela II observa-se que acima de $286,9 \mathrm{eV}$ há uma pequena oxidação da superfície da PANI, ocasionada provavelmente pelo oxigênio do ar, uma vez que esta técnica revela a composição química de superfícies menores do que $10 \mathrm{~nm}$. Na tabela III observa-se a presença de dois grupos característicos da PANI: o grupo imina $(-\mathrm{N}=)$ e o grupo amina $(-\mathrm{NH}-)$, que aparecem respectivamente em aproximadamente $398,2 \mathrm{eV}$ e $\quad 399,4 \mathrm{eV}$ [15]. Acima de $400 \mathrm{eV}$, segundo a literatura $[70,15,78,79]$ os nitrogênios estariam ligados a oxigênios, como subprodutos de oxidação ou como dopantes inorgânicos, tais como $\mathrm{HNO}_{3}, \mathrm{HNO}_{2}$, etc, acima de $402 \mathrm{eV}[78,79]$. No caso das amostras dopadas com descarga corona estas espécies apareceram em maior quantidade, a PANI dopada com descarga corona negativa apresentou uma banda em 402,0 eV, o que sugere a presença de dopagem por ácido inorgânico do tipo $\mathrm{HNO}_{\mathrm{x}}$. 
Através da análise dos espectros de XPS da PANI desdopada e dopada, observa-se que a PANI dopada com $\mathrm{HCl} 1 \mathrm{M}$ e a desdopada apresentam comportamento muito semelhante a de outras polianilinas obtidas encontradas na literatura, porém as amostras dopadas com descarga corona apresentam uma quantidade maior de nitrogênio e de oxigênio, conforme foi discutido. 
3.1.4. Espectroscopia de absorção de luz na região do Ultravioleta e Visivel (UV-vis)

O objetivo desta técnica foi o de caracterizar a PANI dopada com os diferentes dopantes. Os espectros de UV-vis foram feitos utilizando filmes de compósitos de PET/PANI. Os filmes de PET não absorvem na região do UV-vis e portanto, os resultados se referem apenas aos filmes de PANI que estavam sobre o substrato.

$\mathrm{Na}$ tabela IV estão expostos os valores de absorbância ótica da PANI em diferentes condições de dopagem.

Tabela IV: Valores de absorbância ótica da PANI desdopada, dopada com HCl 1M, TSA $1 \mathrm{M}$, TFA $1 \mathrm{M}$, descarga corona positiva $(\mathrm{DC}(+))$ e descarga corona negativa $(\mathrm{DC}(-))$.

\begin{tabular}{|c|c|c|}
\hline PANI (dopada com) & Absorbåncia & $\lambda(\mathbf{n m})$ \\
\hline desdopada & 1,010 & 620 \\
\hline TSA 1M & 1,333 & 830 \\
\hline TFA 1M & 1,083 & 850 \\
\hline HCI 1M & 1,329 & 870 \\
\hline DC(+) & 0,719 & 900 \\
\hline DC(-) & 0,563 & 920 \\
\hline
\end{tabular}

Neoh et al. [58] obtiveram resultados de UV-vis muito semelhantes com outros dopantes e atribuíram os valores de comprimento de onda acima de $900 \mathrm{~nm}$ a possibilidade de que os efeitos intercadeias sejam mais predominantes do que os efeitos intracadeias, o qual pode ser resultado de cadeias poliméricas relativamente curtas do recobrimento de PANI sobre o substrato $[80,81]$.

Na figura 3.17 pode-se ver os espectros de UV-vis das amostras de PANI desdopada e dopada com diferentes tipos de dopantes (ácidos) e descarga corona. 


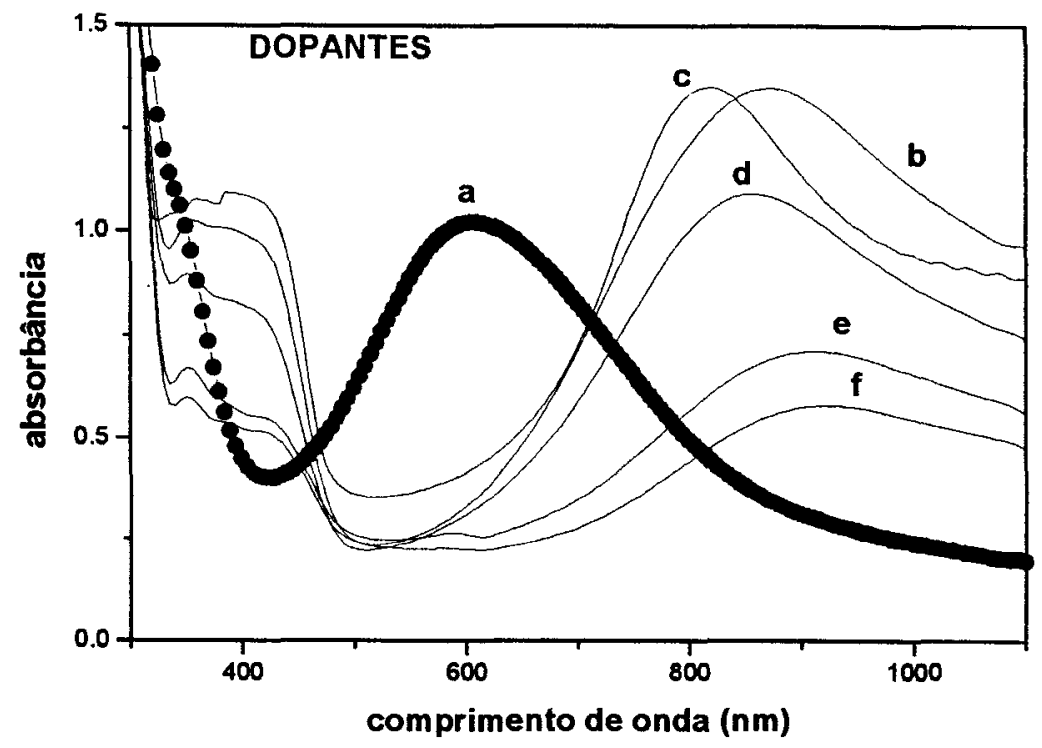

Figura 3.17: Espectro de UV-vis da PANI, onde: a - desdopada em $\mathrm{NH}_{4} \mathrm{OH} 0,1 \mathrm{M}$ e da PANI dopada com: b - HCl 1M, c - TSA 1M, d - TFA 1M, e - descarga corona positiva, $f$ - descarga corona negativa.

A absorbância do espectro também dá uma medida qualitativa indireta da espessura do filme de PANI, sendo mais finos os filmes dopados com descarga corona. O espectro de UV-vis da PANI (desdopada) tem dois picos de absorbância em torno de $325 \mathrm{~nm}$ e em $620 \mathrm{~nm}$, os quais se devem à transição $\pi-\pi^{\star}$ dos anéis benzenóides e à absorção da excitação dos anéis quinóides, respectivamente. Quando os átomos de nitrogênio do grupo imina são protonados, os nitrogênios e os anéis quinóides de sua vizinhança se transformam em radicais cátion semiquinona, provocando diminuição na intensidade do pico de absorção a $620 \mathrm{~nm}$ e a geração de picos de absorção em aproximadamente $420 \mathrm{~nm}$ e acima de $660 \mathrm{~nm}$, devido ao surgimento de pólarons, que são responsáveis pela dopagem e por sua vez, condutividade elétrica da PANI $[10,82,83]$.

Assim, os dados da figura 3.17 e da tabela IV demonstram que os espectros da PANI dopada com descarga corona são bastante semelhantes aos da 
PANI dopada com ácidos protônicos, diferindo apenas em intensidade (devido a espessura) e um deslocamento no máximo de absorção (de $830 \mathrm{~nm}$ a $920 \mathrm{~nm}$ ).

A importância do uso desta técnica se deu na caracterização do estado isolante e condutor dos materiais anteriormente citados, bem como na avaliação qualitativa da espessura dos filmes. 


\subsubsection{Microscopia Ótica (MO)}

O objetivo desta técnica foi avaliar as possiveis mudanças na topografia da superfície da PANI que pudessem ter ocorrido após tratamento de dopagem com descarga corona, uma vez que as amostras dopadas por descarga corona apresentaram um valor de condutividade elétrica 1 ordem de grandeza menor do que as amostras dopadas por ácidos. Na figura 3.18 observa-se que dependendo do tipo de dopagem, a PANI pode assumir um aspecto diferente, o que pode influenciar no valor da condutividade elétrica. Por exemplo, os compósitos PET/PANI dopados com $\mathrm{HCl} 1 \mathrm{M}$ apresentaram condutividade elétrica igual a 2 $\mathrm{S} / \mathrm{cm}$, os dopados por descarga corona negativa e positiva, apresentaram um valor em tomo de $0,3 \mathrm{~S} / \mathrm{cm}$.

Há uma hipótese de que isso possa ser atribuído à diminuição dos grãos da PANI, que é provocada pela descarga elétrica que sofre o material durante o processo de dopagem (que pode ser observado por AFM, item 3.1.7). Nas fotomicrografias da figura 3.18 pode-se ver que inicialmente em (a) e (b) as amostras apresentavam coloração verde-esmeralda que são as amostras dopadas por $\mathrm{HCl} 1 \mathrm{M}$, quando a amostra é dopada por descarga corona positiva, apresenta uma tonalidade verde-amarelado (que pode ser melhor visualizada na fotomicrografia (c)). Após a dopagem por descarga corona negativa, conforme a fotomicrografia (e), da figura a seguir, aparece uma tonalidade amarela escura.

A diferença de tons de verde pode ser atribuída à menor espessura das camadas de PANI dopadas por descarga corona. É provável que durante o processo de dopagem por descarga corona ocorra, com o "vento corona", uma uniformização da topografia da superfície da PANI, ou seja, os grãos maiores poderiam estar sendo eliminados ou achatados, diminuindo a espessura da amostra, porém uniformizando a superfície da mesma, como pode ser observado no item 3.1.7 (AFM). 


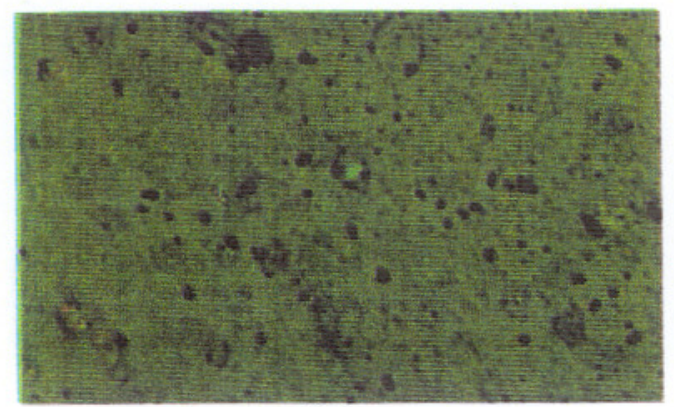

(a)

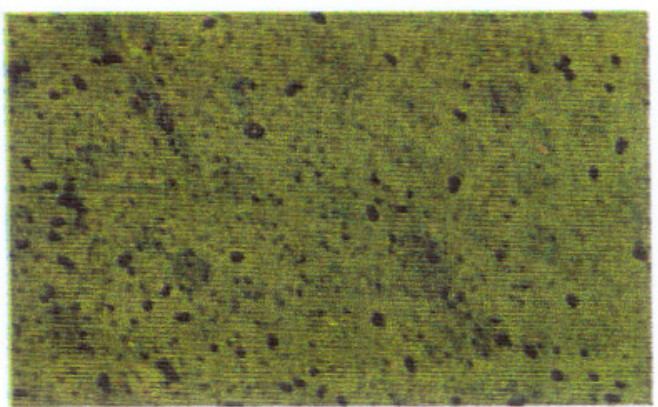

(c)

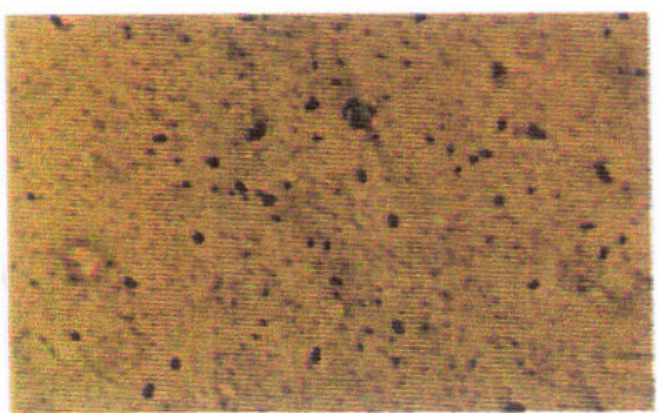

(e)

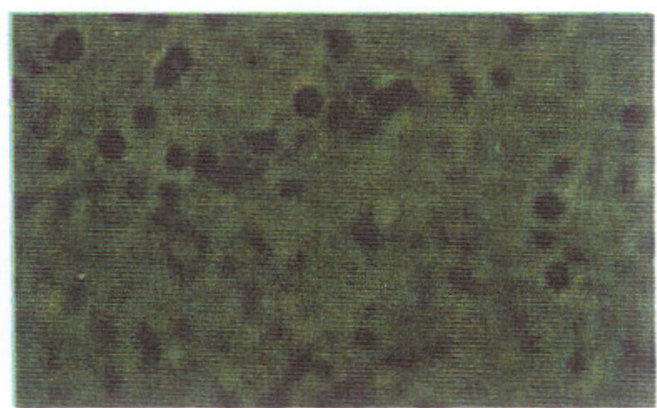

(b)

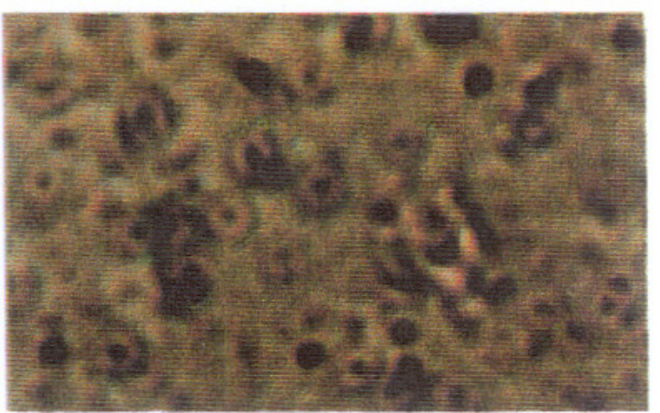

(d)

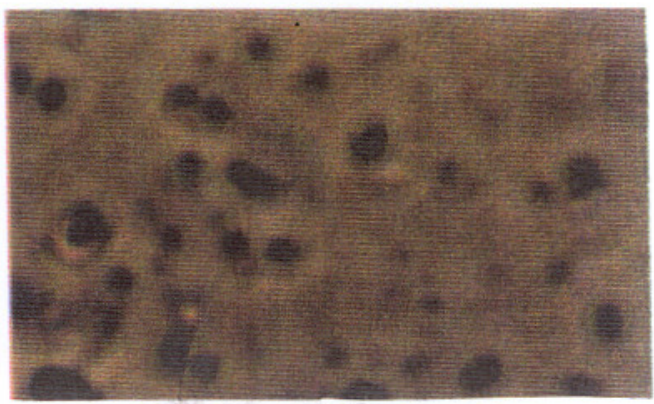

(f)

Figura 3.18: Fotomicrografias de MO de compósitos PET/PANI, onde observase a superfície da PANI dopada com: (a) $\mathrm{HCl} 1 \mathrm{M}(400 \mathrm{x}),($ b) $\mathrm{HCl} 1 \mathrm{M}(1.000 \mathrm{x})$, (c) descarga corona positiva $(400 \mathrm{x})$, (d) descarga corona positiva $(1.000 \mathrm{x}),(\mathrm{e})$ descarga corona negativa $(400 \mathrm{x})$, (f) descarga corona negativa $(1.000 \mathrm{x})$. 
A Microscopia Ótica contribuiu para ajudar a explicar a absorção de luz UV-vis acima de $900 \mathrm{~nm}$ nas amostras dopadas com descarga corona, bem como, este efeito também pode estar relacionado com uma diminuição da espessura da PANI nas amostras dopadas com descarga corona. 


\subsubsection{Microscopia Eletrônica de Varredura (MEV)}

Neste item, apresentamos as fotomicrografias da superfície do PET e PC, e compósitos PET/PANI e PC/PANI em diferentes tipos de tratamento.

Nas fotomicrografias das figuras 3.19 e 3.20, pode-se ver a morfologia da superfície dos filmes dos compósitos PET/PANI e PC/PANI dopados e desdopados, sem tratamento térmico e com tratamento térmico.

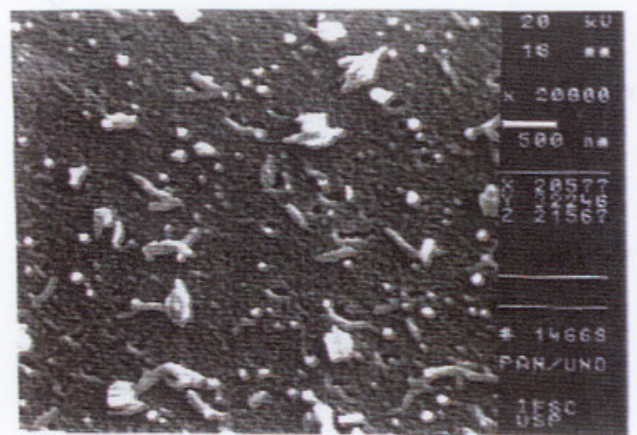

(a)

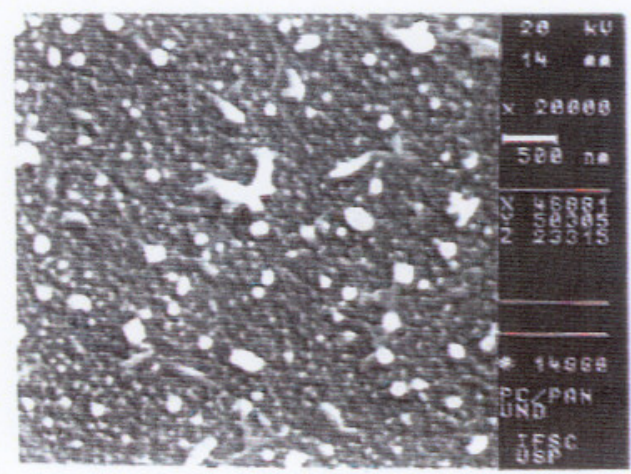

(c)

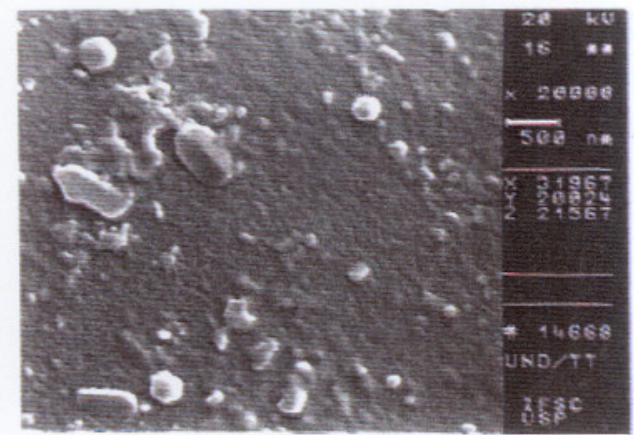

(b)

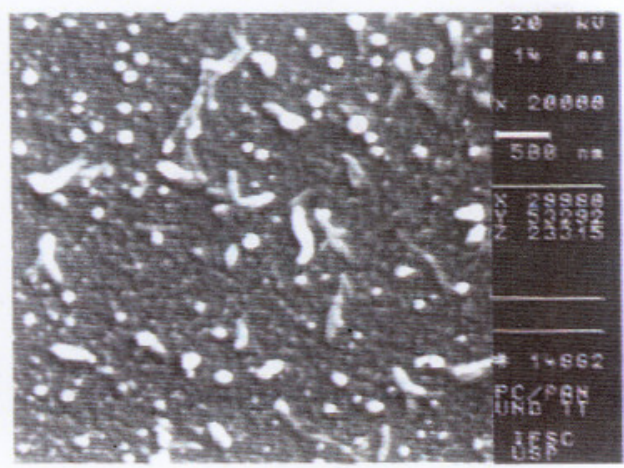

(d)

Figura 3.19: Fotomicrografias de MEV de filmes de PET/PANI-desdopada em

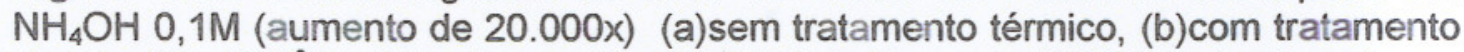
térmico $\left(2 \mathrm{~h}, 200^{\circ} \mathrm{C}\right)$; fotomicrografias de MEV de filmes de PC/PANI-desdopada em $\mathrm{NH}_{4} \mathrm{OH}$ 0,1 M (aumento de 20.000x): (c)sem tratamento térmico, (d)com tratamento térmico $\left(2 \mathrm{~h}, 200^{\circ} \mathrm{C}\right)$.

Em todas as fotomicrografias observa-se que a PANI depositada nos substratos possui morfologia do tipo granular (em forma de grãos) [84,85], sendo que no caso do PC, aparentemente, os grãos parecem estar mais arredondados (globulares) do que os grãos da PANI depositados sobre o PET, provavelmente devido a influência da morfologia do substrato. Os grãos da PANI das amostras que sofreram tratamento térmico estão mais achatados e interligados entre si. 


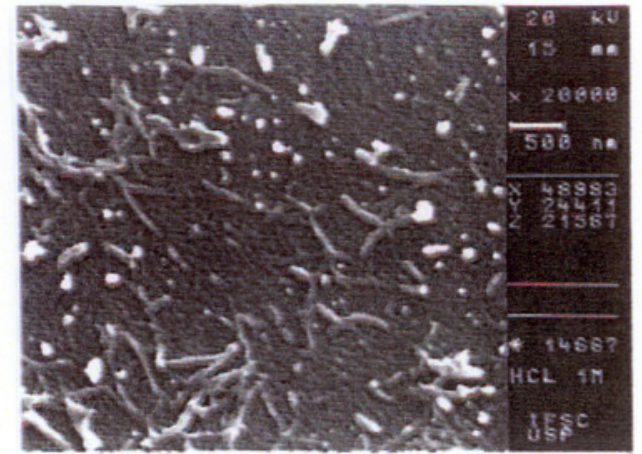

(a)

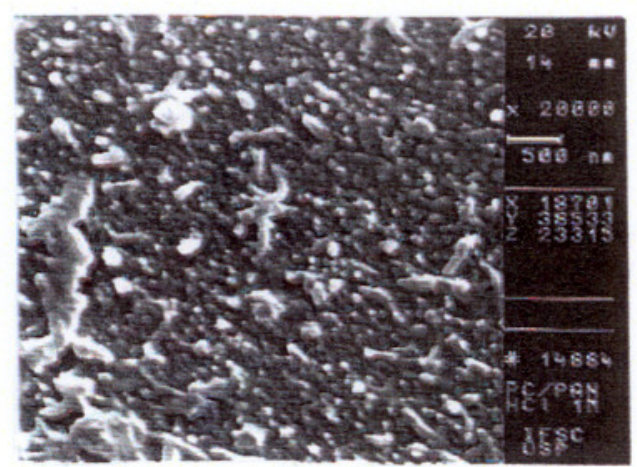

(c)

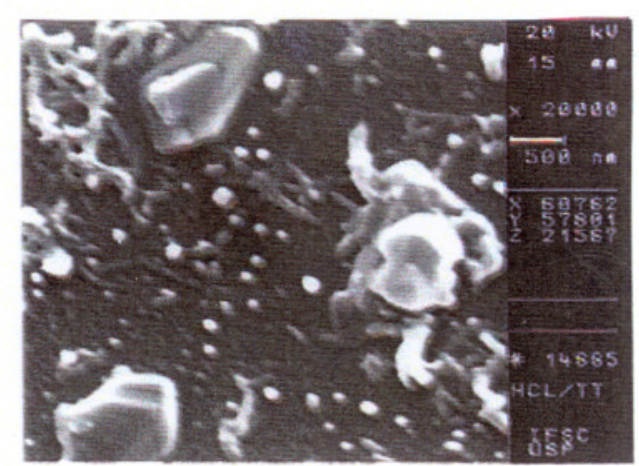

(b)

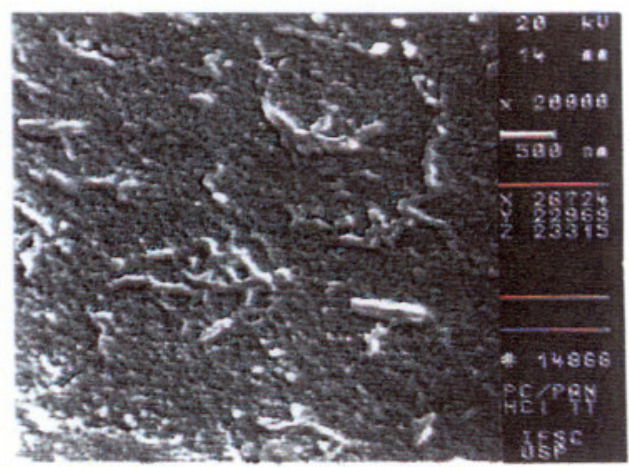

(d)

Figura 3.20: Fotomicrografias de MEV de filmes de PET/PANI-dopada em $\mathrm{HCl} 1 \mathrm{M}$ (aumento de 20.000x): (a)sem tratamento térmico, (b)com tratamento térmico ( $2 \mathrm{~h}$, $200^{\circ} \mathrm{C}$ ); fotomicrografias de MEV de filmes de PC/PANI-dopada em $\mathrm{HCl} 1 \mathrm{M}$ (aumento de 20.000x): (c)sem tratamento térmico, (d)com tratamento térmico (2h, $\left.200^{\circ} \mathrm{C}\right)$.

$\mathrm{Na}$ figura 3.21 são apresentadas fotomicrografias de filmes de PET/PANI e PC/PANI dopados com TFA 1M. 


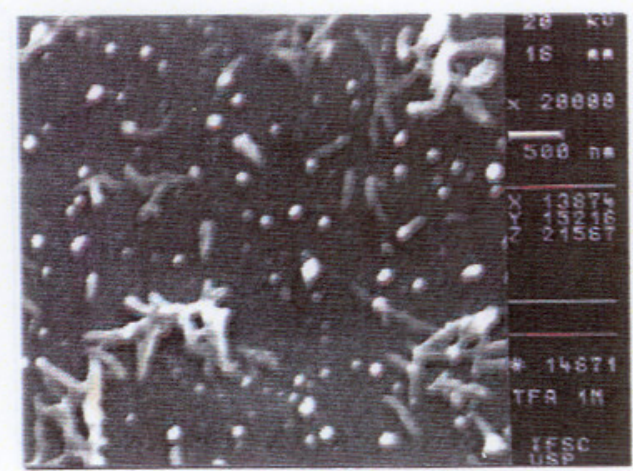

(a)

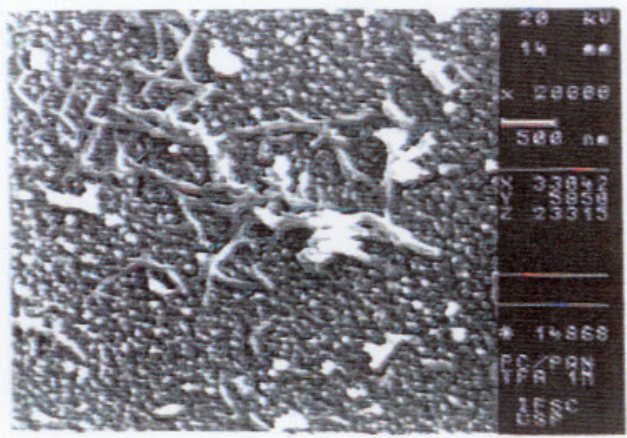

(c)

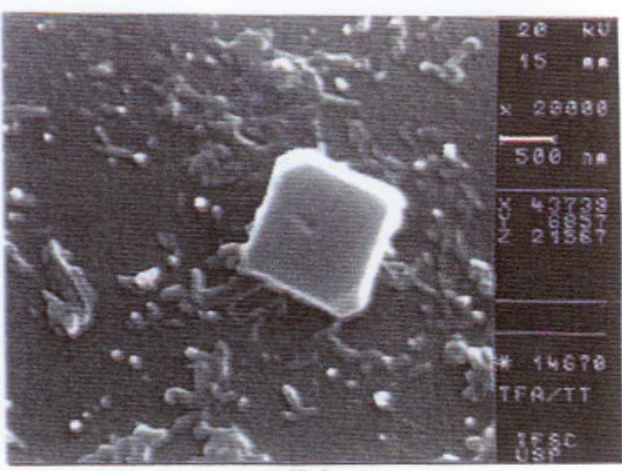

(b)

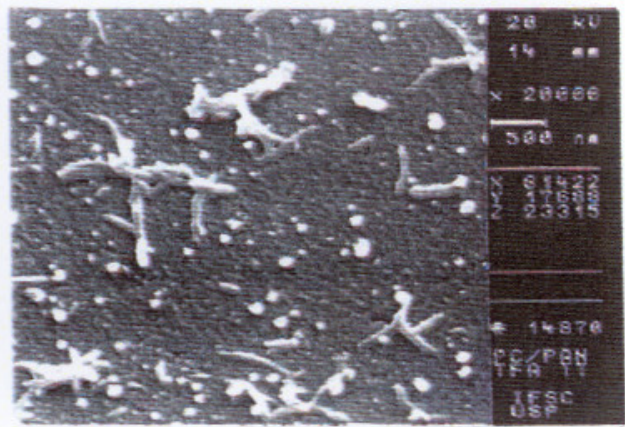

(d)

Figura 3.21: Fotomicrografias de MEV de filmes de PET/PANI-dopada com TFA $1 \mathrm{M}$ (aumento de $20.000 \mathrm{x}$ ): (a)sem tratamento térmico, (b)com tratamento térmico $\left(2 \mathrm{~h}, 200^{\circ} \mathrm{C}\right)$; fotomicrografias de MEV de PC/PANI-dopada com TFA $1 \mathrm{M}$ (aumento de 20.000x): (c)sem tratamento térmico, (d)com tratamento térmico $\left(2 \mathrm{~h}, 200^{\circ} \mathrm{C}\right)$.

Observa-se que as imagens das amostras dos filmes de PET/PANI e PC/PANI dopadas com TFA $1 \mathrm{M}$, com ou sem tratamento térmico, foram semelhantes as imagens de MEV dos filmes dopados com $\mathrm{HCl} 1 \mathrm{M}$. Talvez isso ocorra devido ao fato dos ácidos $\mathrm{HCl}$ e TFA terem comportamento químico muito semelhante, como por exemplo, serem muito voláteis, dissociarem-se rapidamente, protonando a PANI de forma similar, conferindo este aspecto à topografia de superfície da PANI.

Na figura 3.22 vê-se a superfície dos filmes de PET/PANI e PC/PANI dopados com TSA $1 \mathrm{M}$. 


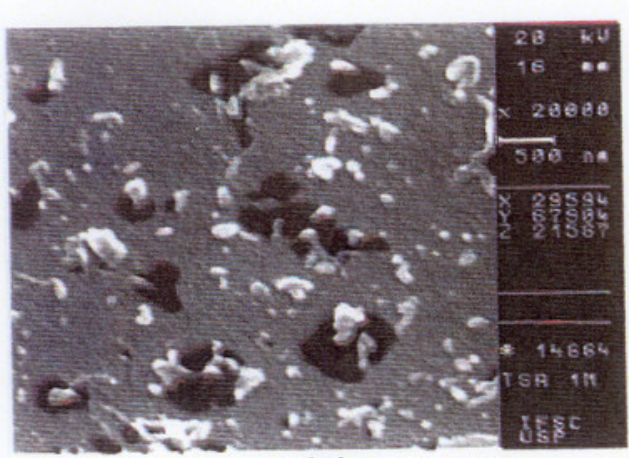

(a)

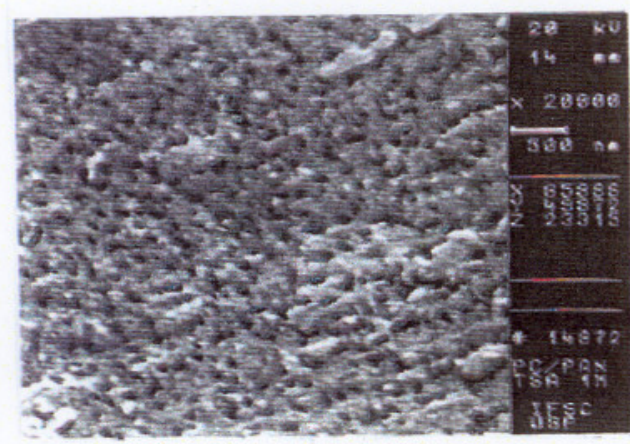

(c)

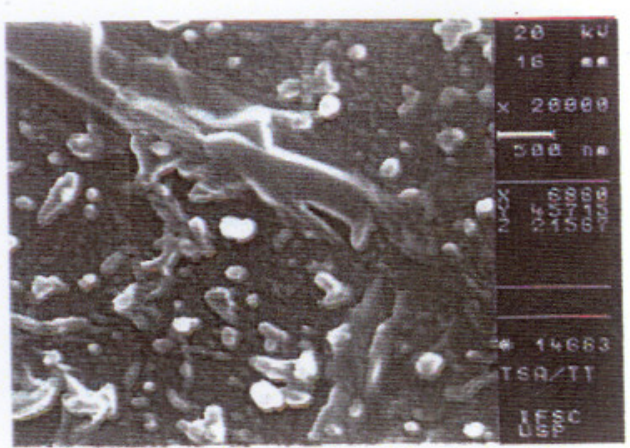

(b)

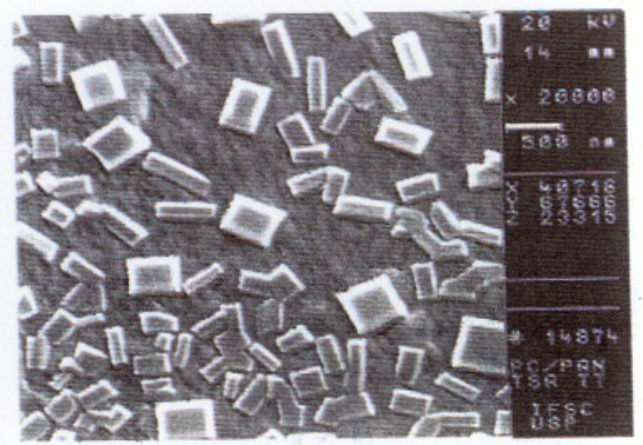

(d)

Figura 3.22: Fotomicrografias de MEV de filmes de PET/PANI-dopada com TSA $1 \mathrm{M}$ (aumento de 20.000x): (a)sem tratamento térmico, (b)com tratamento térmico $\left(2 \mathrm{~h}, 200^{\circ} \mathrm{C}\right)$; fotomicrografias de filmes de MEV de PC/PANI-dopada em TSA $1 \mathrm{M}$ (aumento de 20.000x) ; (c)sem tratamento térmico, (b)com tratamento térmico ( $2 \mathrm{~h}$, $\left.200^{\circ} \mathrm{C}\right)$.

Nas figuras 3.22 (a) e 3.22 (c), as manchas negras se devem a remoção de porções de camadas de PANI, que devido ao fato do TSA conferir solubilidade a PANI e também ser muito higroscópico, isso promove pouca aderência da PANI ao substrato, fazendo com que a mesma seja removida mais facilmente. Os cristais com morfologia retangular, que aparecem na amostra tratada termicamente, são provenientes do excesso do dopante TSA que ao sofrer tratamento térmico, perde sua água de hidratação e forma cristais na superfície da PANI. 
Observa-se na figura 3.23 as fotomicrografias dos filmes de PET/PANI

e PC/PANI dopados com descarga corona.

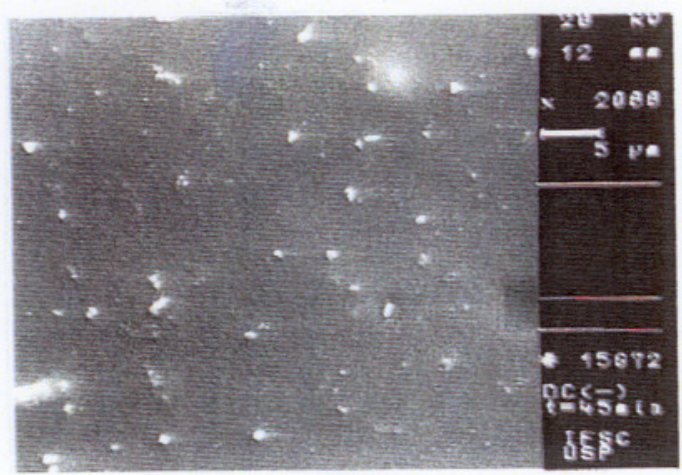

(a)

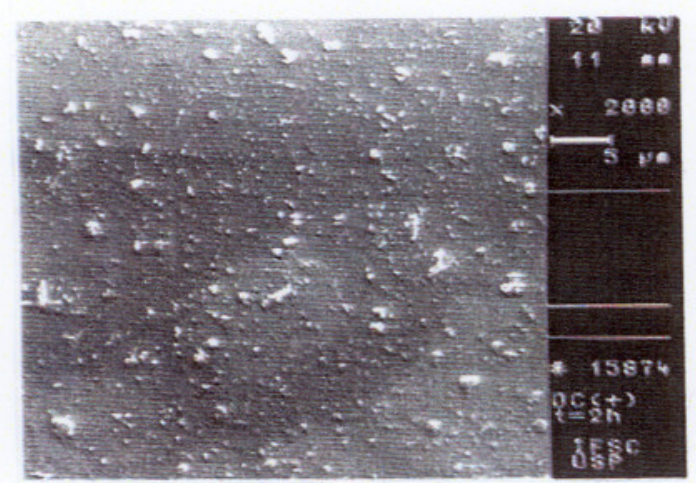

(c)

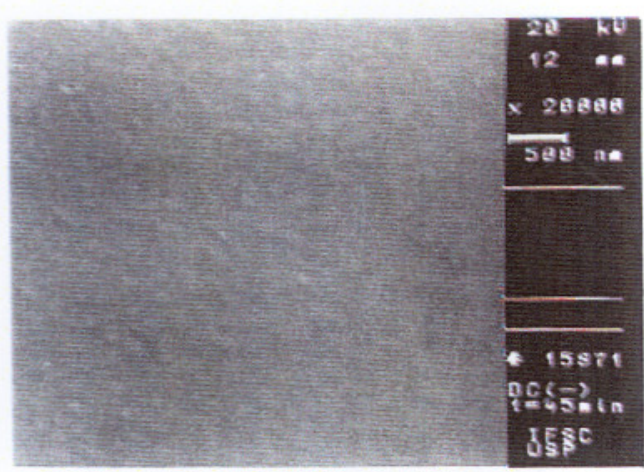

(b)

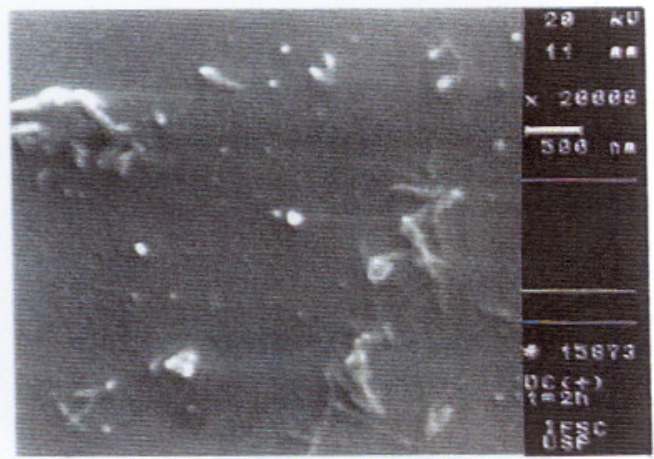

(d)

Figura 3.23: Fotomicrografias de MEV de filmes de PET/PANI - dopados em cada face, com descarga corona negativa $\left(t=45 \mathrm{~min}, i=10 \mu \mathrm{A}, \mathrm{d}_{\text {ponta grade }}=18 \mathrm{~mm}, \mathrm{~d}_{\text {grade }}\right.$ amostra $=6 \mathrm{~mm}$ ): (a) aumento de 2.000x, (b) aumento de 20.000x; fotomicrografias de MEV de filmes de PET/PANI-dopada em cada face, com descarga corona positiva $\left(\mathrm{t}=2 \mathrm{~h} ; \mathrm{i}=20 \mu \mathrm{A}, \mathrm{d}_{\text {ponta grade }}=18 \mathrm{~mm}, \mathrm{~d}_{\text {grade amostra }}=6 \mathrm{~mm}\right)$ : (c)aumento de $2.000 x$, (d)aumento de $20.000 x$.

Na figura 3.23 nota-se uma profunda mudança na morfologia da PANI, em relação as fotomicrografias anteriores. Neste caso, aparecem em todas as regiões das fotomicrografias analisadas, poucos grãos grandes de PANI. As amostras dopadas com descarga corona negativa são as que apresentam menor número de grãos grandes, sugerindo que quando a amostra é dopada com descarga corona, o "vento corona" deva achatar os grãos maiores da PANI, uniformizando a superfície da mesma. 
Os substratos poliméricos (PET e PC) que foram usados para depositar a PANI, também foram analisados por MEV porque conforme a literatura $[3,64]$ um dos fatores que pode influenciar a morfologia da PANI é a morfologia do substrato. A morfologia dos filmes de PET e PC antes do tratamento térmico e após tratamento térmico, pode ser vista na figura 3.24 a seguir.

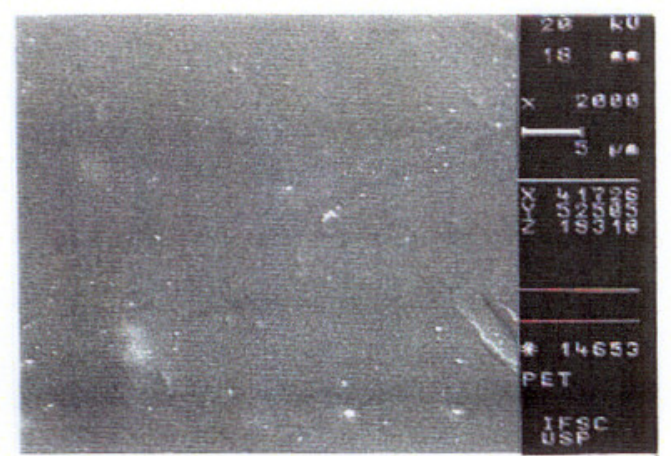

(a)

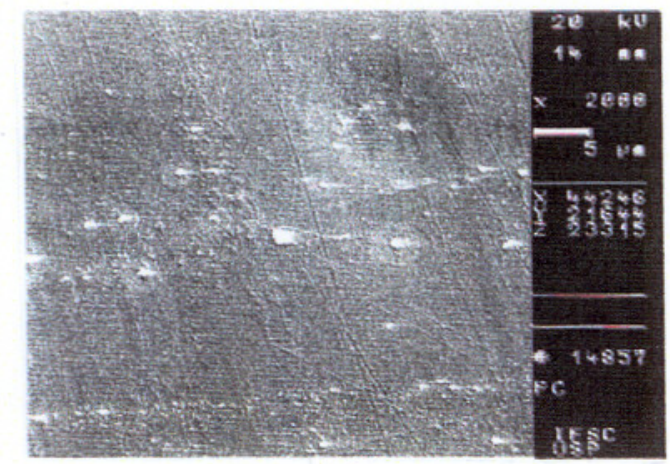

(c)

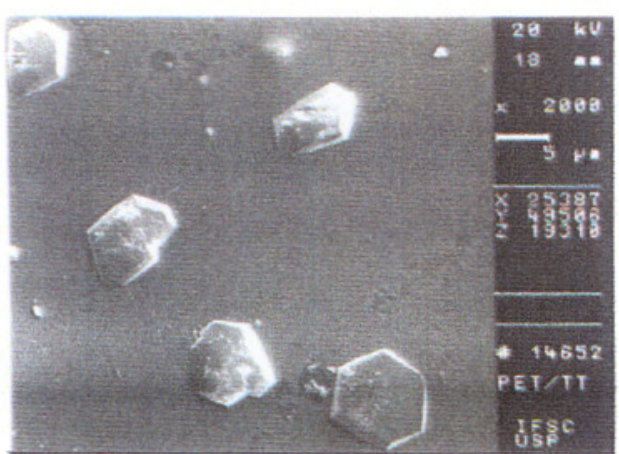

(b)

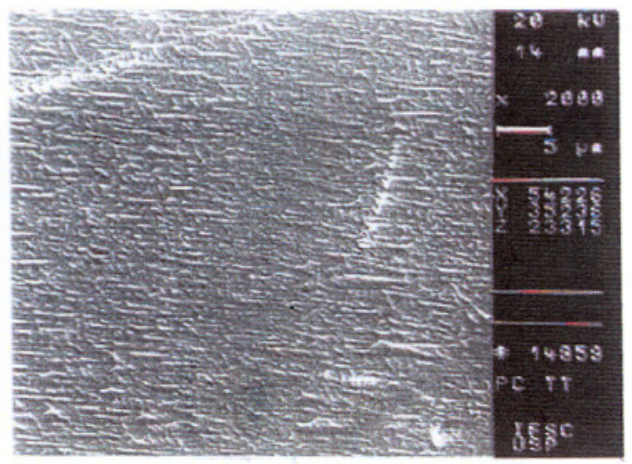

(d)

Figura 3.24: Fotomicrografias de MEV de filmes de PET (aumento de 2.000x): (a) sem tratamento térmico, (b) com tratamento térmico $\left(2 \mathrm{~h}, 200^{\circ} \mathrm{C}\right)$; Fotomicrografias de MEV de filmes de PC (aumento de 2.000x): (c) sem tratamento térmico,(d) com tratamento térmico $\left(2 \mathrm{~h}, 200^{\circ} \mathrm{C}\right)$.

Na superfície dos filmes de PET e PC (sem tratamento térmico) observa-se alguns defeitos oriundos do processo de fabricação dos filmes. Após tratamento térmico, tanto no PET, como no PC, pode-se ver mudanças em sua superfície. Observa-se estrias ao longo de toda a extensão do PC em formato radial. O PET cristaliza após tratamento térmico em mufla (com aquecimento e 
resfriamento controlado), formando cristais hexagonais com tamanho em torno de $\overline{7}$ $\mu \mathrm{m}$, a composição quimica desses cristais foi analisada por XPS, conforme apresentado no item 3.1.3 (XPS), e foi constatado que não havia nenhum elemento químico diferente dos que constituem o PET, excluindo a hipótese de ser alguma impureza do polimero.

$\mathrm{Na}$ figura 3.25 pode-se ver a superfície de filmes de PET/PANI-HCl $1 \mathrm{M}$ e $\mathrm{PC} / \mathrm{PANI}-\mathrm{HCl} 1 \mathrm{M}$ que foram estirados até a ruptura, afim de observar a influência do substrato sobre a morfologia da PANI. Nota-se uma diferença nítida do comportamento da morfologia que a PANI adquire após estes testes. No caso dos compósitos de PET/PANI os grãos de PANI parecem se orientar de forma retilínea ao longo do substrato (PET), conforme figuras 3.25 (a) e (b). Os compósitos de PC/PANI, ao se romperem, sugerem que os grãos de PANI ficam sobrepostos desordenadamente sobre o PC. Isto pode ser explicado devido ao fato do filme de PET ser cristalino ( $95 \%$ ) e bi-orientado, e o filme de PC ser amorfo, sugerindo que o substrato deva influenciar na morfologia do filme de PANI depositado sobre o mesmo. 


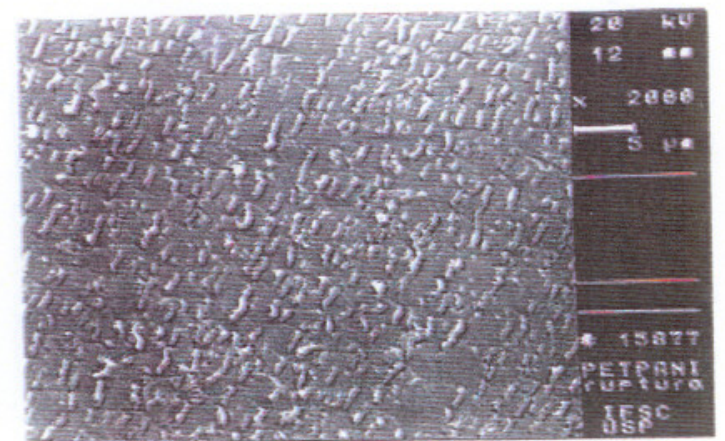

(a)

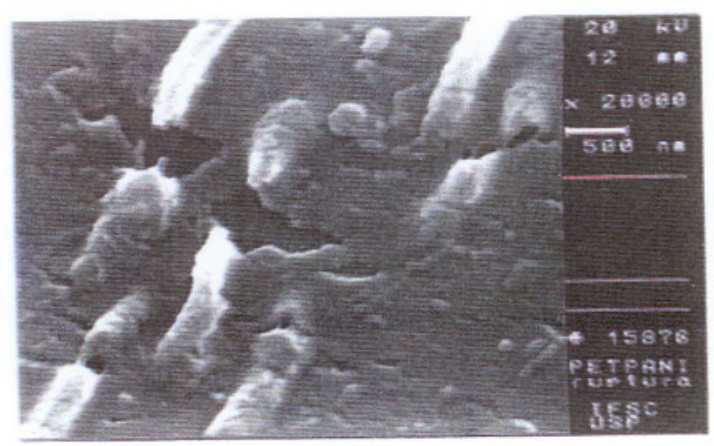

(c)

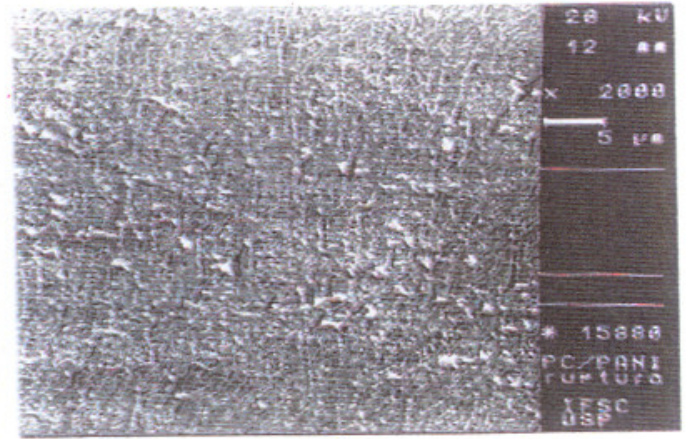

(b)

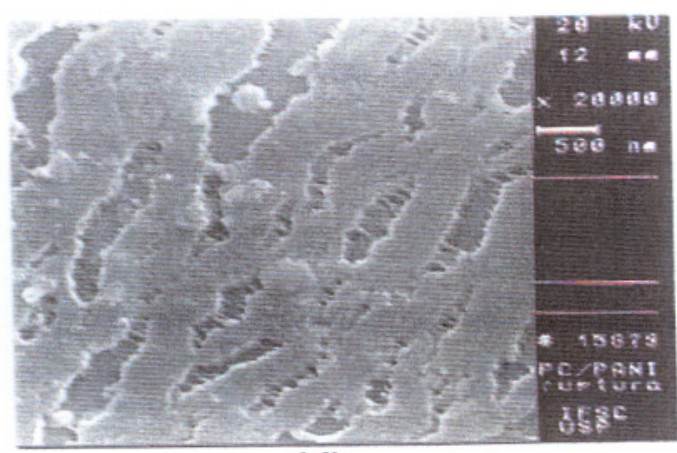

(d)

Figura 3.25: Fotomicrografias de MEV de compósitos que foram esticados até a ruptura: (a) PET/PANI-HCl $1 \mathrm{M}$ (aumento de $2.000 \mathrm{x}$ ); (b) PC/PANI-HCl $1 \mathrm{M}$ (aumento de 2.000 x), (c) PET/PANI-HCl 1M (aumento de 20.000 x) e (d) $\mathrm{PC} / \mathrm{PANI}-\mathrm{HCl} 1 \mathrm{M}$ (aumento de $20.000 \mathrm{x}$ ).

O estudo por MEV foi importante para observar a morfologia dos compósitos de PANI estudados e os efeitos dos tratamentos feitos. Observou-se também que a dopagem por descarga corona confere uma morfologia superficial bem mais homogênea do que a da PANI dopada com ácidos protônicos. 


\subsubsection{Microscopia de Força Atômica (AFM)}

A Microscopia de Força Atômica vem sendo utilizada em diversos trabalhos em Ciência dos Materiais. Esta técnica foi pela primeira vez usada no estudo de polímeros no ano de 1988 [64]. Desde então, inúmeros trabalhos envolvendo análise por AFM tem sido feitos. As vantagens do AFM no estudo de polímeros são: podem ser feitas imagens em 3 dimensões; não é necessário recobrir a amostra com camada condutora; a amostra não necessita de métodos especiais para preparação; pode-se medir a espessura de camadas superficiais em escala nanométrica; determina-se a morfologia da superfície da amostra e a rugosidade com maior precisão, etc [64].

Esta técnica foi utilizada neste trabalho, porque com ela é possível observar maiores detalhes na superfície da amostra, em comparação à técnica de MEV, tais como a altura e largura dos grãos de PANI. O objetivo foi analisar mais precisamente a superfície da PANI quando a mesma era dopada com descarga corona negativa e comparar a superfície da mesma com amostras dopadas com $\mathrm{HCl} 1 \mathrm{M}$ e desdopada.

Na figura 3.26 encontram-se as imagens de AFM das amostras de PANI desdopada e dopada com $\mathrm{HCl} 1 \mathrm{M}$ e descarga corona negativa. 


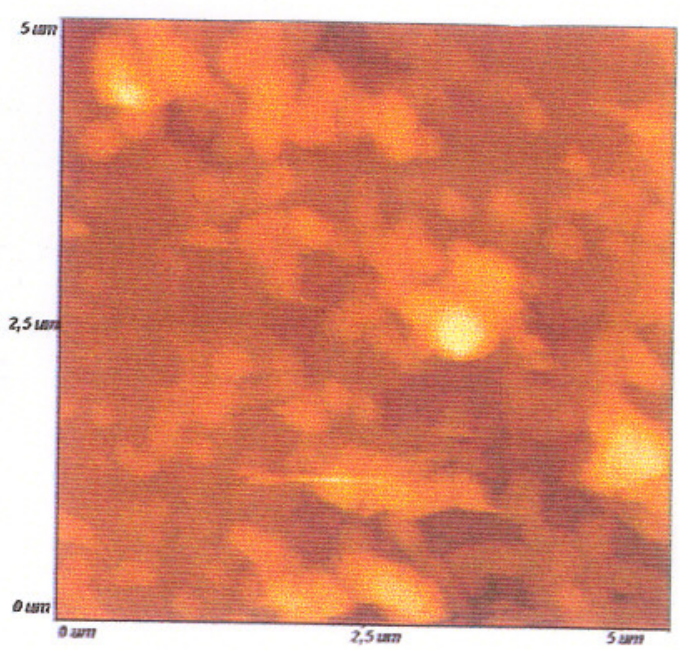

(a)

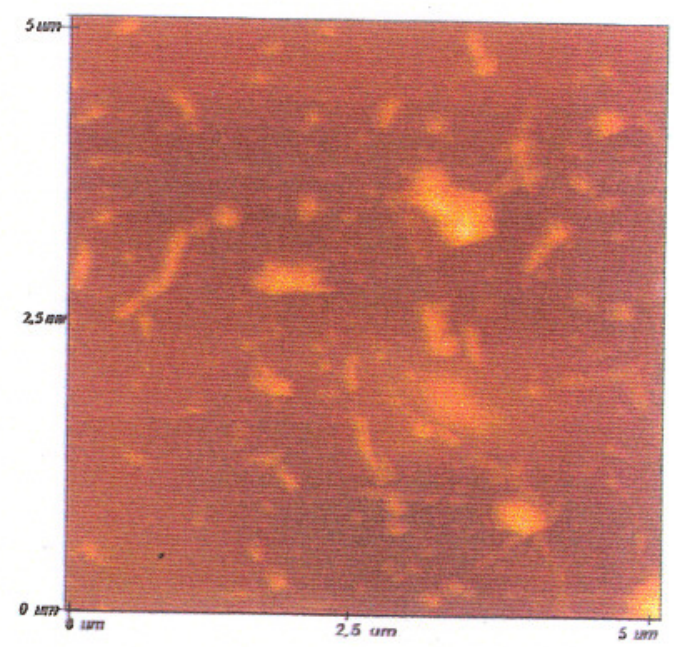

(b)

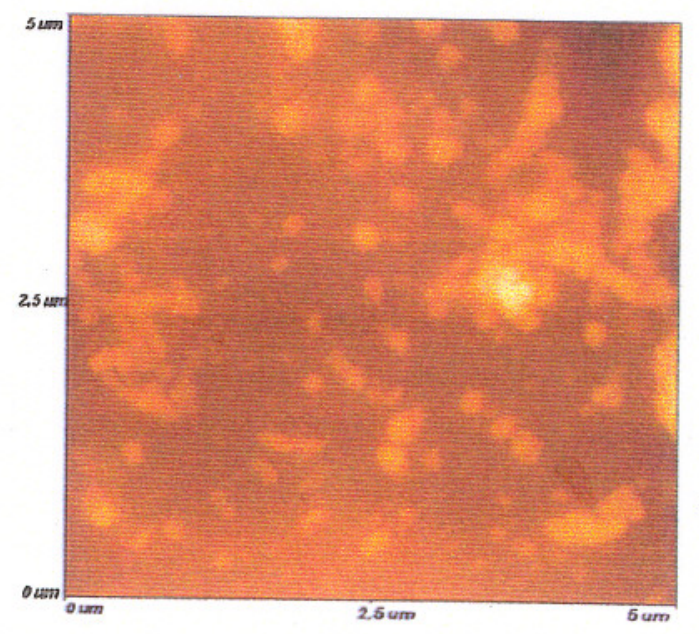

(c)

Figura 3.26: Imagens de AFM da topografia da superfície da PANI (modo nãocontato), onde: (a) amostra dopada com $\mathrm{HCl} 1 \mathrm{M}$, (b) desdopada e (c) redopada com descarga corona negativa.

As imagens da figura 3.26 foram obtidas por AFM (modo não contato), usando uma varredura de $5 \mu \mathrm{m}$. Na figura 3.26 (a) pode-se ver a superfície de uma amostra de um compósito de PET/PANI que foi obtido já na forma dopada com 
$\mathrm{HCl} 1 \mathrm{M}$, em (b) observa-se a superfície do material após tratamento de desdopagem em $\mathrm{NH}_{4} \mathrm{OH} 0,1 \mathrm{M}$ e em (c) tem-se a mesma superfície, porém redopada com descarga corona negativa. Para cada imagem foram selecionados 2 tipos de grãos: menor e maior. Cada um desses grãos foi analisado mediante software da Topometrix, que permite determinar as dimensões em x, y e z de cada grão de PANI que se quer analisar. Foi traçada uma linha horizontal e outra vertical em cada grão e marcou-se 2 pontos no contorno do grão (figura 3.27). A largura vertical do grão é dada pela diferença dos 2 pontos no eixo y, a largura horizontal surge da diferença de 2 pontos no eixo $x$ e a altura é dada pela diferença de 2 pontos no eixo $z$, conforme tabela V. A seguir, nas figuras $3.27 \mathrm{e}$ 3.28 tem-se um exemplo do perfil de uma linha vertical e horizontal, respectivamente, da superfície da PANI (desdopada), apresentando as dimensões de um grão.
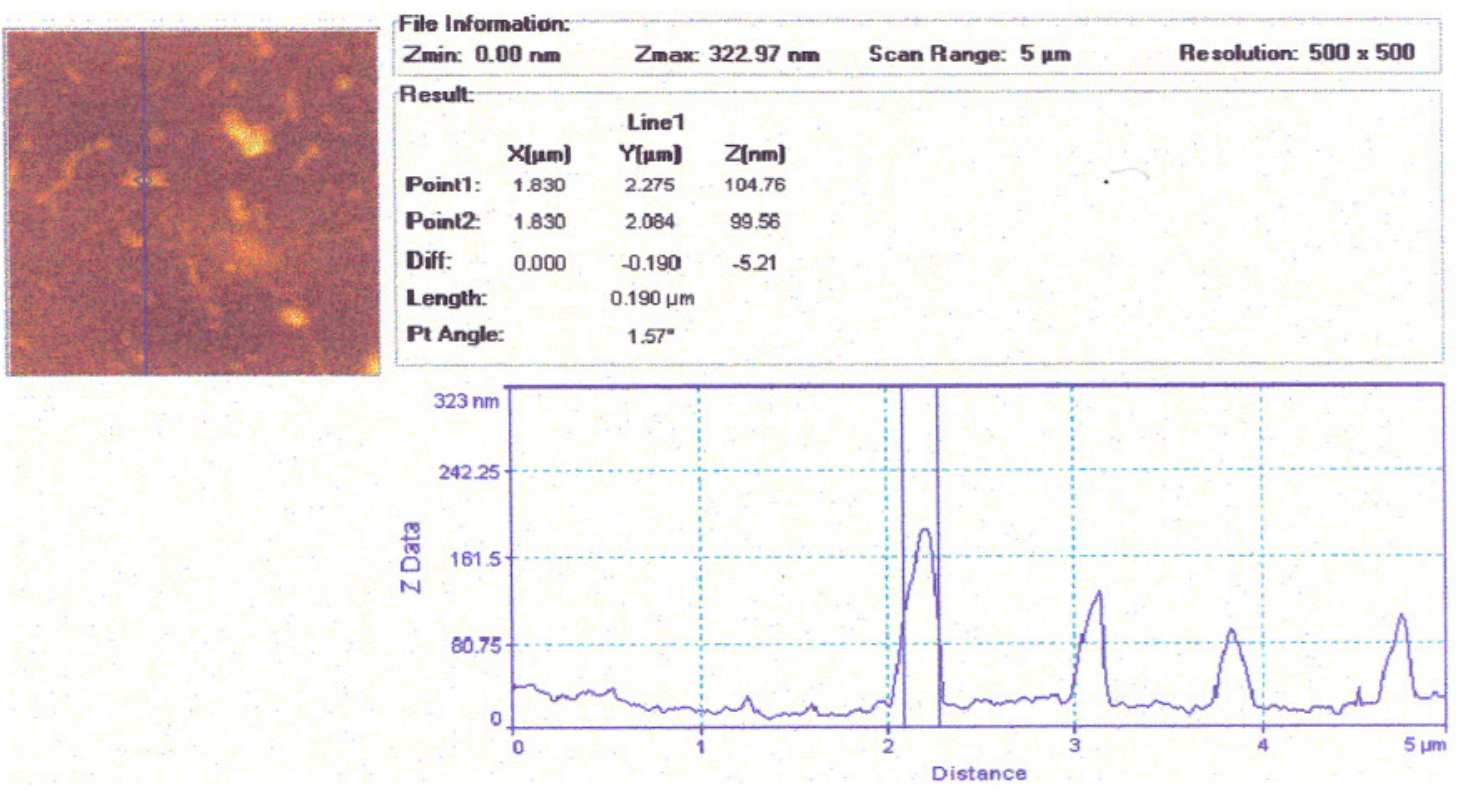

Figura 3.27: Imagem de AFM e perfil de uma linha vertical da superfície da PANI (desdopada) depositada sobre PET, apresentando o comprimento (em y) de um grão. 

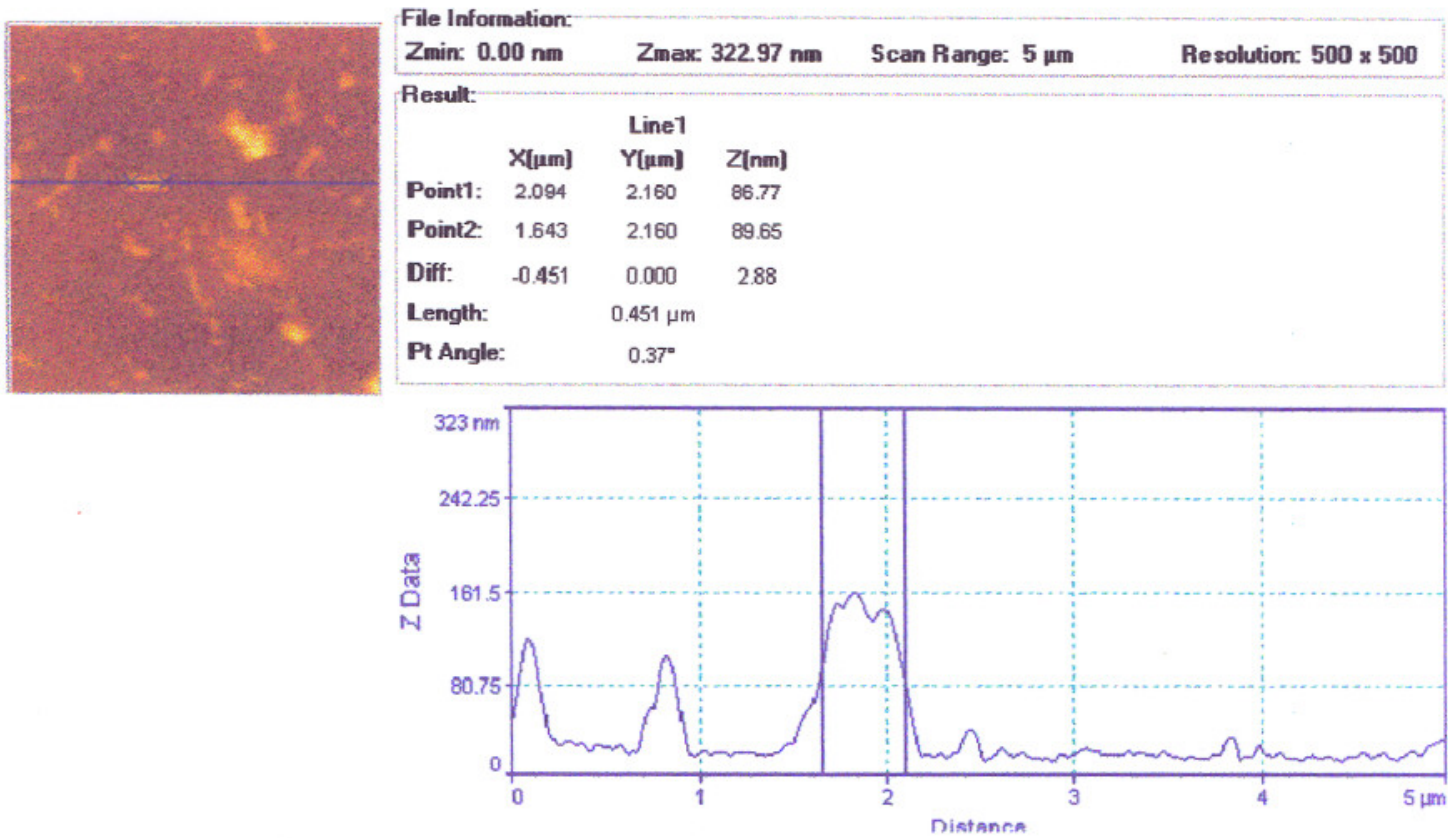

Figura 3.28: Imagem de AFM e perfil de uma linha horizontal da superfície da PANI (desdopada) depositada sobre PET, apresentando o comprimento (em $x$ ) de um grão.

Tabela V: Valores das dimensões de alguns grãos da PANI depositada sobre o $\mathrm{PET}$. Onde: $\mathrm{PANI} / \mathrm{HCl} 1 \mathrm{M}=\mathrm{PANI}$ dopada com $\mathrm{HCl} 1 \mathrm{M} ; \mathrm{PANI} / \mathrm{EB}=\mathrm{PANI}$ desdopada; PANI/DC $(-)=$ PANI dopada com descarga corona negativa.

\begin{tabular}{|c|c|c|c|}
\hline AMOSTRA & LARGURA $(\mathrm{nm})$ & LARGURA $(\mathrm{nm})$ & ALTURA $(\mathrm{nm})$ \\
\hline PANI/HCI 1M & EIXO X & EIXO Y & EIXO Z \\
\hline Grão menor & 220 & 240 & 55 \\
\hline Grão maior & 531 & 421 & 300 \\
\hline PANI/EB & EIXO X & EIXO Y & EIXO Z \\
\hline Grão menor & 100 & 100 & 55 \\
\hline Grão maior & 230 & 190 & 200 \\
\hline PANI/DC(-) & EIXO X & EIXO Y & 70 \\
\hline Grão menor & 240 & 190 & 110 \\
\hline Grão maior & 431 & 381 & \\
\hline
\end{tabular}


Nota-se uma mudança na dimensão dos grãos das amostras em função da condição de dopagem. No caso da PANI inicialmente obtida (dopada com $\mathrm{HCl} 1 \mathrm{M}$ ), observa-se grãos mais interconectados e de maior volume em relação à PANI desdopada. Segundo Epstein et al. [86] quando o polimero sofre desdopagem, as cadeias poliméricas se "enovelam" e os grãos da PANI se tornam mais estreitos. Após a redopagem com descarga corona negativa, os grãos da PANI voltam a se esticarem mais, porém a altura de cada grão é quase a metade do tamanho do grão que é dopado com $\mathrm{HCl} 1 \mathrm{M}$.

Com as imagens de AFM pode-se entender melhor o fenômeno da dopagem por descarga corona. O valor de rugosidade da área (Ra) da PANI dopada com $\mathrm{HCl} 1 \mathrm{M}$ foi de 43,2 nm; o valor de Ra da PANI desdopada foi de 16 $\mathrm{nm}$ e para a PANI dopada com descarga corona negativa foi de 19,1 nm. O valor de rugosidade média superficial (RMS) da PANI dopada com $\mathrm{HCl} 1 \mathrm{M}$ foi de 60,5 $\mathrm{nm}$; o valor de RMS da PANI desdopada foi de $26,6 \mathrm{~nm}$ e para a PANI dopada com descarga corona negativa foi de $26,8 \mathrm{~nm}$. Após a redopagem com descarga corona a superfície da PANI se torna mais homogênea, com grãos distribuidos de tamanho mais uniforme (conforme tabela V). Estes resultados estão de acordo com a hipótese de Job et al. [47] de que quando é produzido o "vento corona", o mesmo desmancharia ou achataria as camadas superficiais menos aderentes da PANI (grãos maiores), tornando mais regular, desta forma, toda a superfície da PANI.

Através desta técnica, foi possível observar a morfologia da PANI desdopada e dopada com descarga corona negativa e $\mathrm{HCl} 1 \mathrm{M}$, comparando os resultados com os obtidos por MEV, os quais indicam que a PANI possui morfologia do tipo granular em todas as condições de dopagem estudadas. Quando foi realizada a dopagem com descarga corona, a superficie da mesma se tornou mais 
regular, sendo que a altura dos grãos menores foi mais próxima da dos grãos maiores, ou seja, a rugosidade da superfície da PANI dopada com descarga corona foi menor do que a dopada com $\mathrm{HCl} 1 \mathrm{M}$. 


\subsubsection{Termogravimetria (TG)}

Esta técnica foi utilizada para caracterizar os seguintes materiais: PC e PET puros, a PANI desdopada (com $\mathrm{NH}_{4} \mathrm{OH} 0,1 \mathrm{M}$ ), dopada com $\mathrm{HCl} 1 \mathrm{M}$ e com ácidos orgânicos (TFA $1 \mathrm{M}$ e TSA 1M). Com este método, analisa-se o comportamento térmico dos materiais, podendo-se avaliar como seria seu desempenho em possiveis aplicações tecnológicas. Inicialmente, analisamos filmes de PET/PANI e PC/PANI desdopados e dopados em ácidos, com o objetivo de verificar se a PANI influenciava na estrutura do substrato (PC ou PET). Nas figuras 3.29 e 3.30 , encontram-se os termogramas dos substratos (PC e PET), respectivamente e dos seus compósitos formados com a PANI.

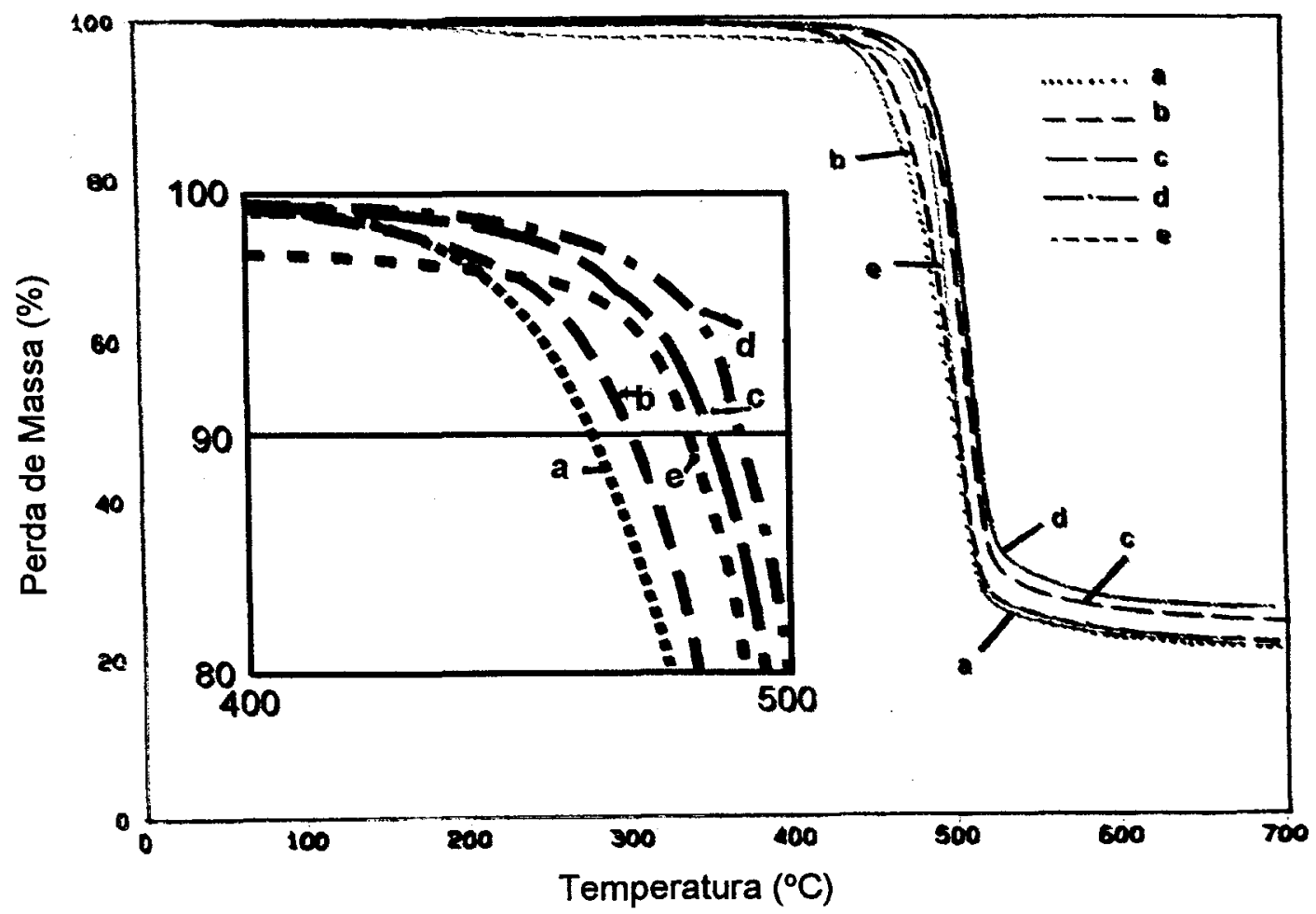

Figura 3.29: Curvas de TG de filmes de (a) PC; (b) PC/PANI (desdopada); PC/PANI dopada com: (c) HCI 1M; (d) TFA 1M e (e) TSA $1 \mathrm{M}$. 


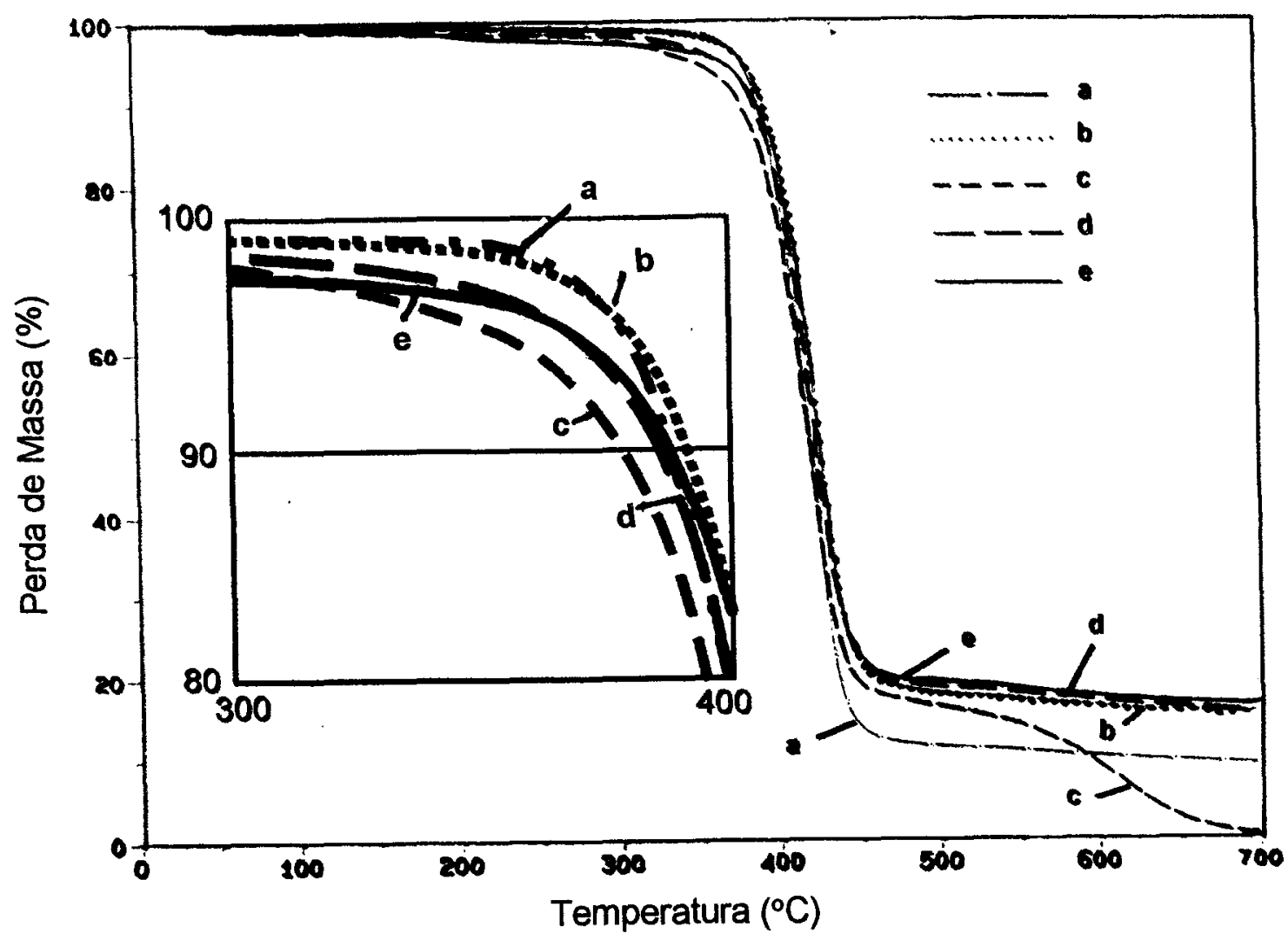

Figura 3.30: Curvas de TG de filmes de (a) PET; (b) PET/PANI (desdopada); PET/PANI dopada com: (c) HCl 1M; (d) TFA 1M e (e) TSA 1M.

Conforme os quadros em destaque das figuras 3.29 e $3.30 \mathrm{em} 10 \%$ de perda de massa, por exemplo, as curvas termogravimétricas do PC, do PET e de seus compósitos formados com a PANI apresentaram as seguintes temperaturas: $457,9^{\circ} \mathrm{C}$ (PC); $467,2^{\circ} \mathrm{C}$ (PC/PANI-desdopada); $479,7^{\circ} \mathrm{C}$ (PC/PANI-TSA); 482,8 ${ }^{\circ} \mathrm{C}$ (PC/PANI-HCl); $489,1^{\circ} \mathrm{C}$ (PC/PANI-TFA); $378,3^{\circ} \mathrm{C}$ (PET/PANI-HCl), $387,5^{\circ} \mathrm{C}$ (PET/PANI-TFA), $\quad 389,0{ }^{\circ} \mathrm{C}$ (PET), $389,7{ }^{\circ} \mathrm{C}$ (PET/PANI-TSA) e $392,9{ }^{\circ} \mathrm{C}$ (PET/PANI-desdopada). Nas figuras 3.29 e 3.30 vê-se que, praticamente, não existem diferenças entre as curvas termogravimétricas, isso pode ser atribuído ao fato de que a espessura do filme de PANI sobre o substrato (PET ou PC) é muito pequena $(\sim 0,2 \mu \mathrm{m})$, em cada face do mesmo, predominando o comportamento térmico do substrato (espessura $\sim 12 \mu \mathrm{m}$ ). 
A contribuição mais significativa nos termogramas apresentados anteriormente está no fato de que tanto no caso dos compósitos de PC como nos de PET, sempre que a PANI era dopada com TSA 1M, o compósito começava a sofrer degradação térmica a partir de $165^{\circ} \mathrm{C}$. Isto pode ser explicado pelo fato do TSA ser bastante higroscópico, absorvendo rapidamente umidade atmosférica. Dessa forma, para podermos observar melhor a estabilidade da PANI dopada nos diferentes dopantes, foram feitas curvas termogravimétricas somente da PANI (em pó), desdopada e dopada com os ácidos: $\mathrm{HCl} 1 \mathrm{M}$, TFA $1 \mathrm{M}$ e TSA $1 \mathrm{M}$.

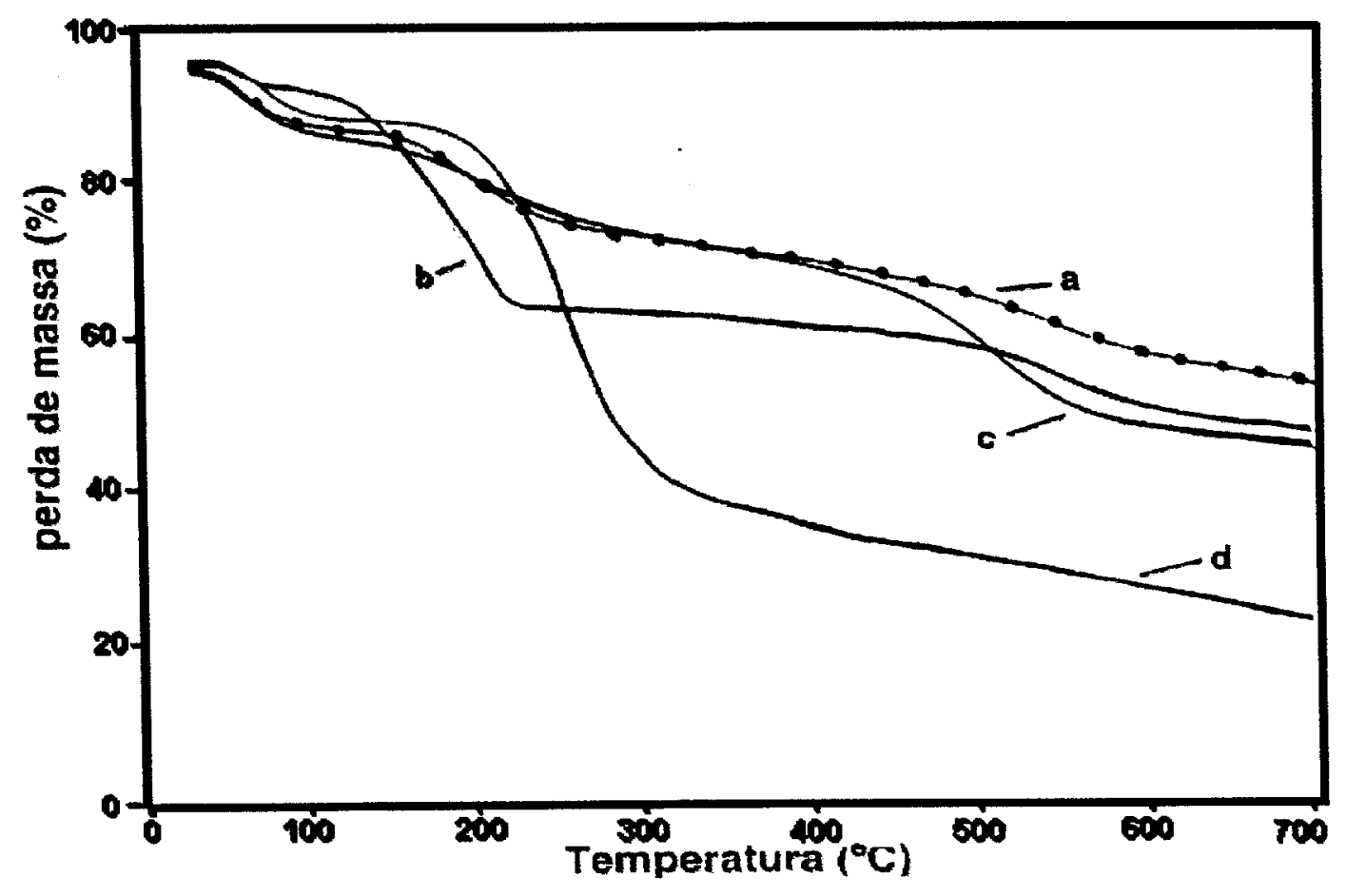

Figura 3.31: Curvas de TG da PANI (a) desdopada; dopada em: (b) TFA 1M; (c) $\mathrm{HCl} 1 \mathrm{M} \mathrm{e}(\mathrm{d}) \mathrm{TSA} 1 \mathrm{M}$. 
Conforme se pode observar na figura 3.31, é possível verificar mais claramente, as diferenças de perda de massa com o aumento da temperatura para os diferentes tipos de PANI dopada. Segundo a literatura $[55,57,69,70]$, as curvas termogravimétricas revelam 3 etapas: perda de água adsorvida nas moléculas da PANI $\left(65\right.$ à $\left.110^{\circ} \mathrm{C}\right)$, remoção do dopante $\left(130\right.$ à $\left.300^{\circ} \mathrm{C}\right)$ e decomposição da PANI acima de $475^{\circ} \mathrm{C}$, no caso da dopada com TSA esse valor cai para $220^{\circ} \mathrm{C}$, ou seja, em todas essas etapas variam conforme o contra-íon do dopante. No presente trabalho, na primeira etapa, entre 65 à $110^{\circ} \mathrm{C}$, houve perda de massa de 2 a $6 \%$ para todas as amostras de PANI desdopada e dopada nos ácidos $\mathrm{HCl} 1 \mathrm{M}$, TFA $1 \mathrm{M}$ e TSA $1 \mathrm{M}$, sendo que a que sofreu menor perda de massa foi a amostra de PANI-TFA ( $2 \%)$ e a que sofreu maior perda foi a de PANITSA (6\%), pelo fato do TSA ser muito higroscópico, retendo maior quantidade de água. A PANI-desdopada sofre segunda perda de massa entre 150 e $200^{\circ} \mathrm{C}$ em torno de $9 \%$, que pode estar associada à perda de oligômeros de baixo peso molecular e não sofre mais nenhuma perda significativa até $\sim 400^{\circ} \mathrm{C}$, segundo Nechtschein et al. [87] a partir desta temperatura, as cadeias de PANI começam a se decompor. Todas as formas protonadas da PANI (amostras dopadas com ácidos, com exceção do TFA) sofreram decomposição à temperaturas mais baixas em comparação à PANI desdopada. Isso nos leva à hipótese de que a segunda perda de massa seja atribuída à saída dos dopantes. A segunda etapa tem inicio nas seguintes temperaturas: $160^{\circ} \mathrm{C}$ (PANI-HCl), $165^{\circ} \mathrm{C}$ (PANI-TSA) e $130^{\circ} \mathrm{C}$ (PANI-TFA). Na terceira etapa a perda de massa é devido à degradação da estrutura da PANI na forma desprotonada, uma vez que os dopantes foram removidos na segunda etapa. No caso da PANI-TSA a temperatura de degradação inicia em $220^{\circ} \mathrm{C}$, para a PANI-HCl inicia em $475^{\circ} \mathrm{C}$ e para a PANI-TFA inicia em $503^{\circ} \mathrm{C} . \quad \quad \grave{A} 700{ }^{\circ} \mathrm{C}$ (temperatura de término das análises 
termogravimétricas) restaram os seguintes resíduos para as amostras de PANI: 57,5\% (PANl-desdopada); 50,5\% (PANI-TFA); 48\% (PANI-HCl) e 25\% (PANITSA). No caso das amostras desdopada e dopadas com $\mathrm{HCl}$ e TFA, podem ter sido formadas estruturas termorrigidas devido ao surgimento de ligações cruzadas intercadeias $[88,89,90]$. $\quad$ fato da amostra dopada com TFA perder pouca quantidade de massa na primeira etapa e muita quantidade de massa na segunda, pode ser devido à formação de ligaçōes de hidrogênio que as moléculas de água adsorvidas na PANI podem ter formado com os átomos de fluor do TFA, e sendo este muito volátil, a $200,5^{\circ} \mathrm{C}$ há a remoção total do dopante. A amostra dopada com TSA é a menos estável termicamente porque no término da análise apresentou apenas $25 \%$ de residuo (à $700^{\circ} \mathrm{C}$ ). A degradação da mesma ocorreu com a remoção gradual do dopante, a partir de $165^{\circ} \mathrm{C}$. Com base nestes resultados de termogravimetria conclui-se que das amostras dopadas com os ácidos citados, a que apresenta comportamento mais interessante (visando aplicações tecnológicas) é a dopada com $\mathrm{HCl} 1 \mathrm{M}$, pois conforme há aumento de temperatura, o dopante vai sendo removido de forma gradual (sem afetar a estrutura da PANI), a amostra dopada com TFA 1M, perde totalmente o dopante a partir de $200,5^{\circ} \mathrm{C}$, pelo fato do TFA ser muito volátil.

Através das análises dos compósitos de PET/PANI e PC/PANI podemos afirmar que estas possuem boa estabilidade térmica, pois apresentam perda de massa menor do que $5 \%$ até em torno de $200^{\circ} \mathrm{C}$. 


\subsection{EFEITO DO TRATAMENTO TÉRMICO NA POLIANILINA DEPOSITADA NOS SUBSTRATOS POLIMÉRICOS}

O entendimento de como se comportam os materiais com variações de temperatura é de fundamental importância para aplicações tecnológicas. Quando um material é exposto a diferentes temperaturas e tempos de aquecimento, pode sofrer alterações em suas propriedades elétricas, mecânicas, óticas, propriedades de superfície (aderência ao substrato e condutividade elétrica, por exemplo), entre outras. Porém, existem poucos trabalhos na literatura que tratam do estudo da estabilidade de materiais compósitos de polianilina e polimeros convencionais. $\mathrm{O}$ objetivo deste capítulo é o estudo da estabilidade de compósitos de PET/PANI e PC/PANI.

\subsubsection{Efeito do tratamento térmico na eficiência da dopagem da PANI em compósitos PET/PANI e PC/PANI}

Submetemos a tratamento térmico (em mufla) amostras de compósitos PET/PANI e PC/PANI, dopadas com ácido clorídrico $(\mathrm{HCl} 1 \mathrm{M})$, ácido trifluoracético (TFA 1M), ácido p-toluenosulfônico (TSA 1M) e na forma desdopada com hidróxido de amônia $\left(\mathrm{NH}_{4} \mathrm{OH} 0,1 \mathrm{M}\right)$. As condições de tratamento térmico (conforme tabelas $\mathrm{VI}$ e VII) foram: velocidade de aquecimento $=10^{\circ} \mathrm{C} / \mathrm{min}$, tempo de patamar $=2$ horas e temperatura $=200^{\circ} \mathrm{C}$. Na tabela VI estão os dados das análises dos compósitos de PET/PANI e na tabela VII estão os dados dos compósitos de PC/PANI. Foram analisados por Teste de Aderência (ASTM D 3359, método de teste B) e Condutividade Elétrica (Método de Quatro Pontas), 3 corpos de prova de cada amostra dos compósitos. As medidas de condutividade elétrica foram feitas antes do tratamento térmico e após o mesmo, para que se pudesse observar a influência do tratamento na condutividade do material, sendo que a aderência foi testada após fazer a medida de 
condutividade elétrica, porque o teste de aderência destrói o compósito. Após o tratamento térmico, as amostras eram redopadas com seus respectivos ácidos (pois os dopantes evaporam com o tratamento térmico em altas temperaturas), após secas, eram feitas as medidas de condutividade elétrica e testes de aderência.

Conforme pode-se observar na tabela VI os filmes de PET/PANI que sofreram tratamento térmico a $200^{\circ} \mathrm{C}$ apresentaram excelente aderência da PANI ao PET, em contrapartida o valor de sua condutividade elétrica diminuiu cerca de duas ordens de grandeza. Os filmes de PET desdopados com $\mathrm{NH}_{4} \mathrm{OH} 0,1 \mathrm{M}$ melhoraram a aderência da PANI ao PET, sendo que antes do tratamento, esses eram menos aderentes. O compósito que apresentou o maior valor de condutividade elétrica foi o PET/PANI dopado com HCl $1 \mathrm{M}(2 \mathrm{~S} / \mathrm{cm})$.

Tabela VI: Compósitos de PET/PANI dopados com: $\mathrm{HCl} 1 \mathrm{M}$; TFA 1M; TSA 1M; desdopados com $\mathrm{NH}_{4} \mathrm{OH} 0,1 \mathrm{M}(\mathrm{EB})$, sem tratamento térmico e com tratamento térmico (TT) à $200^{\circ} \mathrm{C}$ durante $2 \mathrm{~h}$. Valores de aderência e condutividade elétrica.

\begin{tabular}{|l|c|c|}
\hline Compósitos de PET/PANI & $\begin{array}{c}\text { Aderência } \\
\text { (\% de área de PANIdestacada) }\end{array}$ & $\begin{array}{c}\text { Condutividade Elétrica } \\
\text { (S/cm) }\end{array}$ \\
\hline PET/PANI - EB & 15 & $10^{-10}$ \\
\hline PET/PANI - EB - TT & 0 & $10^{-10}$ \\
\hline PET/PANI - HCI 1 M & 65 & 2,0 \\
\hline PET/PANI - HCI 1 M - TT & 0 & 0,01 \\
\hline PET/PANI - TFA 1 M & 65 & 1,5 \\
\hline PET/PANI - TFA 1 M - TT & 0 & 0,01 \\
\hline PET/PANI - TSA 1 M & 65 & 1,0 \\
\hline PET/PANI - TSA 1 M - TT & OBS (1) & $0 B S(1)$ \\
\hline
\end{tabular}


OBS (1): O filme PET/PANI - TSA 1 M se fragmentou após tratamento térmico

Na tabela VII podemos observar que os filmes de PC/PANI, com exceção das amostras de PC/PANI dopadas com TSA 1M, apresentaram excelentes resultados de aderência da PANI ao PC, superando os valores encontrados para PET/PANI. Os valores de condutividade elétrica se mantiveram idênticos aos valores para os filmes de PET/PANI, tratados nas mesmas condições. Tanto os filmes de PET/PANI, como os filmes de PC/PANI tratados termicamente e dopados com TSA 1M se fragmentaram após tratamento térmico.

Tabela VII: Compósitos de PC/PANI dopados com: HCI 1M; TFA 1M; TSA 1M; desdopados com $\mathrm{NH}_{4} \mathrm{OH} 0,1 \mathrm{M}(\mathrm{EB})$, sem tratamento térmico e com tratamento térmico (TT) à $200^{\circ} \mathrm{C}$ durante $2 \mathrm{~h}$. Valores de aderência e condutividade elétrica.

\begin{tabular}{|l|c|c|}
\hline Compósitos de PC/PANI & $\begin{array}{c}\text { Aderência } \\
\text { (\% de área de PANI destacada) }\end{array}$ & $\begin{array}{c}\text { Condutividade Elétrica } \\
\text { (S/cm) }\end{array}$ \\
\hline PC/PANI- EB & 0 & $10^{-10}$ \\
\hline PC/PANI -EB - TT & 0 & $10^{-10}$ \\
\hline PC/PANI - HCI 1 M & 0 & 2,0 \\
\hline PC/PANI - HCI 1 M - TT & 0 & 0,01 \\
\hline PC/PANI - TFA 1 M & 0 & 1,5 \\
\hline PC/PANI - TFA 1 M - TT & 0 & 0,01 \\
\hline PC/PANI - TSA 1 M & 35 & 1,0 \\
\hline PC/PANI - TSA I M - TT & OBS (2) & $0 B S(2)$ \\
\hline
\end{tabular}

OBS (2): O filme de PC/PANI - TSA $1 \mathrm{M}$ se fragmentou após tratamento térmico 
Foram efetuados tratamentos térmicos em outras amostras de PC/PANI e PET/PANI variando as condições de tempo ( $1 / 2 h, 1 h, 2 h$ e $4 h$ ) e temperatura $\left(50{ }^{\circ} \mathrm{C}, 100{ }^{\circ} \mathrm{C}, 130{ }^{\circ} \mathrm{C}, 180{ }^{\circ} \mathrm{C}\right.$ e $\left.200{ }^{\circ} \mathrm{C}\right)$ e foram feitos testes de aderência e medidas de condutividade elétrica nas mesmas. Na tabela VIII encontram-se os valores de aderência para os compósitos dopados com $\mathrm{HCl} 1 \mathrm{M}$, na tabela IX estão os valores para os dopados com TFA $1 \mathrm{M}$ e a tabela $\mathrm{X}$ apresenta os valores para os compósitos dopados com TSA 1M. Este estudo foi feito para observar melhor a estabilidade da condutividade elétrica dos compósitos em função da temperatura em diferentes dopantes, bem como, avaliar a aderência da PANI ao substrato com o aumento da temperatura, variando o dopante. Na tabela VIII, observa-se que os filmes PET/PANI e PC/PANI apresentaram valores de condutividade elétrica na mesma ordem de grandeza.

Todas as amostras de PC/PANI apresentaram excelente aderência da PANI ao PC. No caso dos filmes de PET/PANI, até a temperatura de $100^{\circ} \mathrm{C}$ a PANI apresentou uma aderência ruim ao PET, passando para um valor satisfatório a $130{ }^{\circ} \mathrm{C}$ (foi destacada apenas $20 \%$ de PANI do PET após este tratamento térmico). A partir de $180^{\circ} \mathrm{C}$ a aderência da PANI ao PET tornou-se excelente, não havendo nenhum destaque da PANI do PET, em contrapartida, os valores de condutividade elétrica a partir de $180^{\circ} \mathrm{C}$, diminuíram cerca de 1 ordem de grandeza tanto para os compósitos PET/PANI quanto para os PC/PANI. 
Tabela VIII: Valores de Aderência e Condutividade Elétrica em compósitos PETIPANI e PC/PANI - dopante $\mathrm{HCl} 1 \mathrm{M}$ (antes e após tratamento térmico em diferentes tempos e temperaturas).

\begin{tabular}{|c|c|c|c|c|c|}
\hline \multirow[b]{2}{*}{ Temperatura $\left({ }^{\circ} \mathrm{C}\right)$} & \multirow{2}{*}{ Tempo (horas) } & \multicolumn{2}{|c|}{$\begin{array}{l}\text { Aderência (\% de área de PANI } \\
\text { destacada) }\end{array}$} & \multicolumn{2}{|c|}{$\begin{array}{l}\text { Condutividade Elétrica } \\
(\mathrm{S} / \mathrm{cm}) \mathrm{OBS}\end{array}$} \\
\hline & & PET/PANI & PC/PANI & PET/PANI & PC/PANI \\
\hline Antes do TT & 0 & 65 & 0 & 2,0 & 2,0 \\
\hline 50 & 4 & 65 & 0 & 0,6 & 0,5 \\
\hline 100 & 4 & 65 & 0 & 0,5 & 0,5 \\
\hline 130 & 4 & 20 & 0 & 0,1 & 0,15 \\
\hline 180 & 2 & 0 & 0 & 0,03 & 0,02 \\
\hline 180 & 4 & 0 & 0 & 0,02 & 0,02 \\
\hline 200 & $1 / 2$ & 0 & 0 & 0,02 & 0,015 \\
\hline 200 & 1 & 0 & 0 & 0,015 & 0,015 \\
\hline 200 & 2 & 0 & 0 & 0,010 & 0,010 \\
\hline
\end{tabular}

OBS: Valores de condutividade elétrica após redopagem com $\mathrm{HCl} 1 \mathrm{M}$ por 2 horas.

Os resultados de aderência e condutividade elétrica dos filmes de PET/PANI e PC/PANI dopados com TFA $1 \mathrm{M}$ e tratados termicamente (tabela IX) se mantiveram muito semelhantes (na mesma ordem de grandeza) aos encontrados para os filmes dopados com $\mathrm{HCl} 1 \mathrm{M}$ da tabela VIII. 
Tabela IX: Valores de Aderência e Condutividade Elétrica em compósitos PET/PANI e PC/PANI - dopante TFA $1 \mathrm{M}$ (antes e após tratamento tratamento térmico em diferentes tempos e temperaturas)

\begin{tabular}{|c|c|c|c|c|c|}
\hline \multirow{2}{*}{ Temperatura ( ${ }^{\circ} \mathrm{C}$ ) } & \multirow{2}{*}{ Tempo (horas) } & \multicolumn{2}{|c|}{$\begin{array}{c}\text { Aderência (\% de área de } \\
\text { PANI destacada) }\end{array}$} & \multicolumn{2}{c|}{$\begin{array}{c}\text { Condutividade Elétrica } \\
\text { (S/cm) OBS }\end{array}$} \\
\cline { 3 - 6 } & & PET/PANI & PC/PANI & PET/PANI & PC/PANI \\
\hline \multirow{2}{*}{ Antes do TT } & 0 & 65 & 0 & 1,5 & 1,5 \\
\hline 50 & 4 & 65 & 0 & 0,4 & 0,4 \\
\hline 100 & 4 & 65 & 0 & 0,5 & 0,5 \\
\hline 130 & 4 & 20 & 0 & 0,2 & 0,15 \\
\hline 180 & 2 & 0 & 0 & 0,03 & 0,03 \\
\hline 180 & 4 & 0 & 0 & 0,015 & 0,015 \\
\hline 200 & $1 / 2$ & 0 & 0 & 0,02 & 0,015 \\
\hline 200 & 1 & 0 & 0 & 0,015 & 0,015 \\
\hline 200 & 2 & 0 & 0 & 0,010 & 0,010 \\
\hline
\end{tabular}

OBS: Valores de condutividade elétrica após redopagem com TFA $1 \mathrm{M}$ por 2 horas.

$\mathrm{Na}$ tabela $\mathrm{X}$ observa-se que os valores mais baixos de condutividade elétrica para compósitos não tratados termicamente foram para os dopados com TSA 1M, o que se verificou por UV-visivel (item 3.1.4, deste capitulo). Os espectros de UV-visivel mostraram que O TSA absorveu luz em comprimento de onda um pouco inferior $(830 \mathrm{~nm})$ do que amostras dopadas com TFA e $\mathrm{HCl}(850$ e $870 \mathrm{~nm}$, respectivamente). 
Tabela X: Valores de Aderência e Condutividade elétrica em compósitos PET/PANI e PCIPANI - dopante TSA 1M (antes e após tratamento térmico em diferentes tempos e temperaturas)

\begin{tabular}{|c|c|c|c|c|c|}
\hline \multirow[t]{2}{*}{ Temperatura $\left({ }^{\circ} \mathrm{C}\right)$} & \multirow[t]{2}{*}{ Tempo (horas) } & \multicolumn{2}{|c|}{$\begin{array}{c}\text { Aderência } \\
\text { (\% de área de PANI destacada) }\end{array}$} & \multicolumn{2}{|c|}{$\begin{array}{l}\text { Condutividade } \\
\text { Elétrica } \\
\text { (S/cm) OBS }\end{array}$} \\
\hline & & PET/PANI & PCIPANI & PETIPANI & PCIPANI \\
\hline Antes do TT & 0 & 65 & 35 & 1,0 & 1,0 \\
\hline 50 & 4 & 65 & 35 & 0,8 & 0,7 \\
\hline 100 & 4 & 65 & 35 & 0,6 & 0,6 \\
\hline 130 & 4 & 65 & 35 & 0,5 & 0,5 \\
\hline 180 & 2 & \multirow{5}{*}{\multicolumn{2}{|c|}{$\begin{array}{l}\text { OBS: acima de } 180^{\circ} \mathrm{C} \text { os filmes de } \\
\text { PET/PANI e PC/PANI se fragmentaram } \\
\text { OBS: Valores de condutividade } \\
\text { elétrica após redopagem com TSA 1M } \\
\text { por } 2 \text { horas. }\end{array}$}} & & \\
\hline 180 & 4 & & & & \\
\hline 200 & $1 / 2$ & & & & \\
\hline 200 & 1 & & & & \\
\hline 200 & 2 & & & & \\
\hline
\end{tabular}

Os valores de condutividade elétrica das amostras dopadas com TSA, TFA e $\mathrm{HCl}$, tratadas termicamente, se mantiveram na mesma ordem de grandeza, e em todos os casos diminuíram com o aumento de temperatura. Convém destacar que após o tratamento térmico, as amostras eram redopadas com seus respectivos ácidos, após secas, eram feitas as medidas de condutividade elétrica. Segundo Wang et al. [91,92] quando a polianilina sofre tratamento térmico acima de $180^{\circ} \mathrm{C}$, há formação de ligações cruzadas, com isso sobram poucos sítios livres para a redopagem com o ácido e o valor da condutividade elétrica diminui.

O tratamento térmico a partir de $180^{\circ} \mathrm{C}$ provoca achatamento e aumento de conexão entre os grãos da PANI, alterando sua morfologia e dificultando sua remoção do substrato (aumento da aderência), conforme pode ser visto no item 3.1.6, deste capítulo (fotomicrografias de MEV). No caso das amostras dopadas com TSA $1 \mathrm{M}$, a partir de $180{ }^{\circ} \mathrm{C}$, os filmes de PET/PANI e PC/PANI se 
fragmentaram após tratamento térmico, sendo por esta razão impossível determinar seus valores de aderência e condutividade elétrica. $\quad$ fenômeno da fragmentação dos filmes dopados com TSA $1 \mathrm{M}$ e tratados termicamente acima de $180^{\circ} \mathrm{C}$, está correlacionado com a grande perda de massa que ocorre para o TSA em temperaturas acima de $165^{\circ} \mathrm{C}$, e que levam a liberação de $\mathrm{SO}_{3}{ }^{-}$e subprodutos que atacam o polímero. Segundo Josefowicz et al. [93], os filmes de PANI dopados com ácidos com contra-ion grande como o do TSA, sofrem mudanças muito bruscas em sua superfície, além do fato de este ácido ser muito hidrofílico o que faz com que o mesmo destaque a PANI do substrato polimérico (PET ou PC) com mais facilidade, daí o fato das amostras dopadas com TSA $1 \mathrm{M}$ apresentarem aderência ruim. A figura 3.32 apresenta uma ilustração da fórmula estrutural da PANI dopada com cada um dos três dopantes que foram utilizados ( $\mathrm{HCl}$ 1M, TFA $1 \mathrm{M}$ e TSA 1M). 

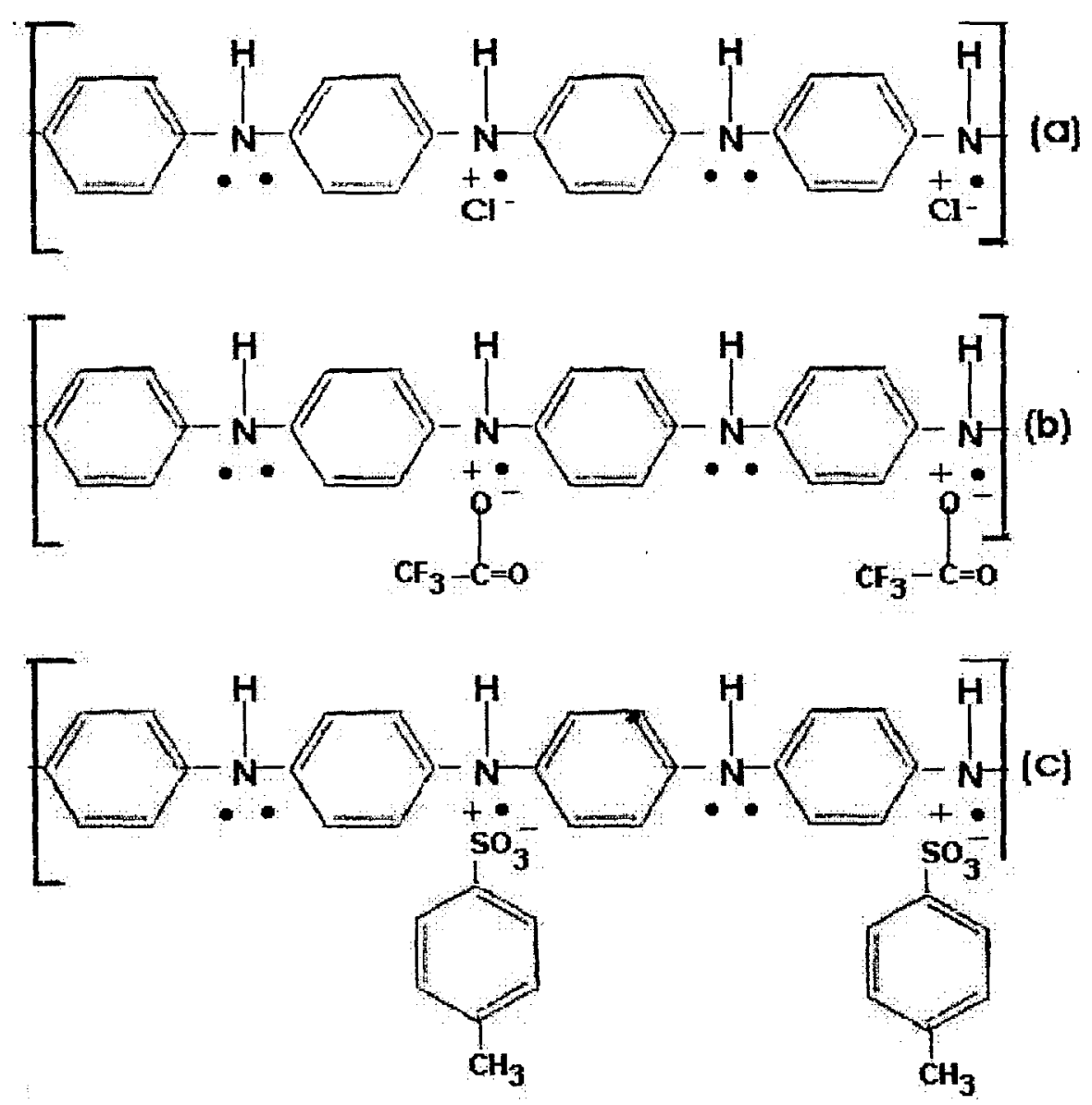

Figura 3.32: Representação da fórmula estrutural da PANI dopada com (a) ácido clorídrico $(\mathrm{HCl} 1 \mathrm{M}),(\mathrm{b})$ ácido trifluoracético (TFA 1M) e (c) ácido p-toluenosulfônico (TSA 1M).

Conforme foi mostrado no item 3.1.6, deste capítulo (fotomicrografias de MEV), a morfologia dos filmes de PANI depositados sobre PC e PET é do tipo granular, sendo que parece existir maior quantidade de grãos de PANI depositados sobre o PC. Diversos são os fatores que influenciam sobre a morfologia da PANI, tais como o substrato, o tipo de síntese, dopantes, entre outros. A morfologia, por sua vez, influencia os valores de condutividade elétrica $[3,94]$.

Dogan et al. [25], obtiveram polianilina do tipo fibrilar para compósitos de PANI e PC, via síntese eletroquímica. Segundo Toppare et al. [95], polímeros tais 
como PC, PET, entre outros, interagem com a polianilina por ligações de hidrogênio (ligações quimicas fortes), sendo que o PC apresentaria maior número de grupos para se ligarem à polianilina e formarem estas ligações. Talvez esta seria uma explicação para a melhor aderência da PANI ao PC, bem como o fato da condutividade elétrica nos compósitos de PC/PANI ser um pouco menor do que no caso dos compósitos de PET/PANI, embora estejam na mesma ordem de grandeza. Segundo Byun e Im $[56,96]$ a presença das ligações de hidrogênio nos compósitos diminui um pouco o valor da condutividade elétrica.

Com este estudo, observou-se que parece haver uma relação inversamente proporcional entre a aderência e a condutividade elétrica na PANI, pois as amostras de PC/PANI apresentaram excelente aderência e condutividade elétrica um pouco menor.

Foi observado que a eficiência da dopagem da PANI se mostrou mais estável com o tratamento térmico dos compósitos. 


\subsubsection{Efeitos da Redopagem da Polianilina depositada sobre o PET -dopada com $\mathrm{HCl}$ (em diferentes concentraçōes)}

O objetivo deste estudo foi verificar como se comportam a condutividade elétrica e a aderência da PANI sobre o PET, se o compósito é desdopado e redopado sucessivas vezes, uma vez que com este substrato obtivemos os mais baixos valores de aderência conforme item 3.2.1. Foi medida a condutividade elétrica do compósito PET/PANI obtido na forma condutora em $\mathrm{HCl} 1 \mathrm{M}$ e foi feito o teste de aderência. A seguir, uma parte da amostra (ciclo 0 , tabela XI) foi desdopada com $\mathrm{NH}_{4} \mathrm{OH} \quad 0,1 \mathrm{M}$ (imersão na solução por 2 horas), seca sob vácuo dinâmico por 6 horas e redopada em $\mathrm{HCl} 1 \mathrm{M}$, seca sob vácuo dinâmico por 6 horas, medida a condutividade e teste de aderência (ciclo 1, tabela XI), após foi novamente desdopada e assim sucessivamente até completarem 5 ciclos de desdopagens-redopagens. O processo de desdopagem e redopagem foi descrito em detalhes nos itens 2.1 .4 e 2.1 .5 do capitulo anterior. Em cada teste foram usados 3 corpos de prova da amostra, portanto os valores tabelados a seguir são valores médios. Os dados se encontram na tabela XI.

Tabela XI: Redopagem da PANI com HCl 1M (05 ciclos) alternados com desdopagem usando $\mathrm{NH}_{4} \mathrm{OH} \quad 0,1 \mathrm{M}$.

\begin{tabular}{|c|c|c|c|c|c|c|}
\hline CICLOS & 0 & 1 & 2 & 3 & 4 & 5 \\
\hline $\begin{array}{l}\text { Aderéncia } \\
\text { (\% de área de PANI destacada) }\end{array}$ & 65 & 80 & 90 & 95 & 97 & 98 \\
\hline Condutividade Elétrica) (S/cm) & 2 & 2 & 2 & 1,5 & 1,5 & 1,5 \\
\hline
\end{tabular}

Os dados da tabela XI mostram que a condutividade elétrica se manteve praticamente constante ao longo dos ciclos, mas a aderência diminuiu. 
Foram feitos mais 5 ciclos de desdopagens e redopagens em uma amostra de PET/PANI obtida na forma condutora e dopada com $\mathrm{HCl} 1 \mathrm{M}$, que apresentava inicialmente, $65 \%$ de área de PANI destacada e $2 \mathrm{~S} / \mathrm{cm}$ de condutividade elétrica, conforme ciclo 0 da tabela XII. A amostra foi desdopada com $\mathrm{NH}_{4} \mathrm{OH} 0,1 \mathrm{M}$ e redopada desta vez com $\mathrm{HCl} 0,01 \mathrm{M}$, durante 5 vezes. Os valores obtidos estão na tabela XII.

Tabela XII: Redopagem com HCl 0,01M (05 ciclos) altemados com desdopagem usando $\mathrm{NH}_{4} \mathrm{OH} \mathrm{0,1} \mathrm{M}$.

\begin{tabular}{|c|c|c|c|c|c|c|}
\hline CICLOS & 0 & 1 & 2 & 3 & 4 & 5 \\
\hline $\begin{array}{l}\text { Aderência } \\
\text { (\% de área de PANI destacada) }\end{array}$ & 65 & 65 & 65 & 65 & 65 & 65 \\
\hline Condutividade Elétrica (S/cm) & 1,5 & 0,5 & 0,3 & 0,5 & 0,5 & 0,5 \\
\hline
\end{tabular}

Quando as redopagens foram feitas com ácido em concentração menor, os valores de aderência se mantiveram constantes. A condutividade elétrica caiu 1 ordem de grandeza e se manteve constante ao longo dos ciclos, ou seja, neste valor de $\mathrm{pH}$ de $\mathrm{HCl}$ não ocorreu nenhuma mudança significativa quanto à aderência da PANI ao PET. Em vista disso, uma outra amostra de PET/PANI dopada com $\mathrm{HCl} 1 \mathrm{M}$, foi desdopada e redopada, desta vez, com $\mathrm{HCl} 0,001 \mathrm{M}$, apresentando como resultado de teste de aderência uma área destacada de $\mathbf{4 0} \%$ e condutividade elétrica na ordem de $10^{-2} \mathrm{~S} / \mathrm{cm}$, ou seja nesta menor concentração de $\mathrm{HCl}$ a aderência foi um pouco melhor. Uma outra parte da amostra dopada com $\mathrm{HCl} 1 \mathrm{M}$ foi desdopada e redopada com $\mathrm{HCl} \mathrm{0,0001M}$, resultando apenas $20 \%$ de área destacada de PANI e condutividade elétrica na ordem de $10^{-7} \mathrm{~S} / \mathrm{cm}$. Com estes testes, vimos que a medida que a concentração do $\mathrm{HCl}$ diminui na redopagem, em 
relação à amostra original (dopada em $\mathrm{HCl} 1 \mathrm{M}$ ), a aderência da PANI ao PET aumenta, e a condutividade, como era esperada, diminui. Singh et al. [97] fizeram estudos com dopagem, desdopagem e redopagem de polianilina com $\mathrm{HCl}$, em concentrações baixas, observaram estranhas mudanças na morfologia da PANI, o que deu origem a novas aplicações para a mesma, como por exemplo, membrana separadora de gases. Segundo os autores, os resultados de aderência se tornam interessantes apenas quando a redopagem é feita com concentrações de ácido muito inferiores à original. No presente estudo, notou-se que o número de ciclos de redopagem não alterou significativamente a aderência, as mudanças só ocorrem quando se desdopada uma amostra originalmente dopada em alta concentração de $\mathrm{HCl}$, desdopa e redopa com solução de $\mathrm{HCl}$ com concentrações baixas. Fizemos um estudo da morfologia de amostras redopadas em diferentes concentrações de $\mathrm{HCl}$ usando Microscopia Eletrônica de Varredura (MEV). As imagens obtidas são apresentadas a seguir.

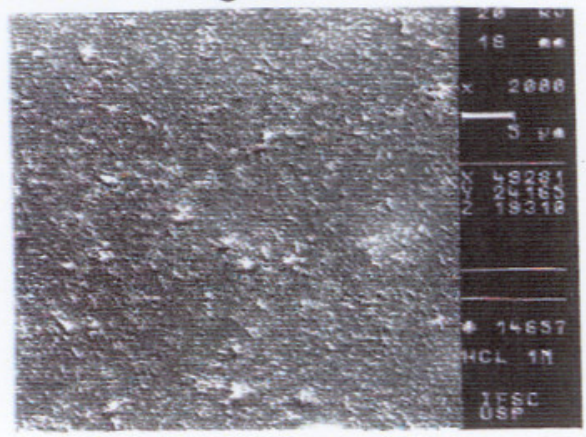

(a)

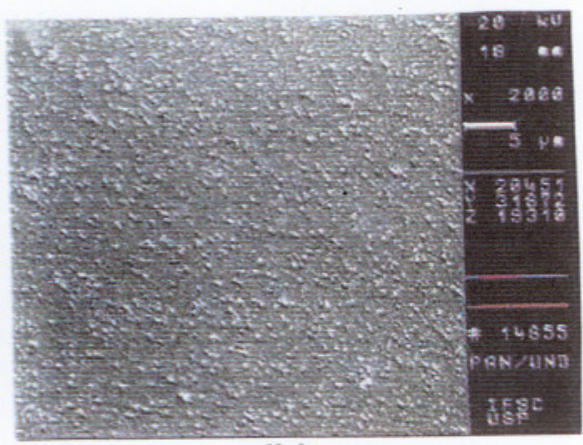

(b)

Figura 3.33: Fotomicrografias de PET/PANI, onde observa-se a superfície da PANI (aumento de 2.000 x): (a) originalmente obtida na forma dopada em $\mathrm{HCl} 1 \mathrm{M}$; (b) desdopada em $\mathrm{NH}_{4} \mathrm{OH} 0,1 \mathrm{M}$.

Na figura 3.33 (a) observa-se que os grãos de PANI estão maiores em relação aos grãos da figura 3.33 (b). Quando é feita a desdopagem, o tamanho dos grãos diminui. No processo de redopagem, os grãos voltam a incharem, porém como a PANI está depositada sobre um substrato, há alguma perda de massa de PANI, durante este processo, bem como os grãos parecem aumentar de tamanho, como pode ser visto nas figuras 3.34 (a) e 3.34 (b). Quando a 
redopagem é feita em concentrações muito baixas de $\mathrm{HCl}$, os grãos se alongam, apresentando um aspecto quase fibrilar e parecem estar mais conectados e aderidos ao substrato, segundo figuras 3.34 (c) e 3.34 (d).

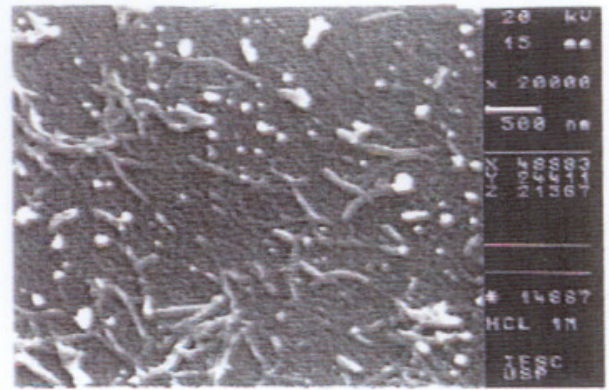

(a)

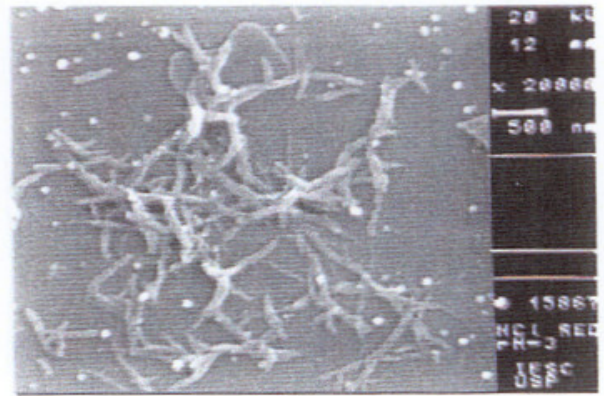

(c)

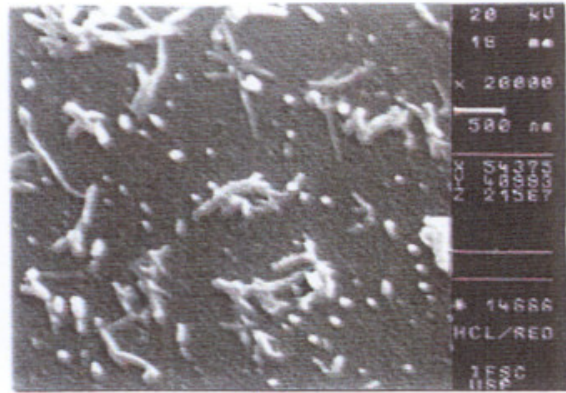

(b)

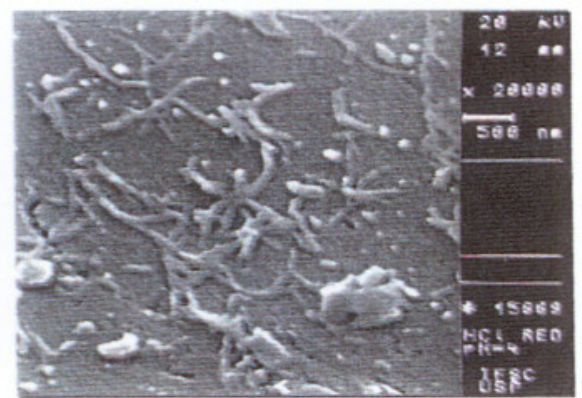

(d)

Figura 3.34: Fotomicrografias de MEV de compósitos de PET/PANI dopados em $\mathrm{HCl}$ (aumento de $20.000 \mathrm{x}$ ), nas concentrações: (a) $\mathrm{HCl} 1 \mathrm{M}$ (PET/PANI originalmente obtidos da síntese); PET/PANI desdopados e redopados em: (b) $\mathrm{HCl}$ $1 \mathrm{M}$; (c) $\mathrm{HCl} 0,001 \mathrm{M}$ e (d) $\mathrm{HCl} 0,0001 \mathrm{M}$.

A morfologia destes materiais também foi estudada por Microscopia Ótica, conforme figura 3.35 . 


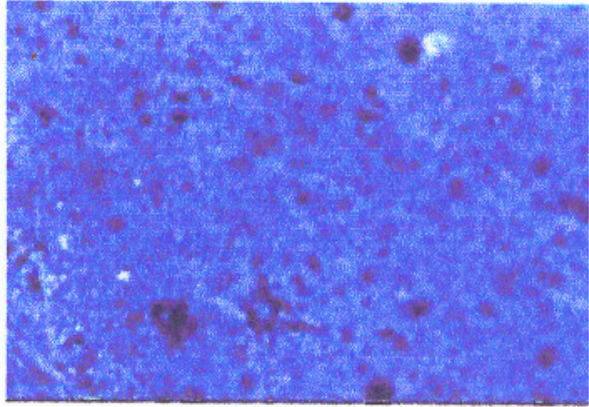

(a)

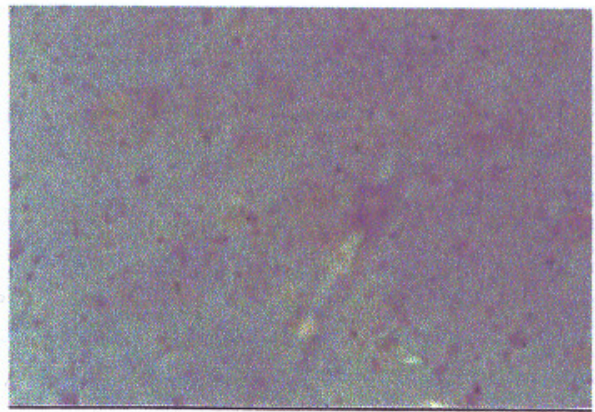

(b)

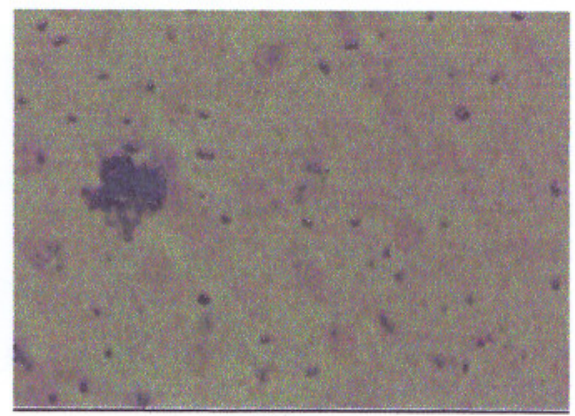

(b)

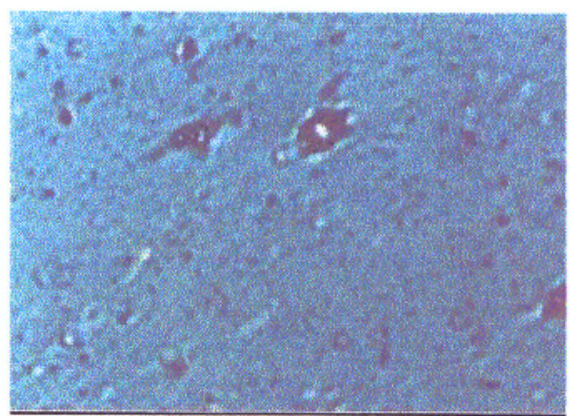

(d)

Figura 3.35: Fotomicrografias de $\mathrm{MO}$ de filmes de PET/PANI (aumento de $400 \mathrm{x}$ ): (a) desdopada; (b)obtida na forma dopada em $\mathrm{HCl} \mathrm{1M;}$ (c) redopada em $\mathrm{HCl}$ $0,001 \mathrm{M}$ e (d) redopada em $\mathrm{HCl} 0,0001 \mathrm{M}$.

Com esta técnica observa-se nitidamente a mudança de cor que sofre a polianilina quando passa da forma condutora (verde) para a isolante (azul). A medida que a polianilina vai sendo redopada com $\mathrm{HCl}$ em concentrações mais baixas, a sua cor verde na forma dopada vai tendendo ao azul, conforme se pode ver na figura 3.35 (d). Estas amostras foram analisadas por Espectroscopia UVvis, conforme figura 3.36. 


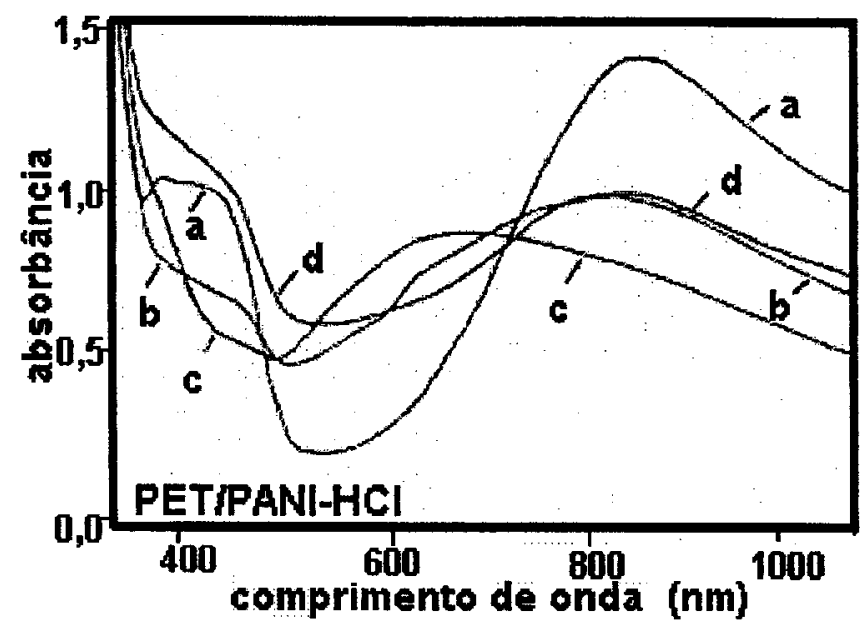

Figura 3.36: Espectros de absorção de UV-vis de compósitos PET/PANI, com os valores dos seus picos máximos de absorção:(a) dopado em $\mathrm{HCl} 1 \mathrm{M}(870 \mathrm{~nm})$; redopados em: (b) $\mathrm{HCl} \mathrm{0,001M} \mathrm{(830} \mathrm{nm);} \mathrm{(c)} \mathrm{HCl} \mathrm{0,0001M}(680 \mathrm{~nm})$; (d) tratado termicamente $\left(200^{\circ} \mathrm{C}, 2 \mathrm{~h}\right)$ e redopado em $\mathrm{HCl} 1 \mathrm{M}(835 \mathrm{~nm})$.

Através de análise de UV-vis pode-se observar que após desdopagem ou tratamento térmico há diminuição da massa de PANI no compósito, conforme a diminuição dos valores de absorbância que aparecem nos espectros da figura acima. Redopagens de compósitos PET/PANI com HCl em concentrações mais baixas, deslocam o espectro para menores comprimentos de onda, tendendo à forma isolante. As amostras tratada termicamente e redopada em $\mathrm{HCl} 1 \mathrm{M}$ e a redopada em $\mathrm{HCl} 0,001 \mathrm{M}$, absorveram praticamente no mesmo comprimento de onda, bem como apresentaram o mesmo valor de condutividade elétrica $\left(10^{-2}\right.$ S/cm). Com este estudo, observou-se que a aderência da PANI ao PET é melhorada à medida que o compósito sofre desdopagem e redopagem em concentrações mais baixas de $\mathrm{HCl}$, porém havendo diminuição do valor da condutividade elétrica. 


\subsubsection{Solubilidade da Polianilina em Solventes Orgânicos à Temperatura Ambiente \\ Compósitos PET/PANI dopados em $\mathrm{HCl} 1 \mathrm{M}$, dopados com descarga} corona positiva e negativa, e compósitos desdopados em $\mathrm{NH}_{4} \mathrm{OH} 0,1 \mathrm{M}$ foram imersos, sob agitação lenta, nos seguintes solventes orgânicos: clorofórmio $\left(\mathrm{CHCl}_{3}\right)$, n,n-dimetilformamida (DMF), n-metilpirrolidona (NMP) e m-cresol, com o objetivo de observar a estabilidade da dopagem da PANI (dopada em diferentes meios), bem como testar a sua aderência ao substrato e solubilidade. O estudo da solubilidade da PANI é importante na indústria micro-eletrônica, pois é necessário dissolver a PANI em solventes orgânicos para fazer a revelação de padrões de microcircuitos impressos. Estes microcircuitos podem ser construídos por trilhas de PANI depositadas sobre substratos flexiveis e transparentes, tais como o PET, por exemplo.

A solubilidade da PANI no solvente foi avaliada por espectroscopia de UV-vis. A imersão ocorreu em tempos cronometrados. Foram usados 3 corpos de prova para cada tipo de ensaio. Cada amostra do compósito foi imersa em um solvente por 1 minuto, após foi seca em dessecador sob vácuo dinâmico $(\sim 2 \mathrm{~h})$, a seguir, foi feita análise por UV-vis (para observar se ocorreu alguma alteração na polianilina), retomou à imersão no mesmo solvente por um período de 15 minutos, após foi seca, feita nova análise por UV-vis, e assim sucessivamente, até completar um tempo total de até $1 \mathrm{~h}$, dependendo da amostra, conforme será visto adiante. Em alguns casos, quando após um minuto de imersão no solvente, a PANI solubilizava um pouco, deixava-se em imersão por intervalos de tempo de $1 \mathrm{em}$ um minuto, até que não havia mais desprendimento de PANI do substrato, daí retornava-se a imergir por um intervalo de tempo maior, até que se tivesse uma nova alteração. 
A seguir são apresentados os espectros de UV-vis das amostras que foram imersas nos diversos solventes orgânicos.

\section{A - Imersão em NMP}

$\mathrm{Na}$ figura 3.37 encontram-se os espectros de UV-vis dos compósitos de PET/PANI desdopada e dopada em $\mathrm{HCl} 1 \mathrm{M}$.

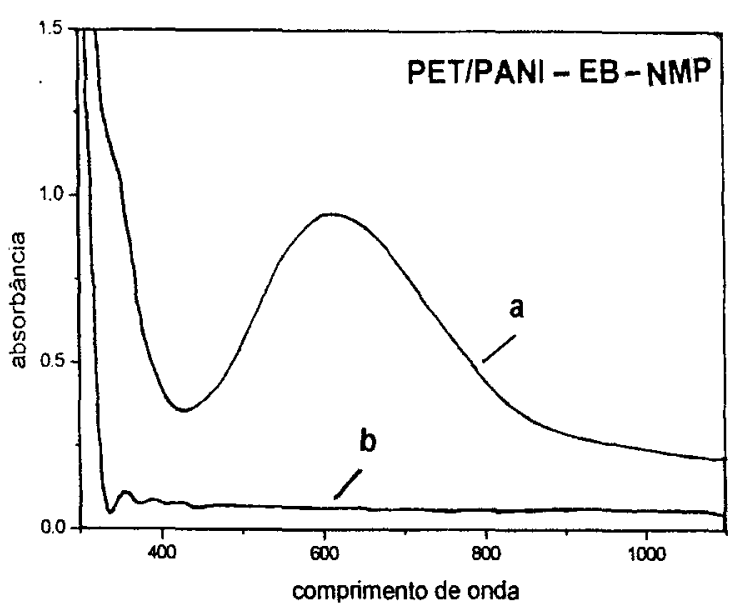

(A)

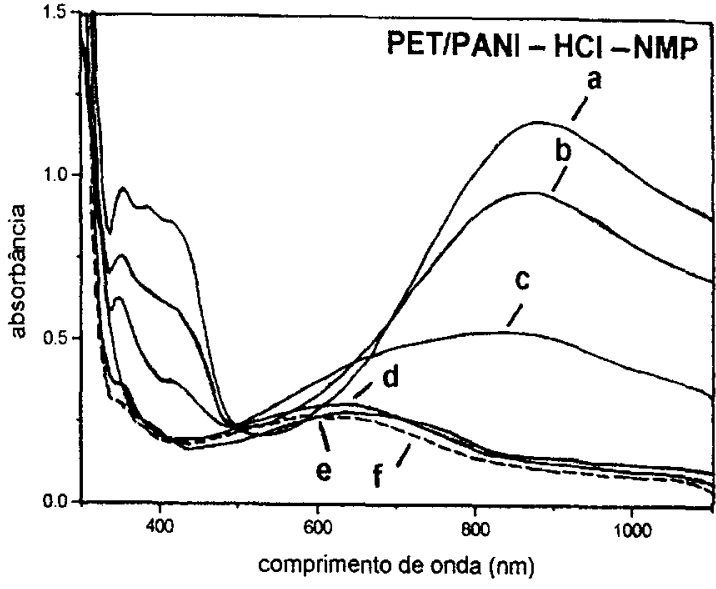

(B)

Figura 3.37: Espectros de UV-vis de PET/PANI em diversos tempos de imersão (t) em NMP: (A) PET/PANI-EB (desdopada), onde: a) antes da imersão; b) $t=1 \mathrm{~min}$; (B) PET/PANI-HCl (dopada em HCl 1M), onde: a) antes da imersão; b) $t=1 \mathrm{~min}$; C ) $\mathrm{t}=2 \mathrm{~min}$, d) $\mathrm{t}=3 \mathrm{~min}, \mathrm{e}) \mathrm{t}=4 \mathrm{~min}, \mathrm{f}) \mathrm{t}=19 \mathrm{~min}$.

Através desta técnica observa-se os deslocamentos de absorção de luz ultravioleta (em comprimento de onda), nos espectros das amostras dopadas, por exemplo, e nota-se que ao longo do tempo, dependendo do solvente, a PANI vai sendo desdopada, além de ir perdendo massa, que pode ser observada pela diminuição da absorbância máxima. Visualmente pode-se notar que as amostras dopadas, dependendo do solvente, iam se tomando azuladas e a cobertura de PANI se desprendendo ao longo do tempo, ou seja, a mesma estava sendo desdopada com o solvente, que era de natureza básica.

Na figura 3.37 observa-se que a PANI desdopada é totalmente solúvel em NMP em apenas 1 minuto de imersão. A PANI dopada com $\mathrm{HCl} 1 \mathrm{M}$ foi sendo desdopada ao longo do tempo, bem como sendo removida do substrato, como se 
pode notar no espectro da figura $3.37(B)$, após a sexta imersão no solvente a absorbância máxima da PANI havia se deslocado para $620 \mathrm{~nm}$ (região correspondente à base de esmeraldina). Na figura 3.38 são apresentados os espectros de UV-vis dos compósitos PET/PANI dopada com descarga corona negativa e positiva.

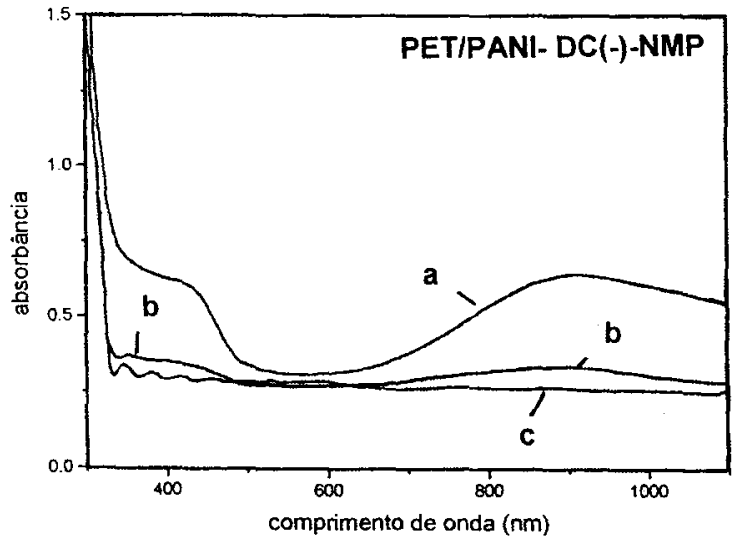

(A)

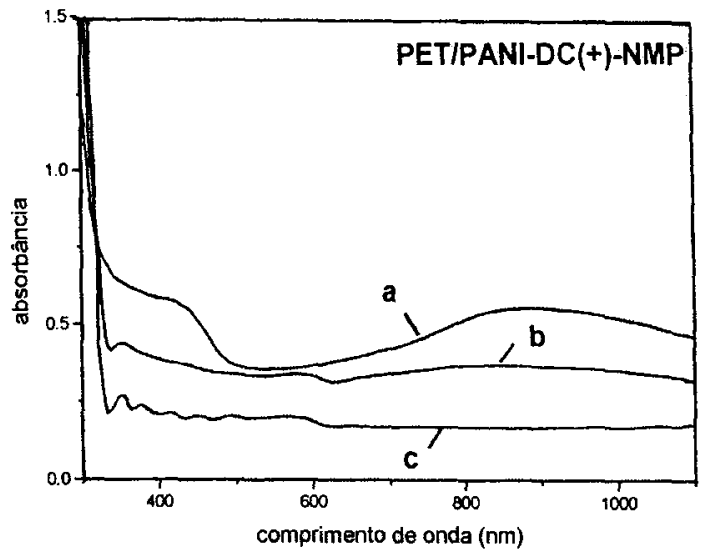

(B)

Figura 3.38: Espectros de UV-vis de PET/PANI em diversos tempos de imersão (t) em NMP: (A) PET/PANI-DC(-) (dopada com descarga corona negativa) e (B) PET/PANI-DC $(+)$ (dopada com descarga corona positiva), onde: a) antes da imersão; b) $\mathrm{t}=1 \mathrm{~min} ; \mathrm{c}) \mathrm{t}=1 \mathrm{~h}$.

As amostras dopadas com descarga corona negativa e positiva apresentaram comportamento similar após imersão em NMP. Em comparação com à PANI dopada com $\mathrm{HCl} 1 \mathrm{M}$, as dopadas com descarga corona, ficaram azuladas no primeiro minuto de imersão no solvente, porém foram removidas apenas cerca de metade das camadas de PANI do substrato, sendo totalmente removidas após a segunda imersão em NMP. No caso da PANI desdopada, a remoção das camadas foi após a primeira imersão.

\section{B - Imersão em DMF}

Na figura 3.39 estão os espectros dos compósitos PET/PANI desdopada e dopada em $\mathrm{HCl} 1 \mathrm{M}$. 


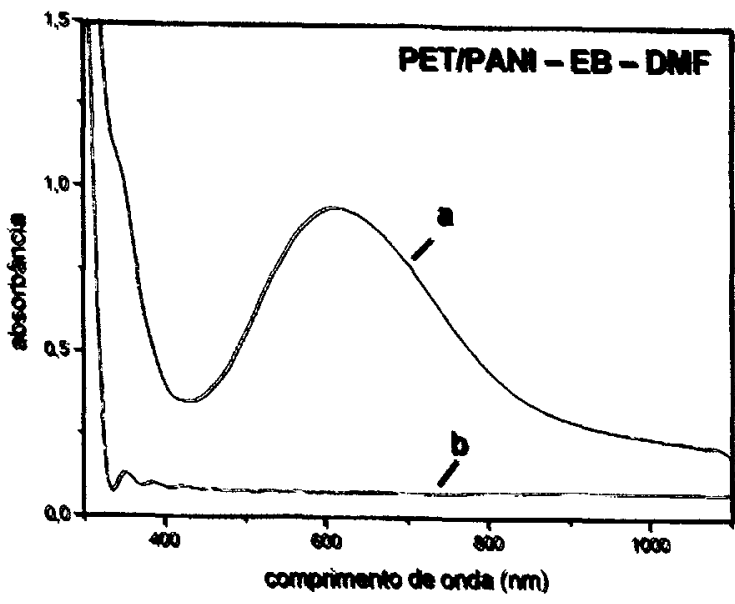

(A)

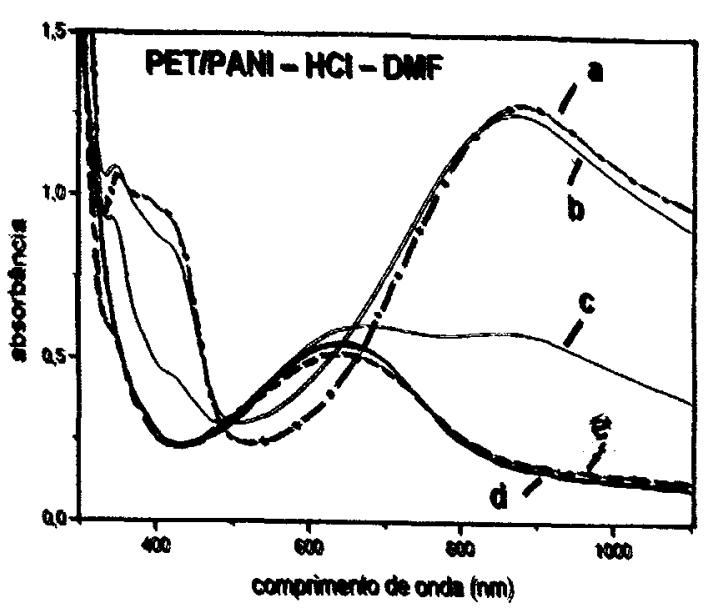

(B)

Figura 3.39: Espectros de UV-vis de PET/PANI em diversos tempos de imersão (t) em DMF: (A) PET/PANI-EB (desdopada), onde: a) antes da imersão; b) $t=1 \mathrm{~min}$, (B) PET/PANI-HCl (dopada em $\mathrm{HCl} 1 \mathrm{M}$ ), onde: a) antes da imersão; b) $\mathrm{t}=1 \mathrm{~min}$, C) $\mathrm{t}=2 \mathrm{~min}$, d) $\mathrm{t}=3 \mathrm{~min}, \mathrm{e}) \mathrm{t}=18 \mathrm{~min}$.

A PANI desdopada é completamente destacada do substrato e se dissolve em DMF após 1 minuto de imersão. A PANI dopada em $\mathrm{HCl} 1 \mathrm{M}$ começa a se desdopar após o terceiro minuto de imersão em DMF e se desdopa totalmente, atingindo 630 nm de absorbância máxima, após 3 minutos de imersão.

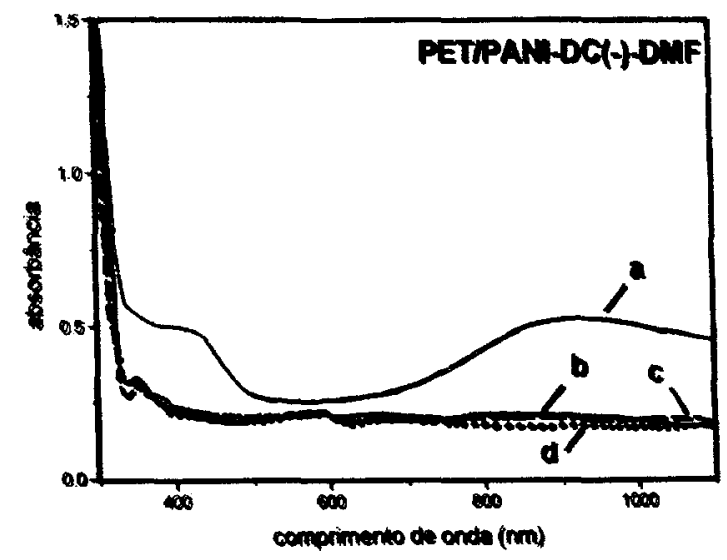

(A)

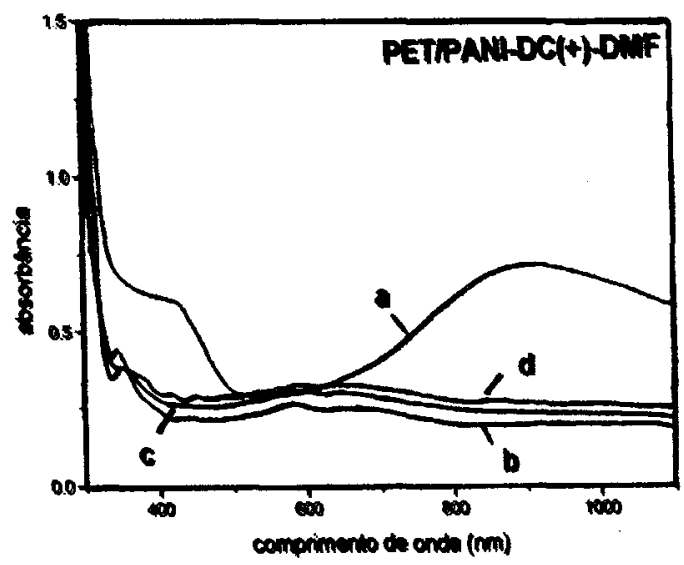

(B)

Figura 3.40: Espectros de UV-vis de PET/PANI em diversos tempos de imersão (t) em DMF: (A) PET/PANI-DC(-) (dopada com descarga corona negativa) e (B) PET/PANI-DC $(+)$ (dopada com descarga corona positiva), onde: a) antes da imersão; b) $\mathrm{t}=1 \mathrm{~min}$; c) $\mathrm{t}=2 \mathrm{~min}$; d) $\mathrm{t}=12 \min$. 
As amostras de PANI dopadas com descarga corona positiva e negativa apresentaram o mesmo comportamento após imersão em DMF. Sendo desdopadas e destacadas do substrato após 1 minuto de imersão (na primeira imersão).

C - Imersão em m-cresol

Na figura 3.41 estão os espectros dos compósitos PET/PANI dopada em $\mathrm{HCl} 1 \mathrm{M}$, descarga corona negativa e descarga corona positiva.

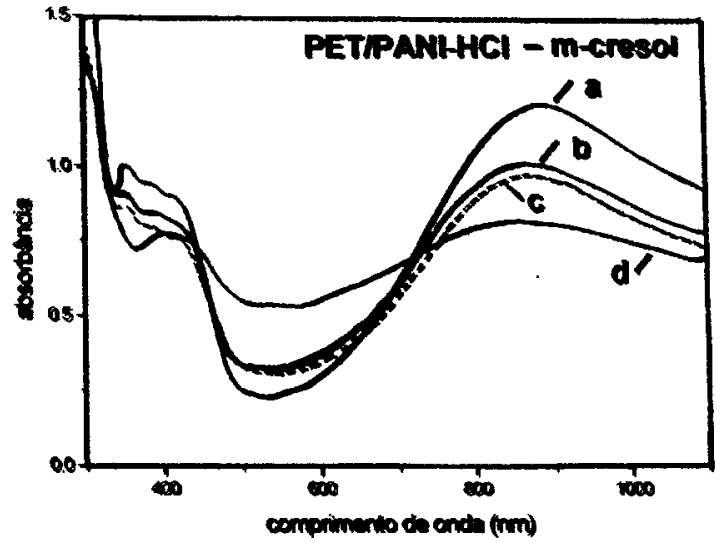

(A)

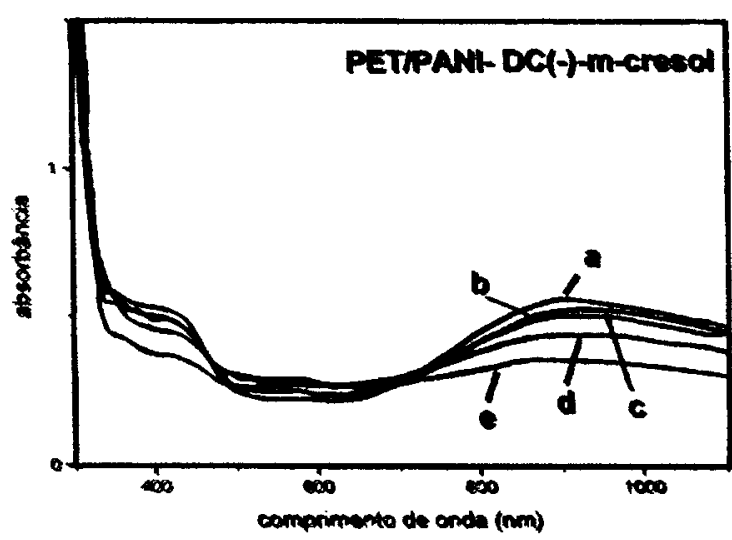

(B)

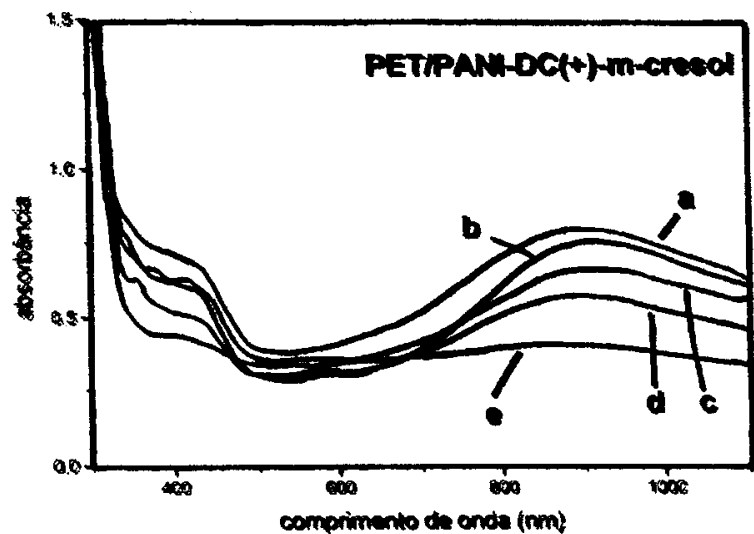

(C)

Figura 3.41: Espectros de UV-vis de PET/PANI em diversos tempos de imersão (t) em m-cresol: (A) PET/PANI-HCl 1M, onde: a) antes da imersão; b) $t=1 \mathrm{~min}$; c) $\mathrm{t}=2 \mathrm{~min}$, d) $\mathrm{t}=17 \mathrm{~min}$; (B) PET/PANI-DC(-) (descarga corona negativa) e (C) PET/PANI-DC $(t)$ (descarga corona positiva), onde: a) antes da imersão; $b$ ) $t=1$ $\min$; c) $\mathrm{t}=2 \mathrm{~min}$; $) \mathrm{t}=17 \mathrm{~min}$; $\mathrm{e}) \mathrm{t}=47 \mathrm{~min}$.

Não foi possivel obter espectros de UV-vis de PANI desdopada porque a PANI se dissolveu no m-cresol e em seguida, o PET também se dissolveu 
parcialmente no solvente. As amostras de PET/PANI dopadas foram imersas no m-cresol por um tempo total de 47 minutos, por três ciclos de imersão. Não foi possivel imergí-las pela quarta vez porque os compósitos se tornaram parcialmente solúveis no solvente, devido ao fato do PET ser parcialmente solúvel no m-cresol. A cobertura de PANI (ES) se manteve inalterada quimicamente, mas foi sendo parcialmente destacada do substrato ao longo dos ciclos de imersão.

D - Imersão em $\mathrm{CHCl}_{3}$

Na figura 3.42 encontram-se espectros de UV-vis de PET/PANI desdopada e dopada em $\mathrm{HCl} 1 \mathrm{M}$.
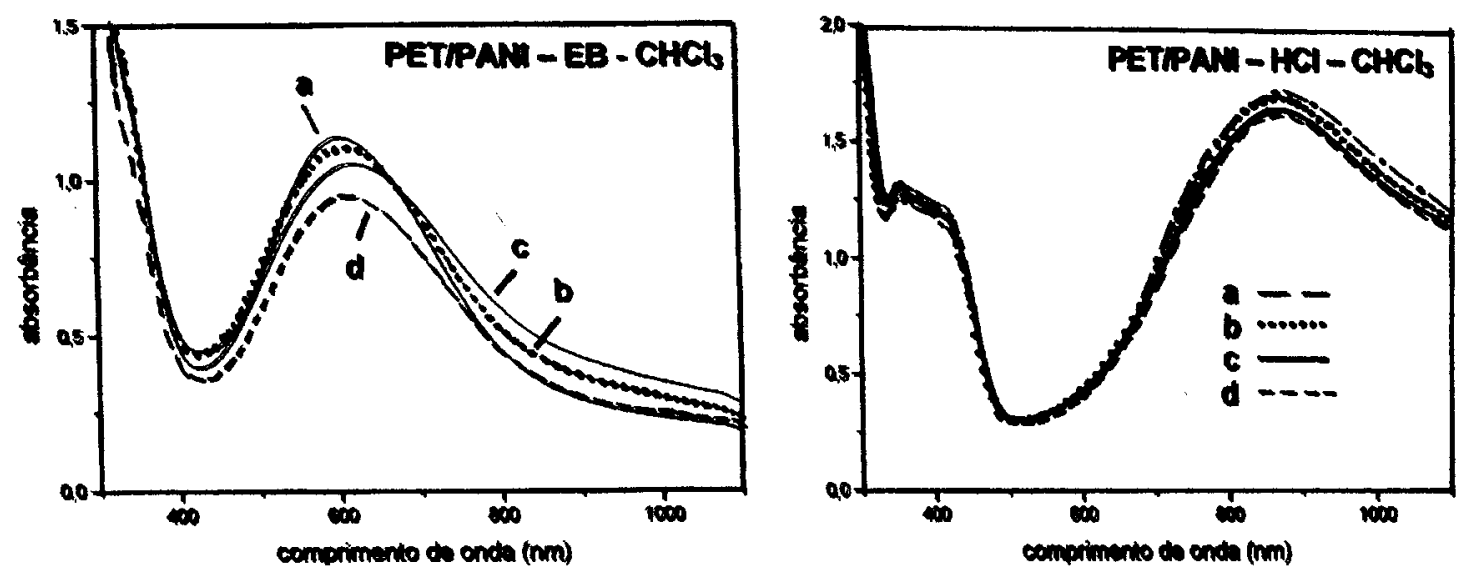

Figura 3.42: Espectros de UV-vis de PET/PANI em diversos tempos de imersão ( $t$ ) em $\mathrm{CHCl}_{3}$, (A) PET/PANI-EB (desdopada) e (B) PET/PANI-HCl (dopada em $\mathrm{HCl}$ $1 \mathrm{M})$, onde: a) antes da imersão, b) $t=1 \mathrm{~min}$, c) $t=16 \mathrm{~min}$, d) $t=61 \mathrm{~min}$.

Na figura 3.43 observa-se espectros de UV-vis de PETIPANI dopada com descarga corona positiva e negativa. 


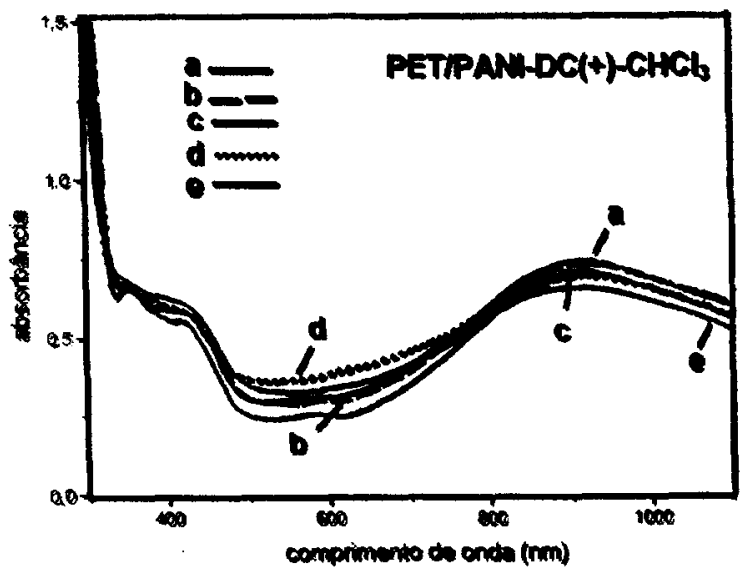

(A)

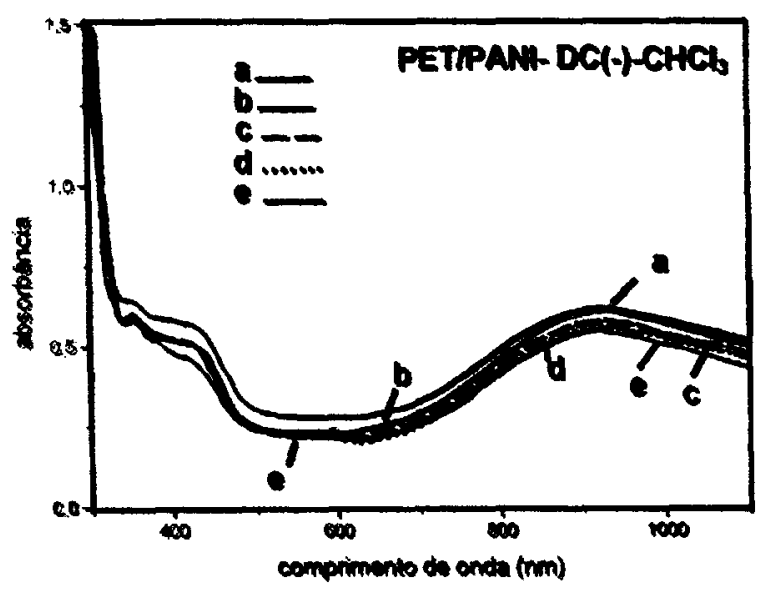

(B)

Figura 3.43: Espectros de UV-vis de PET/PANI em diversos tempos de imersão ( $t$ ) em $\mathrm{CHCl}_{3}$, (A) PET/PANI-DC(+) (dopada com descarga corona positiva) e (B) PETIPANI-DC( - ) (dopada com descarga corona negativa), onde: a) antes da imersão; b) $\mathrm{t}=1 \mathrm{~min}$; c) $\mathrm{t}=2 \mathrm{~min}$, d) $\mathrm{t}=22 \mathrm{~min}, \mathrm{e}) \mathrm{t}=82 \mathrm{~min}$.

Todas as amostras de PET/PANI desdopadas ou dopadas não se dissolveram em $\mathrm{CHCl}_{3}$. As amostras sofreram um tempo de imersão total mínimo de 1 hora. Segundo autores que testaram a solubilidade da PANI (sintetizada por sintese quimica), a PANI desdopada (EB) apresentava solubilidade parcial nos seguintes solventes orgânicos: tetrahidrofurano (THF) [98], ácido fórmico 80\% [68] e ácido sulfúrico 97\% [57]. A PANI na forma de base de esmeraldina mostrou-se ser totalmente solúvel, segundo alguns autores, em: NMP [14], e m-cresol [96]. A PANI na forma de sal de esmeraldina (ES), segundo autores, dificilmente é solúvel em algum solvente, sendo solủvel em ácido sulfúrico 97\% [57], daí o fato da dificuldade do processamento da PANI. No caso das amostras analisadas neste trabalho, devido a PANI estar depositada sobre um substrato, a superfície de contato da mesma é maior do que se estivesse na forma de pastiha prensada, facilitando a solubilidade da PANI, bem como a desdopagem. No caso das amostras que foram imersas em $\mathrm{m}$-cresol, pelo fato do PET ser parcialmente solúvel no mesmo, parte de algumas amostras foram dissolvidas no solvente. 
A importância deste estudo foi observar que existem diferenças de solubilidade entre as amostras dos compósitos dopados com $\mathrm{HCl} 1 \mathrm{M}$ ou descarga corona e as desdopadas. Isto se deve ao fato da PANI ser solúvel em alguns solventes estudados (DMF e NMP) somente no estado desdopado. A solubilidade das amostras dopadas só ocorreu após a desdopagem da PANI provocada pelo próprio solvente. Essa diferença de solubilidade permite, por exemplo, dopar seletivamente padrões pré-definidos e eliminar as partes não dopadas por extração com solventes, o que pode ter grande potencial de aplicação na indústria de microeletrônica. 


\subsection{Estudo da estabilidade da dopagem da PANI (análise de imagens por softwares)}

O objetivo deste estudo foi verificar como o dopante age na PANI em termos de migração ou evaporação durante o periodo de observação. Este estudo foi feito pensando-se em futuras aplicações da PANI na construção de microcircuitos impressos, por exemplo. A PANI seria dopada apenas em certas regiōes especificas, formando-se trilhas condutoras. Para que estes sistemas funcionem perfeitamente e tenham aplicação industrial, é importante avaliar se suas linhas ou trilhas condutoras não perdem o formato facilmente com o tempo. Para tanto, depositamos PANI em substratos flexiveis (filmes) de PET (conforme item 2.13), desdopamos a PANI (item 2.14) e redopamos com vapores de $\mathrm{HCl}$ concentrado, descarga corona negativa e descarga corona positiva. A dopagem foi feita apenas em regiōes determinadas, com auxilio de uma máscara de chapa fina de cobre, com abertura central (item 2.1.17). O monitoramento da dopagem da PANI foi feito com auxílio de softwares apropriados, desenvolvidos na Embrapa Instrumentação Agropecuária (item 2.1.17). As imagens pré-tratadas foram binarizadas (item 2.1.17) e foi feita a contagem dos pixels da regiāo dopada, e do percentual de área, automaticamente pelo software SIARCS 3.0 ( (este software foi desenvolvido na Embrapa Instrumentação Agropecuária para o estudo em projetos voltados para a Agricultura e é a primeira vez que é usado para monitorar a dopagem em polímeros condutores). Com os valores obtidos foram construídos os gráficos a seguir, com - Origin 5.0, onde se pode ver os valores percentuais de área de dopagem versus tempo (horas) (figura 3.44), para as amostras dopadas nos 3 diferentes tipos de dopantes. 
Os gráficos indicam que entre as duas técnicas de dopagem por descarga corona (negativa e positiva) praticamente não existem diferenças no comportamento das curvas, que apresentam comportamento quase constante. No caso da dopagem com $\mathrm{HCl}$ concentrado (vapor), a partir do tempo de 112 horas, começou a haver diminuição da área de dopagem da PANI. Foram feitos gráficos de barras, nos quais estes efeitos podem ser melhor observados, conforme figura 3.44.

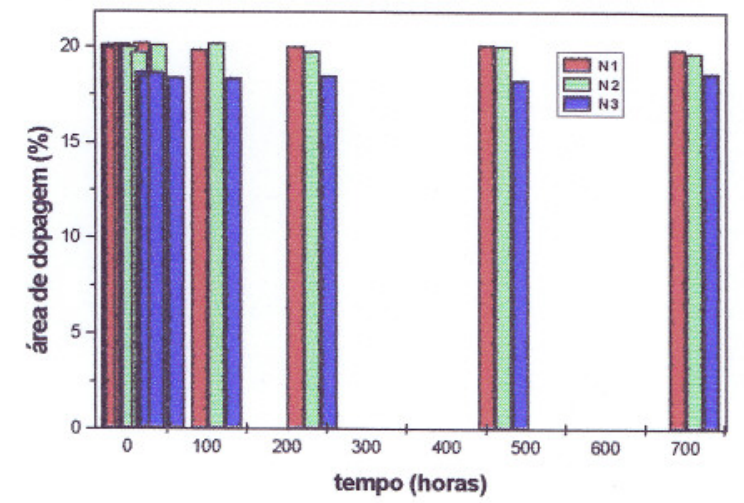

(a)

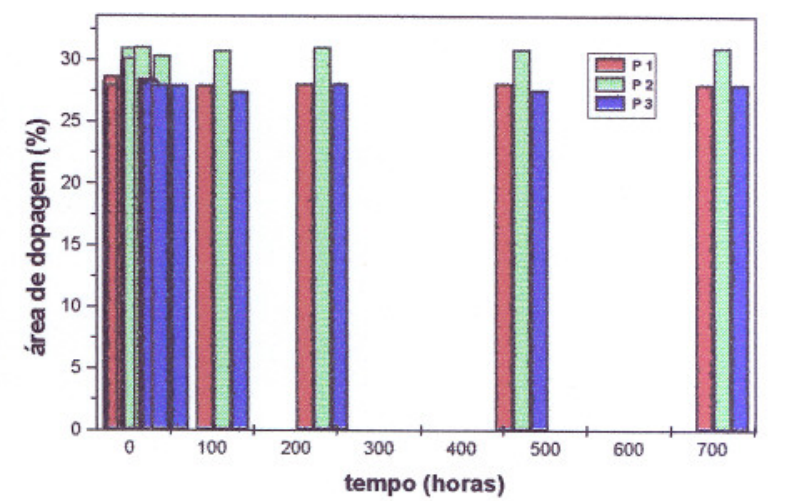

(b)

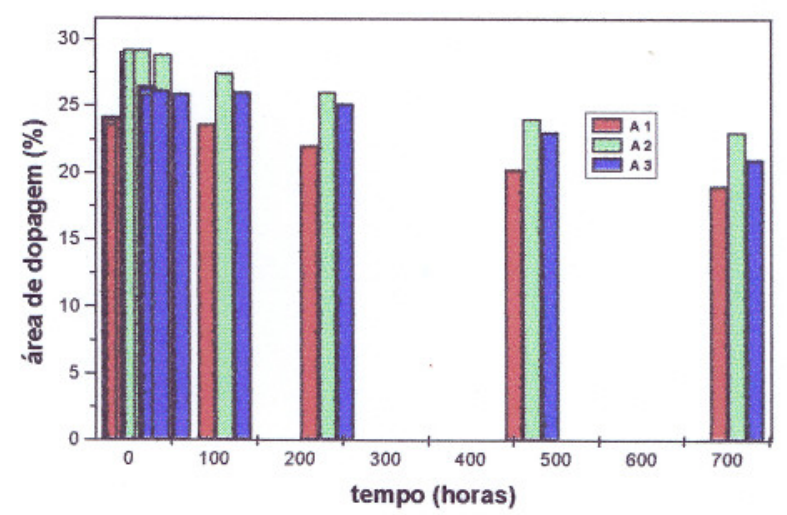

(c)

Figura 3.44: Área de dopagem (\%) da PANI versus tempo de observação (horas), onde: (a) amostras dopadas por descarga corona negativa $(\mathrm{N})$, (b) dopagem por descarga corona positiva (P), e (c) dopagem com $\mathrm{HCl}$ concentrado (vapor) (A). As cores das barras representam os 03 corpos de prova usados para cada tipo de dopagem. 
Nos gráficos de barras pode-se observar os valores da área de dopagem da PANI em percentual e constatou-se que houve as seguintes variações nos mesmos, após o período de 712 horas de observação: amostras dopadas com $\mathrm{HCl}$ apresentaram um valor médio de decréscimo de área dopada $\sim 5,54 \%(\sigma=0,31)$, as amostras dopadas com descarga corona negativa tiveram uma diminuição de área dopada em torno de $0,2 \% \quad(\sigma=0,10)$ e nas amostras dopadas por descarga corona positiva o valor de decréscimo foi de aproximadamente $0,57 \%(\sigma=1,38)$. Com base nestes resultados, foi observado que em todos os casos, independentemente do tipo de dopagem, houve diminuição da área de dopagem. Nas amostras dopadas com descarga corona (positiva e negativa), os valores de decréscimo de área são menores do que $1 \%$. No caso das amostras dopadas por $\mathrm{HCl}$, o valor de decréscimo foi mais significativo em comparação com a técnica de dopagem por descarga corona (em torno de 5,54\%). A diminuição da área de dopagem com $\mathrm{HCl}$ deve ser atribuída à evaporação de dopante ao longo do período. Diante dos resultados obtidos com estes métodos de dopagem, observamos que o método de dopagem por descarga corona (positiva ou negativa) possui melhor estabilidade, o que pode vir a ser importante para a produção de materiais para a indústria micro-eletrônica, em especial na confecção de microcircuitos impressos, uma vez que estes materiais necessitam que suas linhas de condução não tenham falhas em um certo periodo, bem como o fato do método de dopagem por descarga corona ser livre de produtos químicos corrosivos ou líquidos (como foi apresentado na Revisão Bibliográfica, item 1.4) e ser um método economicamente viável e simples. Esta técnica de tratamento de dados com o uso do software SIARCS $3.0 \circledast$ é uma técnica muito recente e a sua aplicação no estudo da dopagem da PANI é um trabalho novo que ainda pode ser melhor 
explorado, utilizando mais corpos de prova, e aumentando o período de observação da estabilidade da dopagem. 


\section{CONCLUSõES}

Foram obtidos por sintese química diluída à temperatura ambiente, compósitos de PET/PANI e de PCIPANI com alta transparência, flexibilidade e valores de condutividade elétrica interessantes para futuras aplicações. Estes materiais foram submetidos a medidas de condutividade elétrica e testes de aderência após tratamento térmico por intervalos de tempo variados e observouse que os compósitos de PC/PANI mostraram melhor aderência do que os compósitos de PET/PANI, com aproximadamente mesma condutividade elétrica.

Os compósitos dopados com ácidos apresentaram valores de condutividade elétrica (antes de sofrerem tratamento térmico) em torno de $2 \mathrm{~S} / \mathrm{cm}$ e os dopados com descarga corona (negativa ou positiva) apresentaram condutividade elétrica em torno de $0,3 \mathrm{~S} / \mathrm{cm}$.

Os resultados de termogravimetria indicaram que a PANI não interferiu na estabilidade térmica dos substratos (PET ou PC).

Os espectros de FTIR, Raman, XPS e UV-vis das amostras dopadas com descarga corona positiva e negativa são semelhantes aos da PANI dopada com $\mathrm{HCl} 1 \mathrm{M}$, indicando a possibilidade de um mecanismo similar de dopagem por protonação.

A técnica de XPS indicou que houve pequena oxidação da superfície da PANI em todas as amostras analisadas. Esta técnica foi útil na determinação da composição química das amostras dopadas com descarga corona positiva e negativa.

As amostras dopadas com descarga corona apresentaram maior quantidade de oxigênio do que as dopadas com $\mathrm{HCl}, \quad$ e as dopadas com 
descarga corona negativa apresentaram maior quantidade de nitrogênio do que as demais.

As técnicas de RAMAN e UV-vis forneceram uma medida qualitativa indireta da espessura do filme de PANI sobre o substrato, sendo mais finos os filmes dopados com descarga corona negativa.

A morfologia da PANI depositada sobre os substratos, bem como a morfologia dos mesmos foi analisada por MO, MEV e AFM. A PANI desdopada e a dopada apresentaram morfologia do tipo granular, sendo que os grãos maiores foram os da PANI dopada com $\mathrm{HCl} 1 \mathrm{M}$ e os grãos menores foram os dopados com descarga corona negativa. As amostras dopadas com descarga corona apresentaram grãos de tamanho mais uniforme, com menor rugosidade da superfície, devido ao "vento corona" que se forma na câmara durante a descarga corona, e desmancha as camadas superficiais menos aderentes (grãos maiores), homogeneizando melhor a superficie da PANI. Estes resultados são consistentes com a menor espessura obtida para a PANI dopada com descarga corona, conforme observado por Raman e UV-vis.

No estudo da estabilidade da área de dopagem da PANI foi utilizado um novo método, trata-se do uso do software SIARCS 3.0 \& (desenvolvido na Embrapa Instrumentação Agropecuária). Foi demonstrado com este software que as amostras de PANI dopadas por descarga corona foram as mais estáveis, pois não foi constatada alteração significativa na sua área de dopagem.

Diante dos resultados apresentados, concluimos que a dopagem por descarga corona pareceu ser mais estável do que a dopada por ácidos, os valores de condutividade elétrica das amostras dopadas por descarga corona 
foram uma ordem de grandeza inferior aos valores de condutividade elétrica das amostras dopadas por ácidos, mesmo assim ainda são valores interessantes para aplicações tecnológicas. 


\section{SUGESTÕES PARA TRABALHOS FUTUROS}

- Preparação e caracterização de polianilina depositada sobre outros polímeros convencionais e realizar estudos de aderência e de medida de ângulo de contato.

- Analisar as propriedades mecânicas destes materiais, tais como tensão versus deformação e Análise Térmica Mecânico-Dinâmica (DMTA).

- Ampliar o estudo de análise de imagem da estabilidade da dopagem da polianilina, aumentando o intervalo de tempo de observação e variando a temperatura de tratamento térmico das amostras. 


\section{REFERÊNCIAS BIBLIOGRÁFICAS}

[1] HEEGER, A.J. et al. J.C.S.Chem. Comm., p-578-580, 1977.

[2] ROTH, S.; GRAUPNER, W. Synthetic Metals, v. 55-57, p.3623-3631, 1993.

[3] MATTOSO, L.H.C. Química Nova, v.19, n.4, p.388-399, 1996.

[4] MAC DIARMID, A.G. et al. J. Chem. Soc. Faraday Trans. V.1, n.82, p.2385$2400,1986$.

[5] BALL, I.J. et al. Permselectivity and Temperature-Dependent Permeability of Polyaniline Membranes. (artigo extendido). In: INTERNATIONAL CONFERENCE ON SCIENCE AND TECHNOLOGY OF SYNTHETIC METALS, (ICSM), França, 1996.

[6] KANER, R.B. et al. Synthetic Metals, v.55-57, p.4047-4052, 1993.

[7] TOPPARE, L. et al. Synthetic Metals, v.60, p.27-30, 1993.

[8] KANATZIDIS, M.G. Chemical Engineering, v.68, p.36-54, 1990.

[9] ZOPPI, R.A.; DE PAOLI, M.A. Química Nova, v.16, n.6, p.560-569, 1993.

[10] DE MELO, C.P. Ciência Hoje, v.6, n.36, p.38-47, 1987.

[11] MALMONGE, L.F. Preparação e Caracterização de Blendas de Poliffluoreto de vinilideno) com Polianilinas. São Carlos, SP, 1996, 80 p., Tese (Doutorado) - Química - Universidade de São Paulo (São Carlos).

[12] KUMAR, D.; SHARMA, R.C. Eur. Polym. J. , v.34, n.8, p.1053-1060, 1998.

[13] DA SILVA, J.E.P.; TEMPERINI, M.L.A.; DE TORRESI, S.I.C. Electrochimica ACTA, v.44, p.1887-1891, 1999.

[14] WEN, L.; KOCHERGINSKY, N.M. Synthetic Metals, v. 106, p. 19-27, 1999.

[15] TAN, K.L. et al. Polymer, v.40, p.5285-5296, 1999.

[16] WINOKUR, M.J.; MATTES, B.R. Macromolecules, v.31, p.8183-8191, 1998.

[17] EPSTEIN, J.A.; MAC DIARMID, A.G. Synthetic Metals, v.65, p.103-110, 1994.

[18] MATTOSO, L.H.C.; MAC DIARMID, A.G. Polyanilines, oxidation states. In: Polymeric Materials Encyclopedia, CRC PRESS, v.7, p.5505-5513, 1996.

[19] LETHEBY, H. Journal of the Chemical Society, v.224, p.161, 1862.

[20] CUSHMAN, RJ. et al. J.Chem.Soc.Chem.Commun. p.1556-1559, 1985.

[21] BOUTROIS, J.P.; JOLLY, R.; PÉTRESCU, C. Process of Polypyrrole deposit on textile. Product characteristics and applications. (artigo extendido). In: INTERNATIONAL CONFERENCE ON SCIENCE AND TECHNOLOGY OF SYNTHETIC METALS, (ICSM), França, 1996. 
[22] KULKARNI, V.G. Synthetic Metals, v.71, p.2129-2131, 1995.

[23] ROVER, Jr.; DE OLIVEIRA NETO, G.; KUBOTA, L.T. Química Nova, v.20, n.5, p.519-527, 1997.

[24] YANG, S.M.; LI, C.P. Synthetic Metals, v.55-57, p.636-641, 1993.

[25] DOGAN, S.; AKBULUT, U.; TOPPARE, L. Synthetic Metals, v.53, p.29-35, 1992.

[26] AKHEEL, A.S.; MARAVATTICKAL, K.D. Talanta, v.38, n.8, p.815-837, 1991.

[27] TRAVERS, J.P. et al. Synthetic Metals, v.25, p.311-322, 1988.

[28] DE PAOLI, M.A.; TASSI, E.L. J.C.S., Chem. Comm. ,p.155-156, 1990.

[29] MATTOSO, L.H.C. et al. Polymer, v.35, p.5104-5108, 1994.

[30] GUPTA, S.K.S.; GUPTA, M.K.; BHADANI, S.N. Journal of Applied Polymer Science, v.49, p.397-403, 1993.

[31] TSINTAVIS, C. et al. Synthetic Metals, v.36, p.139-182, 1990.

[32] MUSIANI, M.M. et al. Journal of Applied Polymer Science, v.26, p.4247-4257, 1981.

[33] KÓTZ, R. et al. Journal of Electrochemistry Society, v. 138, p. 669-672, 1991.

[34] TRIVEDI, D.C. ; DHAWAN, S.K. Journal of Applied Eletrochemistry, v.22, p.563-570, 1992.

[35] MAC DIARMID, A.G. et al. Molecular Crystals and Liquid Crystals, v.160, p.151-163, 1988.

[36] YANG, S.; RUCKENSTEIN, E. Synthetic Metals, v.53, p.283-292, 1993.

[37] JOSHI, N.V.; BHAT, N.V. Journal of Applied Polymer Science, v.50, p.14231427, 1993.

[38] MATTOSO, L.H.C.; EPSTEIN, A.J.; MAC DIARMID, A.G. Síntese de polianilina com peso molecular alto e controlável. In: III Congresso Brasileiro de Polímeros, v.2, p.1117-1120, Rio de janeiro, RJ, 1995.

[39] NARAYANA, B.H.; PALANIAPPAN, S. Joumal of Polymer Science: Part A: Polymer Chemistry, v.32, p.2431-2436, 1994.

[40] KUHN, H.H.; KIMBRELL, C.W.; GREGORY, R.V. Synthetic Metals, v.28, p.C823-C835, 1989.

[41] DE PAOLI, M.A.; RODRIGUES, M.A. Synthetic Metals, v.41-43, p.2957, 1991.

[42] MAC DIARMID, A.G. et al. Molecular Crystals and Liquid Crystals, v.121, p.173-177, 1985. 
[43] NECHTSCHEIN, M. et al. Synthetic Metals, v.24, p.193-201, 1988.

[44] WALLACE, G.G.; PRICE, W.E.; ANSARI, R. Polymer, v.37, p.917-923, 1996.

[45] MALMONGE, J.A. ; MATTOSO, L.H.C. Synthetic Metals, v.84, p.779-781, 1997.

[46] WOLSZCZAK, M. ; KROH, J.; ABDEL-HAMID, M.M. Radiation Physical Chemistry, v.45, p.71-75, 1995.

[47] JOB, A.E. et al. Joumal of Applied Physics, v.87, n.8, 2000 /no prelo/

[48] MOORE, A.D. Eletrostatics and its Applications. John Wiley, New York, 1973.

[49] MANO, E.B. Introdução a Polímeros. Ed. Edgard Bucher, São Paulo, SP, 1985.

[50] MARK, H.F. et al. Polyesters. In: Encyclopedia of Polymer Science and Engineering, $2^{\text {nd }}$ ed., v.12, p.19-25, Ed. John Wiley \& sons, NY, USA, 1988.

[51] MANO, E.B. Polimeros como materiais de engenharia. Ed. Edgard Blücker LTDA, São Paulo, 1991.

[52] BOTTENBRUCH, L. Polycarbonate. In: Encyclopedia of Polymer Science and Engineering, $2^{\text {nd }}$ ed., v.10, Ed. John Wiley \& sons, NY, USA, 1986.

[53] PAUL, et al. Macromolecules, v.24, p.6332-6334, 1991.

[54] GRAYSON, M. Composites. In: Encyclopedia of Composite Materials and Components, p.367, Ed. John Wiley \& sons, NY, USA, 1983.

[55] BYUN, S.W.; IM, S.S. Polymer, v.39, n.2, p.485-489, 1998.

[56] BYUN, S.W.; IM, S.S. Synthetic Metals, v.69, p.219-220, 1995.

[57] LI, W.; WAN, M. Journal of Applied Polymer Science, v.71, p.615-621, 1999.

[58] NEOH, K.G.; TEO, H.W.; KANG, E.T. Langmuir, v.14, p.2820-2826, 1998.

[59] TRIVEDI, D.C.; DHAWAN, S.K. J.Mater. Chem., v.2, n.10, p.1091-1096, 1992.

[60] BUCKLEY, L.J. ; BYERS, W.A.; SCHOCH Jr., K.F. Synthetic Metals, v.72, p.13-23, 1995.

[61] HEEGER, A.J.; PEI, Q.; YU, G. Applied Physic Letters, v.70, n.8, p.934937, 1997.

[62] PUGLIESE, P.B. Influência de sistemas radiculares de absorção na resistência ao cisalhamento do solo. São Paulo, SP, 1998, Tese (Doutorado), Agronomia, Universidade de São Paulo.

[63] VIEIRA Jr., P.A. Emprego da técnica de análise de imagem na determinação do comprimento e da largura de sementes de milho. Piracicaba (SP), 1998, Dissertação (Mestrado), Agronomia, Universidade de São Paulo (Piracicaba). 
[64] JOB, A.E. Estudos em filmes de Poli(tereftalato de etileno) recoberto com Polianilina Condutora. São carlos, SP, 1998. 126p. Tese (Doutorado) Interunidades (IFSC, IQSC, EESC) Ciência e Eng. de Materiais, Universidade de São Paulo (São Carlos).

[65] AMERICAN SOCIETY FOR TESTING AND MATERIALS (ASTM) (1996). Standard Test Methods for Measuring Adhesion by Tape Test, ASTM D3359-B. EUA

[66] SMITS, F.M. The Bell System Technology Joumal, v.20, p.711-718, 1958.

[67] NEOH, K.G.; KANG, E.T.; TAN, K.L. Polymer, v.34, p.3921-3925, 1993.

[68] CHAUDHARI, H.K.; KELKAR, D.S. Polymer International, v.42, p.380-384, 1997.

[69] KIM, S.; CHUNG, I.J. Synthetic Metals, v.97, p.127-133, 1998.

[70] NEOH, K.G. et al. Synthetic Metals, v. 73, p.209-215, 1995.

[71] NASEF, M.M. Journal of Applied Polymer Science, v.77, n.5, p.1003-1012, 2000.

[72] PINTO, G.V.D.V. et al. Macromolecular Symposia, v.148, n.dec, p.333-343, 2000.

[73] LEE, S.; PARK, O.O. Joumal of Applied Polymer Science, v.77, n.6, p.1338$1347,2000$.

[74] ZHENG, S.X. et al. Journal of Applied Polymer Science, v.73, n.7, p.11811190, 1999.

[75] COCHET, M. et al. Synthetic Metals, v.84, p.757-758, 1997.

[76] HEEGER, A.J. et al. Synthetic Metals, v.62, p.107-112, 1994.

[77] LI, Z.F. et al. Synthetic Metals, v.87, p.45-47, 1997.

[78] MUILENBERG, G.E. et al. Handbook of X-Ray Photoelectron Spectroscopy, Perkin-Elmer Corp., USA, 1979.

[79] BEAMSON, G.; BRIGGS, D. High Resolution XPS of Organic Polymers - The Scienta ESCA 300 Data base, John Wiley \& sons, England, 1992.

[80] CAO, Y.; SMITH, P.; HEEGER, A.J. Synthetic Metals, v.32, p.263-267, 1989.

[81] CAO, Y. et al. Synthetic Metals, v.16, p.305-309, 1986.

[82] HEEGER, A.J. et al. Journal of American Chemical Society, v.109, p.3677$3681,1987$.

[83] HEEGER, A.J. et al. Polymer, v.30, p.2305-2309, 1989.

[84] LI, W.; WAN, M. Synthetic Metals, v.92, p.121-126, 1998. 
[85] LI, C.; SONG, Z. Sỳnthetic Metals, v.40, p.23-27, 1991.

[86] EPSTEIN, A.J. et al. Macromolecules, v.25, p.4106-4113, 1992.

[87] NECHTSCHEIN, M.; RANNOU, P. Synthetic Metals, v.84, p.755-756, 1997.

[88] NEOH, K.G. et al. Journal of Applied Polymer Science, v.64, n.3, p.519-526, 1997.

[89] MATVEEVA, E.S. Synthetic Metals, v.79, p.127-139, 1996.

[90] MATVEEVA, E.S.; CALLEJA, R.D. Synthetic Metals, v.67, p.207-210, 1994.

[91] WANG, X.H. et al. Synthetic Metals, v.69, p.263-264, 1995.

[92] WANG, X.H. et al. Synthetic Metals, v.69, p.265-266, 1995.

[93] JOSEFOWICZ, J. et al. Journal of Materials Science, v.29, p.4200-4204, 1994.

[94] MATTOSO, L.H.C. et al. Polymer, v.39, p.6977-6982, 1998.

[95] TOPPARE, L.; BAHÇECI, S.; YURTSEVER, E. Synthetic Metals, v.68, p.57-60, 1994.

[96] BYUN, S.W.; IM, S.S. Journal of Applied Polymer Science, v.56, p.425-431, 1995.

[97] SINGH, S. et al. Journal of Materials Science, v.33, p.2067-2071, 1998.

[98] EPSTEIN, A. et al. Synthetic Metals, v.84, p.63-64, 1997. 